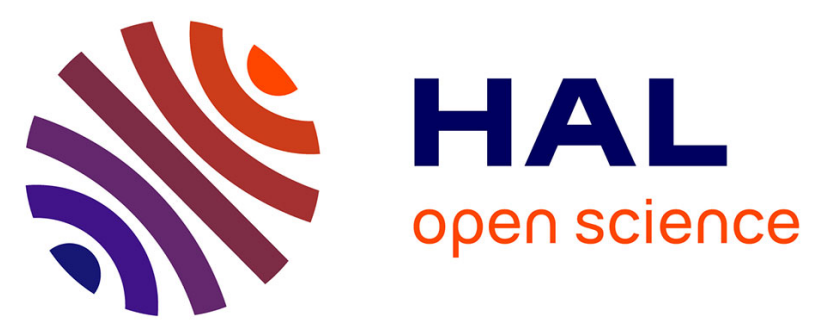

\title{
Automated Backbone NMR Resonance Assignment of Large Proteins Using Redundant Linking from a Single Simultaneous Acquisition
}

Jan Stanek, Tobias Schubeis, Piotr Paluch, Peter Güntert, Loren B Andreas, Guido Pintacuda

\section{To cite this version:}

Jan Stanek, Tobias Schubeis, Piotr Paluch, Peter Güntert, Loren B Andreas, et al.. Automated Backbone NMR Resonance Assignment of Large Proteins Using Redundant Linking from a Single Simultaneous Acquisition. Journal of the American Chemical Society, 2020, 142 (12), pp.5793-5799. 10.1021/jacs.0c00251 . hal-02900518

\section{HAL Id: hal-02900518 https://hal.science/hal-02900518}

Submitted on 16 Jul 2020

HAL is a multi-disciplinary open access archive for the deposit and dissemination of scientific research documents, whether they are published or not. The documents may come from teaching and research institutions in France or abroad, or from public or private research centers.
L'archive ouverte pluridisciplinaire HAL, est destinée au dépôt et à la diffusion de documents scientifiques de niveau recherche, publiés ou non, émanant des établissements d'enseignement et de recherche français ou étrangers, des laboratoires publics ou privés. 


\title{
Automated backbone NMR resonance assignment of large proteins using redundant linking from a single simulta- neous acquisition
}

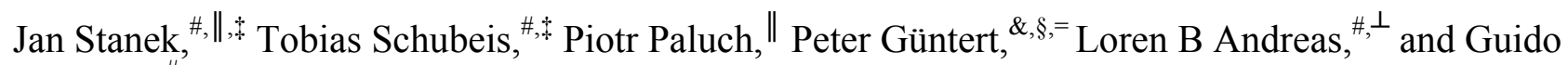 \\ Pintacuda ${ }^{\#, *}$ \\ ${ }^{\#}$ Centre de RMN à Très Hauts Champs, FRE (FRE 2034 CNRS, UCB Lyon 1, ENS Lyon), Université de Lyon, 5 rue de la

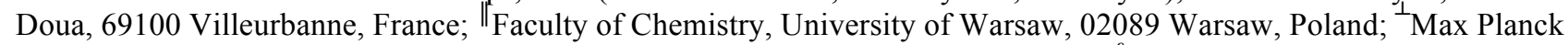 \\ Institute for Biophysical Chemistry, Am Fassberg 11, D-37077 Göttingen, Germany, ${ }^{\&}$ Physical Chemistry, Eidgenössische \\ Technische Hochschule Zurich, Zurich, Switzerland; ${ }^{\S}$ Center for Biomolecular Magnetic Resonance, Institute of Biophysical \\ Chemistry, Goethe University Frankfurt, Frankfurt, Germany; 'Department of Chemistry, Tokyo Metropolitan University, \\ Hachioji, Japan
}

Supporting Information Placeholder

\begin{abstract}
Thanks to magic-angle spinning (MAS) probes with frequencies of $60-100 \mathrm{kHz}$, the benefit of high sensitivity ${ }^{1} \mathrm{H}$ detection can now be broadly realized in biomolecular solid-state NMR for the analysis of microcrystalline, sedimented, or lipid-embedded preparations. Nonetheless, performing the assignment of all resonances remains a rate-limiting step in protein structural studies, and even the latest optimized protocols fail to perform this step when the protein size exceeds $\sim 20 \mathrm{kDa}$. Here we leverage the benefits of fast (100 kHz) MAS and high $(800 \mathrm{MHz})$ magnetic fields to design an approach that lifts this limitation. Through the creation, conservation and acquisition of independent magnetization pathways within a single triple-resonance MAS NMR experiment, a single self-consistent dataset can be acquired, providing enhanced sensitivity, reduced vulnerability to machine or sample instabilities, and highly redundant linking that supports fully-automated peak picking and resonance assignment. The method, dubbed RAVASSA (Redundant Assignment Via A Single Simultaneous Acquisition), is demonstrated with the assignment of the largest protein to date in the solid state, the $42.5 \mathrm{kDa}$ maltose binding protein, using a single fully protonated microcrystalline sample and one week of spectrometer time.
\end{abstract}

\section{INTRODUCTION}

The proton is inherently the most sensitive nuclear spin since it has the highest gyromagnetic ratio among all stable isotopes. This is recognized in solution NMR spectroscopy, where standard acquisition schemes are centered around amide protons for protein resonance assignment and structure determination. For solid-state NMR, following years of pioneering developments, ${ }^{2-5}$ the benefit of high sensitivity ${ }^{1} \mathrm{H}$ detection can now be broadly realized thanks to magic-angle spinning (MAS) probes with frequencies of $60-100 \mathrm{kHz}^{6-7}$ and beyond. ${ }^{8}$ With these advances in instrumentation, high-resolution "fingerprint" correlation spectra can now be obtained for deuterated $^{9-10}$ and fully protonated proteins ${ }^{11-12}$ and RNA $^{13}$ within minutes using a sub-milligram sample quantity. This has led to the development of a palette of triple-resonance experiments for accelerating the sequential assignment ${ }^{1,14-17}$ and expanding the repertoire of proteins for which nearly complete resonance assignment can be obtained. Currently, however, the complexity of spectra in solids permits the analysis of microcrystalline, sedimented or lipid-embedded preparations of small proteins, and only few examples above 250 amino acid residues (aa) were reported, for which either deuteration ${ }^{18-21}$ and/or a combination of differently labeled samples ${ }^{12,22-24}$ was required.

A potential solution to overcome this size barrier is provided by the study of fully protonated proteins at $100 \mathrm{kHz}$ MAS and above, with the design of complementary approaches based on the detection of narrow $\alpha$-proton resonances. ${ }^{25-26}$ However, the acquisition of such an expanded dataset also approximately doubles the spectrometer time required, which makes the entire acquisition vulnerable to machine or sample instabilities, ${ }^{27}$ and increases severely the complexity of the data analysis. Deviations in peak position exceeding the linewidth are not unusual in these approaches, in particular if multiple samples are analyzed. While these deviations can sometimes be recognized by expert manual analysis, they can be catastrophic for automated approaches which rely on strict resonance matching thresholds. ${ }^{28}$ With a manual approach, assignment of thousands of resonances is cumbersome and time consuming, commonly demanding years of data analysis. We show in the following that these issues can be addressed by automated analysis of a single self-consistent dataset composed of six simultaneously acquired ${ }^{1} \mathrm{H}$-detected three-dimensional (3D) spectra employing MAS at frequencies exceeding $100 \mathrm{kHz}$. The method, hereafter dubbed redundant assignment via a single simultaneous acquisition (RAVASSA), enhances sensitivity, with a 2-3-fold reduction in experimental time, and results in spectra that support fully-automated peak picking and resonance assignment. We demonstrate its efficiency with the 371 aa maltose binding protein (MBP), using a single fully-protonated sample ( $<1 \mathrm{mg}$ of uniformly ${ }^{13} \mathrm{C},{ }^{15} \mathrm{~N}$-labelled material). 


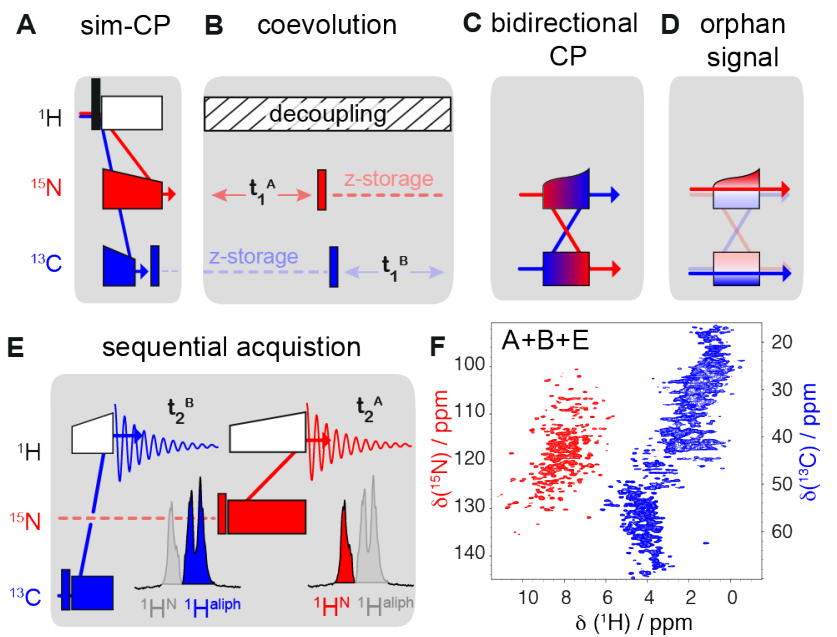

Figure 1. Scheme of radiofrequency building blocks for multiple pathway coherence transfers: (A) simultaneous cross-polarization of amide ${ }^{15} \mathrm{~N}$ and ${ }^{13} \mathrm{C} \alpha$ spins from spatially proximal protons; (B) unconstrained co-evolution of ${ }^{15} \mathrm{~N}$ and ${ }^{13} \mathrm{C}$ chemical shifts; (C) bidirectional ${ }^{15} \mathrm{~N}-{ }^{13} \mathrm{C} \mathrm{CP}$ without and (D) with recovery of orphan coherence; (E) a single scan sequential acquisition of $\alpha$ and amide ${ }^{1} \mathrm{H}$ signal following respective $\mathrm{CPs}$ from ${ }^{13} \mathrm{C} \alpha$ and ${ }^{15} \mathrm{~N}$. (F) Simultaneous dipolar-based ${ }^{13} \mathrm{C},{ }^{15} \mathrm{~N}-\mathrm{HSQC}$ spectrum of maltose binding protein (see SI for a detailed RF scheme of this experiment).

\section{RESULTS}

Figure 1 depicts the key building blocks needed to implement RAVASSA, by creating, conserving and recording independent magnetization pathways within a single triple-resonance MAS NMR experiment: (A) simultaneous cross-polarization (SIM-CP) from ${ }^{1} \mathrm{H}$ to both ${ }^{15} \mathrm{~N}$ and ${ }^{13} \mathrm{C} ;{ }^{29-30}$ (B) co-evolution (time-sharing) of indirect ${ }^{15} \mathrm{~N}$ and ${ }^{13} \mathrm{C}$ chemical shifts; ${ }^{31}$ (C) bidirectional crosspolarization allowing simultaneous polarization transfer from ${ }^{13} \mathrm{C}$ to ${ }^{15} \mathrm{~N}$ and vice-versa; ${ }^{29}$ (D) recovery of orphan terms left over due to incomplete $\mathrm{CP}$ transfers; ${ }^{32-33}$ and (E) separated acquisition of ${ }^{1} \mathrm{H} \alpha$ and ${ }^{1} \mathrm{H}^{\mathrm{N}}$ signals, one occurring immediately after the other. ${ }^{33}$ In panel (F), we show the simplest case of a co-acquired CP${ }^{13} \mathrm{C}$, ${ }^{15} \mathrm{~N}-\mathrm{HSQC}{ }^{31,33}$ spectrum of MBP which takes advantage of blocks A, B and E. The amide and aliphatic 2D correlations were acquired simultaneously in 1 hour, as compared to $2 \mathrm{~h}$ for recording two separate spectra, on a $800 \mathrm{MHz}$ spectrometer at $107 \mathrm{kHz}$ MAS. Samples with $100 \%$ abundance of protons, which recently became available to proton-detected NMR analysis with $\geq 100$ $\mathrm{kHz}$ MAS, are central to the performance of SIM-CP, since they contain independent reservoirs of ${ }^{1} \mathrm{H}$ magnetization for ${ }^{1} \mathrm{H}^{15} \mathrm{~N}$ and ${ }^{1} \mathrm{H}_{-}{ }^{13} \mathrm{C} \alpha$ pathways as demonstrated both experimentally and by quantum-mechanical calculations in Fig S1-S3. Note that, while our main focus here is on the backbone nuclei, simultaneous polarization in fully protonated proteins can also be exploited to generate correlations of side-chain spins, e.g. through-space contacts using broadband ${ }^{1} \mathrm{H},{ }^{1} \mathrm{H}$ RFDR-techniques. ${ }^{31}$ Concerning the mode of detection (Fig 1E), deferring the acquisition of ${ }^{1} \mathrm{H}^{\mathrm{N}}$ signal comes at virtually no cost due to very slow relaxation of the ${ }^{15} \mathrm{~N} z$ polarization in solids ( $T_{1}$ of the order of seconds). ${ }^{29}$ Additionally, simpler radiofrequency (RF) conditions are used for separate "back" $\mathrm{CP}$, and the cross-talk between pathways $\left({ }^{15} \mathrm{~N} \rightarrow{ }^{1} \mathrm{H} \alpha\right.$ and ${ }^{13} \mathrm{C} \alpha \rightarrow{ }^{1} \mathrm{H}^{\mathrm{N}}$ transfers) is avoided. Also, ${ }^{1} \mathrm{H} \alpha$ and ${ }^{1} \mathrm{H}^{\mathrm{N}}$ signals, with partially overlapping chemical shift ranges, are cleanly separated.

These design principles are used to construct the more complex pulse sequences discussed below. Figure 2 shows the pulse sequence for an implementation of RAVASSA based around a direct amide-to-amide transfer experiment $(\mathrm{NNH}) .{ }^{15-16}$ A comparison of panels (A) and (B) shows the additional transfer blocks used to record a total of eight unique transfer pathways. The NNH scheme contains five coherence transfers between consecutive nuclei along the protein backbone and therefore contains multiple opportunities for the incorporation of the building blocks described above (see SI for detailed description of the pulse sequences). Simultaneous $\mathrm{CP}$, coevolution and bidirectional $\mathrm{CP}$ naturally lead to acquisition of an analogous experiment for $\mathrm{H} \alpha$ detected inter-residue $\mathrm{C} \alpha-\mathrm{C} \alpha$ correlation $(\mathrm{CCH})$ together with $\mathrm{NNH}$. By retaining orphan spin operators (Fig1D) left after the ${ }^{13} \mathrm{C}-{ }^{15} \mathrm{~N} \mathrm{CP}$, four additional spectra (and 2-fold redundant resonance linking, as described below) can be co-acquired, namely the intra- and inter-residue $\mathrm{N}-\mathrm{C} \alpha-\mathrm{H} \alpha$ and $\mathrm{C} \alpha-\mathrm{N}-\mathrm{H}^{\mathrm{N}}$ correlations. Overall, a total of six useful pathways can be observed.

Figure 3 shows the resulting eight co-acquired spectra, together with representative data on MBP. A proper separation of data sets requires only a doubling of a spectral window in dimension $\omega_{1}$, and one additional phase-cycle to discriminate pairs of pathways, without any impact on sensitivity. A trivial linear combination of data is used to extract the spectra arranged as shown in Figure 3A. Our implementation makes no compromise on resolution in any dimension, due to the possibility to extend periods of low power proton decoupling during each indirect evolution (see SI). Unconstrained chemical shift evolution times for ${ }^{15} \mathrm{~N}$ and ${ }^{13} \mathrm{C}$ nuclei are indeed essential for the resolution of spectra for proteins as large as MBP. The experiment was performed in less than 5 days (instead of more than 16 days necessary with a regular acquisition) and showed excellent sensitivity, resolution and high information content, as demonstrated with heteronuclear $\left(\omega_{1}-\omega_{2}\right)$ projections of component spectra in Figure 3B. Together, the four-fold redundant sequential linking of the resulting datasets provide highly fault tolerant data for backbone resonance assignment (Figure $3 \mathrm{C}$ ). It consists of all combinations: ${ }^{1} \mathrm{H}^{\mathrm{N}}$-detected spectra with sequential correlations through (1) ${ }^{13} \mathrm{C} \alpha$ or (2) ${ }^{15} \mathrm{~N}$ chemical shifts, and, symmetrically, ${ }^{1} \mathrm{H} \alpha$-detected spectra correlated by (3) ${ }^{15} \mathrm{~N}$ or $(4){ }^{13} \mathrm{C} \alpha$ frequencies. Representative strips from six spectra are shown in Figure 3D. Completeness of the spectra is characterized by automatic identification of 275 to 309 cross-peaks out of a maximum 349 to 371 expected in particular spectra (1770 in total). Peaks were automatically identified using the routine embedded in the spectral analysis software CCPN, ${ }^{34}$ and inevitably contained a certain fraction (approximately $15 \%$ ) of noise peaks.

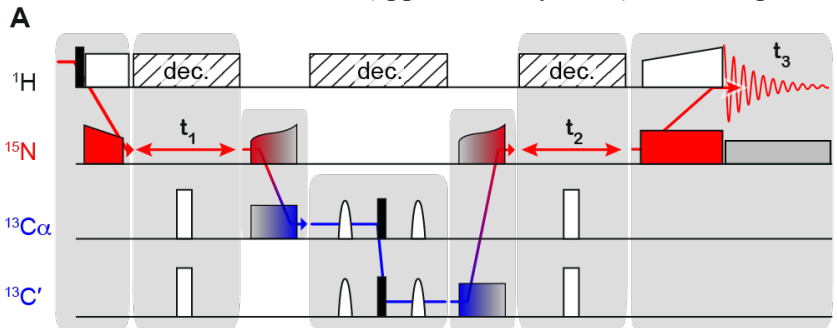

B

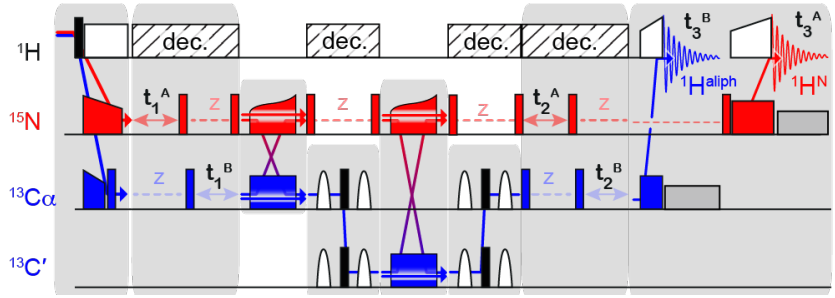

Figure 2. Simplified time diagram of RF irradiation for (A) conventional amide-to-amide proton transfer experiment $(\mathrm{NNH})^{15}$ and (B) its expansion using simultaneous excitation, coevolution and bidirectional CP transfers (RAVASSA). 
The redundancy of information and consistency of chemical shifts in four assignment connectivities makes it perfectly amenable to automation and robust in the presence of spurious peaks.

For assignment automation, we turned to the exceptionally flexible automated resonance assignment algorithm FLYA $^{35}$ that has been applied to ${ }^{13} \mathrm{C} /{ }^{15} \mathrm{~N}$-detected solid state data ${ }^{36}$ and very large methyl-labeled proteins. ${ }^{37}$ The algorithm accommodated unusual $\mathrm{H} \alpha$-detected correlations with straightforward extensions of the FLYA library (provided in SI). Given the discontinuities in sequential linking due to 21 proline residues ( $6 \%$ of the sequence) or otherwise missing correlations, we expanded our data set by intraresidue (but not interresidue) correlations of either amide and $\alpha$-protons to ${ }^{13} \mathrm{C} \beta$ shifts (namely $(\mathrm{H})(\mathrm{CA}) \mathrm{CB}(\mathrm{CA}) \mathrm{NH}^{38}$ and $(\mathrm{H})(\mathrm{CA}) \mathrm{CBCAH}^{25}$ spectra), which provide reliable information on a specific residue type and thus greatly help to locate fragments within the protein sequence. As demonstrated in Figure 4, small deviations of chemical shifts (approximately 0.1 and 0.3 ppm for ${ }^{1} \mathrm{H}$ and ${ }^{13} \mathrm{C} /{ }^{15} \mathrm{~N}$ shifts) and high redundancy of information allowed to overcome critical ambiguity of resonance matching, typically encountered in large proteins, leading to approximately $82 \%$ complete assignment. This is in contrast to the previous state of the art based on the ${ }^{1} \mathrm{H}^{\mathrm{N}}$-detection and matching of ${ }^{13} \mathrm{C}$ chemical shifts ${ }^{1}$ (black curve in Figure 4), which was used to assign a suite of smaller proteins, but fails to assign more than $40 \%$ of MBP resonances regardless of matching tolerances. The lower limit for chemical shift tolerances is imposed by experimental linewidths and sensitivity, and for many important classes of samples (e.g., for integral membrane or fibrillar proteins) larger linewidths are typically found than observed for MBP. It is apparent from Figure 4 that the inherent ambiguity of the large protein MBP is beyond the capability for the five ${ }^{1} \mathrm{H}^{\mathrm{N}}$-detected spectra, while the new approach leads to robust assignment. This is particularly apparent for higher tolerance values that correspond to the case of increased linewidths found for many important biological samples.

To further investigate the key component of RAVASSA, we restricted our data set by independently recording joint intra- and interresidue $\mathrm{N}-\mathrm{C} \alpha-\mathrm{H} \alpha$ and $\mathrm{C} \alpha-\mathrm{N}-\mathrm{H}^{\mathrm{N}}$ correlations (pulse schemes provided in SI). This data also benefits from improved chemical shift consistency inherent for simultaneously acquired spectra, thus the limiting tolerances (lower limit) are identical to RAVASSA. In the case of MBP the extent of assignment is almost as good, however, the restricted data set breaks down rapidly with increasing matching tolerance (blue curve in Figure 4). It is therefore clear that the higher robustness of RAVASSA with respect to large linewidths stems from the $\mathrm{NNH}$ and $\mathrm{CCH}$ correlations. Interestingly, these correlations alone are clearly too ambiguous to yield a complete assignment in an automatic way (cyan curve in Figure 4). In FLYA, the four pathways support each other in resolving assignment ambiguities, with a significant cooperative effect (see supplementary Figure S12 for statistics on how often peaks from the different pathways are assigned for each residue). A relatively wide range of matching tolerances which provide reasonably complete automatic assignment $(0.2-0.6 \mathrm{ppm}$ for heteronuclei) not only simplifies the use of RAVASSA for samples different than studied here, but also suggests its power for

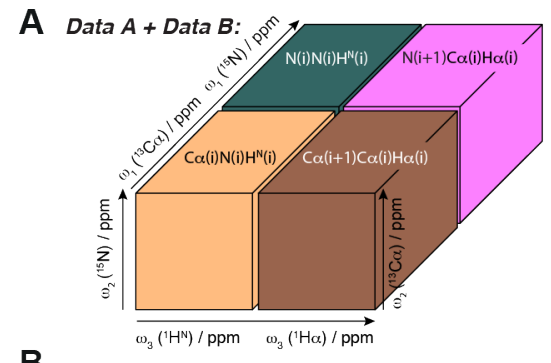

B

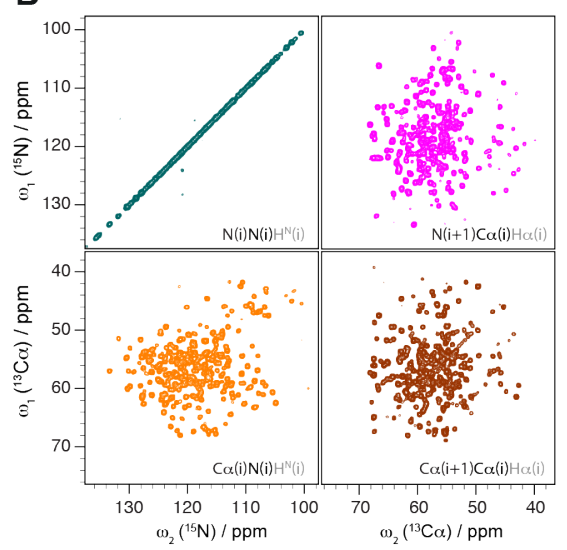

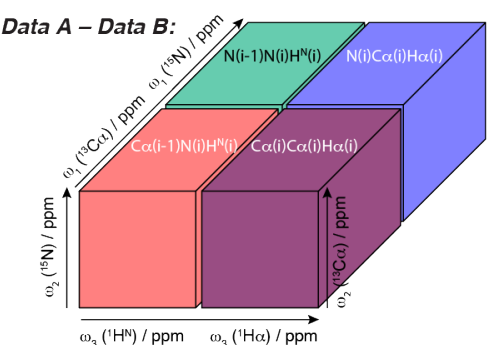

$\omega_{3}\left({ }^{1} H^{N}\right) / p p m \quad \omega_{3}\left({ }^{1} H \alpha\right) / p p m$

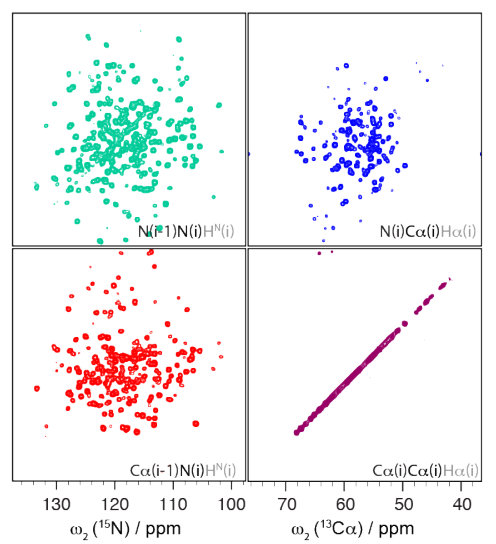

C

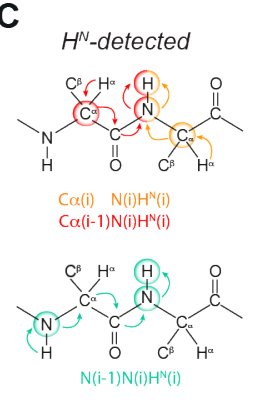

Ho-detected
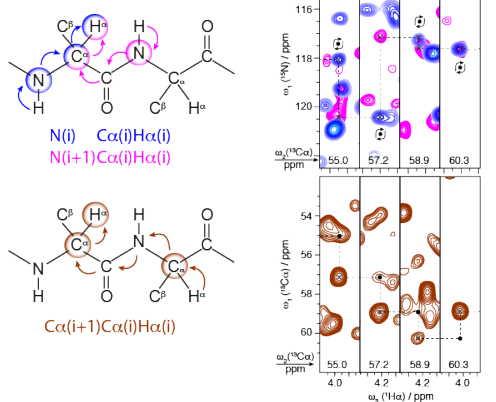

Figure 3. (A) The data layout of 8 simultaneously acquired spectra after addition/subtraction of interleaved signals A and B. Separation of pathways undergoing either ${ }^{13} \mathrm{C} \alpha$ or ${ }^{15} \mathrm{~N}$ evolution in $\omega_{1}$ is achieved by doubled spectral window and TPPI-type up- and downfield frequency shift, while separation in $\omega_{2}$ is unnecessary since the frequency range $\left({ }^{13} \mathrm{C} \alpha\right.$ or ${ }^{15} \mathrm{~N}$ ) is implied from the detected nucleus. (B) Skyline projections of the 8 spectra onto the $\omega_{1}-\omega_{2}$ plane $\left({ }^{13} \mathrm{C} \alpha\right.$ or ${ }^{15} \mathrm{~N}$, and combinations thereof). (C) Scheme of simultaneously observed coherence transfer pathways across the protein backbone that give rise to four independent resonance matching methods. (D) Representative strips showing sequential assignment of ${ }^{15} \mathrm{~N},{ }^{13} \mathrm{C} \alpha,{ }^{1} \mathrm{H} \alpha$ and ${ }^{1} \mathrm{H}^{\mathrm{N}}$ resonances of residues A134-K137 of MBP based on intra- (orange and blue contours) and interresidue correlations (red and magenta contours) correlations found in six simultaneously acquired 3D spectra employing ${ }^{1} \mathrm{H}^{\mathrm{N}}$-detection (two top panels, in orange, red and light green) or ${ }^{1} \mathrm{H} \alpha$-detection (two bottom panels, in blue, magenta and brown). For $(\mathrm{H}) \mathrm{N}(\mathrm{CA})(\mathrm{CO}) \mathrm{NH}\left(2^{\text {nd }}\right.$ from the top) and $(\mathrm{H}) \mathrm{CA}(\mathrm{N})(\mathrm{CO}) \mathrm{CAHA}$ (bottom last) spectra the implied positions of diagonal peaks (suppressed in these experiments) are shown with dots to illustrate the sequential walk. The $\omega_{1}$ (either ${ }^{13} \mathrm{C} \alpha$ or $\left.{ }^{15} \mathrm{~N}\right)-\omega_{3}\left({ }^{1} \mathrm{H}\right)$ cross-sections of $3 \mathrm{D}$ spectra are shown at the $\omega_{2}$ (either ${ }^{15} \mathrm{~N}$ or ${ }^{13} \mathrm{C} \alpha$ ) frequency indicated in each strip. 


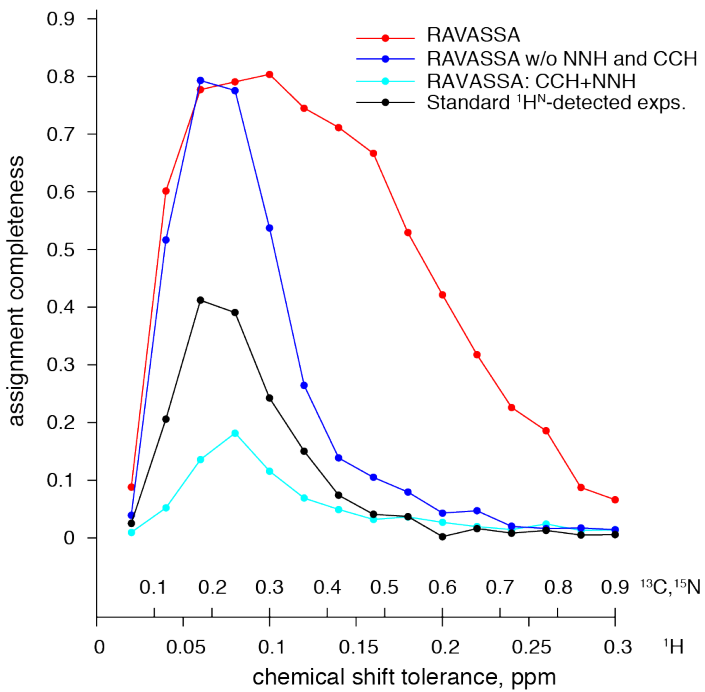

Figure 4. Characterization of the sensitivity of the automated assignment with respect to the matching tolerance. Red, blue, cyan and black dots indicate the assignment completeness, defined as the ratio of strongly assigned to all ${ }^{1} \mathrm{H}^{\mathrm{N}},{ }^{1} \mathrm{H} \alpha,{ }^{13} \mathrm{C} \alpha,{ }^{13} \mathrm{C} \beta$ and ${ }^{15} \mathrm{~N}$ resonances, obtained with the compete and reduced RAVASSA datasets, as well as with the classical ${ }^{1} \mathrm{H}^{\mathrm{N}}$ detected datasets, ${ }^{1}$ respectively. Points are connected for eye guidance only.

assignment of larger proteins (since assignment ambiguity is determined by matching tolerances and protein size).

Figure 5 summarizes the automatically obtained resonance assignment, which is evenly distributed among different structural elements of MBP. About $18 \%$ of $\alpha$ and amide ${ }^{1} \mathrm{H}$ remained unassigned, which are likely undetectable with $\mathrm{CP}$-based methods due to either increased local dynamics or intermediate conformational exchange as suggested by peak counts in the triple resonance spectra (see SI). In lieu of manual verification of the assignment we performed an unbiased correlation of protein dihedral angles $\varphi$ and $\psi$ predicted by TALOS- $\mathrm{N}^{39}$ based on the automatically assigned shifts with respect to those in the X-ray derived structure (PDB 1ANF). A very good agreement (Figure 5D) proves validity of chemical shifts, whereas a very few outliers $(1.5 \%$ of 470 angles) remain well within the limitations of TALOS predictions. We observe a very good match overall between the newly assigned chemical shifts and those of MBP in solution, at least for what concerns ${ }^{13} \mathrm{C} \alpha$ and ${ }^{13} \mathrm{C} \beta$ nuclei (Figure S13). Larger differences are observed for amide ${ }^{15} \mathrm{~N}$ and ${ }^{1} \mathrm{H}$, which are notoriously sensitive to the chemical environment, and vary significantly with the ligand complexation state of the protein and with preparations conditions ( $\mathrm{pH}$, buffer, precipitant).

In comparison with assignment strategies developed for protein solutions, the solid-state samples present unique challenges. While in solution, a main limitation to tackling larger proteins arises due to the decreased sensitivity of slowly tumbling molecules, which is inherently dependent upon particle size. The size limit in solution can, to a certain degree, be extended by increasing temperature, reducing relaxation via deuteration, as well as implementation of TROSY techniques that select for long-lived spin components. ${ }^{40}$ While these issues are absent in the solid, the linewidths of solid protein preparations are typically larger than in solution, and unsurprisingly, the limitation in this case becomes resonance overlap and ambiguity in sequential resonance matching. (Even with the advantages of proton detection, the sensitivity at present limits acquisitions to 3D or 4D datasets, with 3D data being the most common.) The present approach using a large number of co-acquired spectra meets these unique challenges encountered in solid protein preparations.

\section{CONCLUSION}

We have described a novel strategy for backbone NMR assignment of large proteins that does not rely on deuteration, but instead is based on automated analysis of high-resolution proton detected 3D spectra obtained at ultrafast MAS with parallel ${ }^{1} \mathrm{H}^{\mathrm{N}}$ and ${ }^{1} \mathrm{H} \alpha$-detection. We showed that full occupation of proton sites

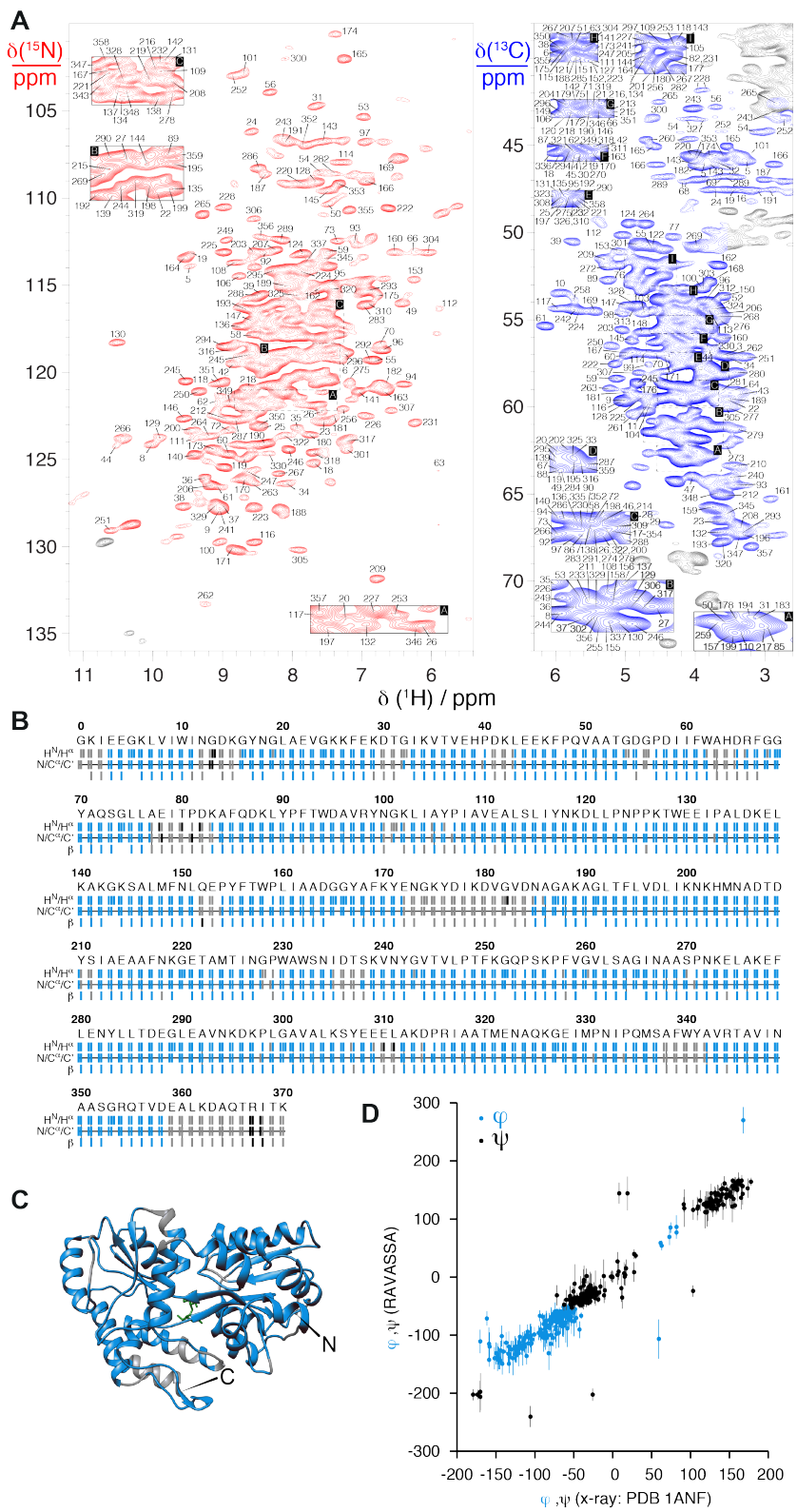

Figure 5. Assigned dipolar heteronuclear correlation spectrum of maltose binding protein: ${ }^{15} \mathrm{~N}-{ }^{1} \mathrm{H}$ (red contours) and $\alpha$-region of ${ }^{13} \mathrm{C}-{ }^{1} \mathrm{H}$ correlations (blue contours), acquired simultaneously. (B) Result of automated FLYA resonance assignment of MBP. Resonances with "strongly" determined chemical shifts are marked in blue (or in black, if located in isolated short fragments and thus discarded), while those below confidence threshold are shown in grey. (C) X-ray derived structural model of maltose binding protein (PDB 1ANF) with assigned residues marked in blue. (D) Backbone dihedral angles $\varphi$ and $\psi$ predicted based on assigned chemical shifts and in the X-ray structure. 
enables a simultaneous acquisition of six different correlation spectra, which offers significant time savings, or equivalently, sensitivity gains. Inherent consistency and redundancy of the data provides an additional benefit to automatic resonance assignment of otherwise overwhelming complexity, as shown on the example of maltose binding protein (371 residues), which to our knowledge is the largest monomeric protein assigned in the solid state. A single uniformly ${ }^{13} \mathrm{C},{ }^{15} \mathrm{~N}$-labelled sample $(<1 \mathrm{mg})$, and approximately one week of $800 \mathrm{MHz}$ NMR instrument time, using a standard single receiver, were used in this study. We furthermore showed that the assignment strategy is particularly robust against the choice of chemical shift matching tolerance, or linewidths observed for a particular sample. We therefore expect that the approach will open an efficient avenue to access sitespecific NMR information in large proteins, and will be readily extended to even larger proteins, or proteins exhibiting more challenging resolution.

\section{EXPERIMENTAL SECTION}

\section{Sample preparation}

${ }^{13} \mathrm{C},{ }^{15} \mathrm{~N}$-labeled $\mathrm{N}$-terminal His-TEV-tagged Maltose Binding Protein (MalE 27-396, E. coli) was expressed in E. coli $\mathrm{C} 41$ cells and purified on a $5 \mathrm{ml} \mathrm{Ni}^{2+}$-sepharose column (GE Healthcare) using standard methods. The His-tag was removed with TEVProtease (in-house production) and MBP further purified by size exclusion and ion exchange chromatography. Eventually, the protein was dialyzed against $10 \mathrm{mM}$ HEPES pH 7.5, $1 \mathrm{mM}$ maltose. Small platelet-like crystals were produced by sitting drop vapor diffusion in 24-well plates using $600 \mu \mathrm{l}$ reservoir $(10 \mathrm{mM}$ HEPES pH 7.5, $\left.3 \mathrm{M}\left(\mathrm{NH}_{4}\right)_{2} \mathrm{SO}_{4}\right)$. In each well, $15 \mu \mathrm{MBP}$ solution $(\mathrm{c}=5 \mathrm{mg} / \mathrm{ml})$ was mixed with $15 \mu \mathrm{l}$ reservoir. Crystals grew at room temperature within 3 days. One 24-well plate yielded sufficient material for one NMR sample. $\left(\mathrm{NH}_{4}\right)_{2} \mathrm{SO}_{4}$ was chosen as precipitant (instead of e.g. PEG) in order to avoid introduction of naturally abundant ${ }^{13} \mathrm{C}$ nuclei. MBP crystals were packed by ultracentrifugation at $100,000 \times g$ at $10{ }^{\circ} \mathrm{C}$ directly into a $0.7 \mathrm{~mm}$ MAS rotor using a $1.3 \mathrm{~mm}$ ultracentrifuge tool (Giotto Biotech). ${ }^{41}$

\section{NMR spectroscopy}

The experiments were performed on a Bruker AVANCE III 18.8 $\mathrm{T}$ spectrometer $\left({ }^{1} \mathrm{H}\right.$ frequency of $\left.800 \mathrm{MHz}\right)$ using a 4-channel (HCND) $0.7 \mathrm{~mm}$ MAS probe. Sample rotation frequency was maintained at $107.00 \pm 0.02 \mathrm{kHz}$, and the sample temperature was approximately $15{ }^{\circ} \mathrm{C}$. Details on RF applied during $\mathrm{CP}$ transfers, pulse program listings and RF schemes are provided in SI. All spectra were processed with nmrPipe ${ }^{42}$ using scripts provided in the SI, peak-picked automatically and converted to Xeasy format in CcpNmr Analysis 2.4. ${ }^{34}$

\section{SIM-CP simulations}

Simulations of simultaneous ${ }^{1} \mathrm{H} \rightarrow{ }^{13} \mathrm{C},{ }^{15} \mathrm{~N}$ CP were performed with SIMPSON ${ }^{43}$ software version $4.0 .0 \mathrm{c}$ for rotation frequencies between 20 and $125 \mathrm{kHz}$. Powder averaging was performed with $168 \times 17=2856$ Euler angles $\left\{\alpha_{M R}, \beta_{M R}, \gamma_{M R}\right\}$ that described the orientation of the molecule in the rotor frame. 168 angle pairs $\left\{\alpha_{M R}, \beta_{M R}\right\}$ were selected according to the Repulsion method, ${ }^{44}$ whereas $17 \gamma_{M R}$ angles were regularly stepped from 0 to $360^{\circ}$. 7 spins were considered to simulate proton bath in the fully protonated proteins: ${ }^{1} \mathrm{H}^{\mathrm{N}},{ }^{1} \mathrm{H} \alpha,{ }^{1} \mathrm{H} \beta_{2},{ }^{1} \mathrm{H} \beta_{3},{ }^{15} \mathrm{~N},{ }^{13} \mathrm{C} \alpha,{ }^{13} \mathrm{C} \beta$. The simulation was performed at $18.8 \mathrm{~T}$ magnetic field strength $\left({ }^{1} \mathrm{H}\right.$ frequency of $800 \mathrm{MHz}$ ). The RF irradiation of ${ }^{15} \mathrm{~N},{ }^{13} \mathrm{C} \alpha$ was considered on resonance, ${ }^{13} \mathrm{C} \beta$ was assumed $-20 \mathrm{ppm}$ off-resonance, and ${ }^{1} \mathrm{H}^{\mathrm{N}}$, ${ }^{1} \mathrm{H} \alpha,{ }^{1} \mathrm{H} \beta_{2} /{ }^{1} \mathrm{H} \beta_{3}$ chemical shift offset with respect to RF carrier (typically $4.7 \mathrm{ppm}$ for solvent signal) was set to $4.0,-0.5$ and -2.2 ppm, respectively. Chemical shift anisotropy was neglected for all spins. RF irradiation strength ranges were $0-250 \mathrm{kHz}$ for ${ }^{1} \mathrm{H},{ }^{13} \mathrm{C}$ and ${ }^{15} \mathrm{~N}$. RF field inhomogeneity was neglected, thus constant RF amplitude was assumed during CP. Only proton thermally equilibrated magnetization was considered at the starting point of the simulation. To simulate CP transfer the propagator for one rotor period was calculated and reused to reach contact time of $300 \mu \mathrm{s}$. The SIM-CP efficiency was evaluated as the ${ }^{15} \mathrm{~N}$ and ${ }^{13} \mathrm{C} \alpha$ magnetization at the end of RF irradiation. Further details, including geometry of the restricted spin system and sample scripts, can be found in SI.

\section{Automated assignment}

Automated analysis of obtained correlations was performed by FLYA as implemented in CYANA package v. 3.98.5. Library extensions for new types of experiments as well as CYANA batch scripts are provided in SI. Optimal assignment was obtained using matching tolerances of $0.1,0.3$ and $0.3 \mathrm{ppm}$ for ${ }^{1} \mathrm{H},{ }^{13} \mathrm{C}$ and ${ }^{15} \mathrm{~N}$ frequencies, respectively. A population size of 50 was set for genetic optimization algorithm. 20 independent runs were performed to identify consensus chemical shifts, with a threshold of 16 self-consistent chemical shift values for a "strong" assignment. Detailed statistics on the assignment completeness for particular nuclei and peak lists are provided in SI.

\section{ASSOCIATED CONTENT}

\section{Supporting Information}

Detailed NMR experimental setup, radiofrequency irradiation schemes with Bruker spectrometer implementation, details on data processing and automated analysis (PDF). The Supporting Information is available free of charge on the ACS Publications website.

\section{AUTHOR INFORMATION}

\section{Corresponding Author}

Guido Pintacuda (guido.pintacuda@ens-lyon.fr)

\section{Author Contributions}

\$These authors contributed equally.

\section{Notes}

The authors declare no competing financial interests.

\section{ACKNOWLEDGMENT}

The MBP plasmid was kindly provided by Prof. Gottfried Otting (ANU). The work was funded by the European Research Council (ERC) under the European Union's Horizon 2020 research and innovation programme (ERC-2015-CoG GA 648974). JS was supported with the European Commission's REA with a MSCA fellowship (GA 661799) and by the Polish National Agency for Academic Exchange (contract No PPN/PPO/2018/1/00098). The computational resources were provided by the Polish Infrastructure for Supporting Computational Science in the European Research Space (PLGRID).

\section{REFERENCES}

(1) Barbet-Massin, E.; Pell, A. J.; Retel, J. S.; Andreas, L. B.; Jaudzems, K.; Franks, W. T.; Nieuwkoop, A. J.; Hiller, M.; Higman, V.; Guerry, P.; Ber- tarello, A.; Knight, M. J.; Felletti, M.; Le Marchand, T.; Kotelovica, S.; Akopjana, I.; Tars, K.; Stoppini, M.; Vittorio, B.; Bolognesi, M.; Ricagno, S.; Chou, J. J.; Griffin, R. G.; Oschkinat, H.; Lesage, A.; Emsley, L.; Herrmann, T.; Pintacuda, G. Rapid proton-detected NMR assignment for proteins with fast magic angle spinning; J. Am. Chem. Soc. 2014, 136, 12489-12497. 
(2) Ishii, Y.; Yesinowski, J. P.; Tycko, R. Sensitivity enhancement in solid-state 13C NMR of synthetic polymers and biopolymers by $1 \mathrm{H}$ NMR detection with high-speed magic angle spinning; J. Am. Chem. Soc. 2001, 123, 2921-2922

(3) Reif, B.; Jaroniec, C. P.; Rienstra, C. M.; Hohwy, M.; Griffin, R. G. $1 \mathrm{H}-1 \mathrm{H}$ MAS correlation spectroscopy and distance measurements in a deuterated peptide; J. Magn. Reson. 2001, 151, 320-327.

(4) Paulson, E. K.; Morcombe, C. R.; Gaponenko, V.; Dancheck, B.; Byrd, R. A.; Zilm, K. W. Sensitive high resolution inverse detection NMR spectroscopy of proteins in the solid state; J. Am. Chem. Soc. 2003, 125, $15831-15836$

(5) Zhou, D. H.; Shea, J. J.; Nieuwkoop, A. J.; Franks, W. T.; Wylie, B. J.; Mullen, C.; Sandoz, D.; Rienstra, C. M. Solid-state protein-structure determination with proton-detected triple-resonance 3D magic-anglespinning NMR spectroscopy; Angew. Chem. Int. Ed. Engl. 2007, 46, 8380-8383.

(6) Andreas, L. B.; Le Marchand, T.; Jaudzems, K.; Pintacuda, G. Highresolution proton-detected NMR of proteins at very fast MAS; J. Magn. Reson. 2015, 253, 36-49.

(7) Böckmann, A.; Ernst, M.; Meier, B. H. Spinning proteins, the faster, the better?; J. Magn. Reson. 2015, 253, 71-79.

(8) Samoson, A. H-Mas; J. Magn. Reson. 2019, 306, 167-172.

(9) Knight, M. J.; Webber, A. L.; Pell, A. J.; Guerry, P.; Barbet-Massin, E.; Bertini, I.; Felli, I. C.; Gonnelli, L.; Pierattelli, R.; Emsley, L.; Lesage, A.; Herrmann, T.; Pintacuda, G. Fast resonance assignment and fold determination of human superoxide dismutase by high-resolution protondetected solid-state MAS NMR spectroscopy; Angew. Chem. Int. Ed. Engl. 2011, 50, 11697-11701.

(10) Lewandowski, J. R.; Dumez, J. N.; Akbey, Ü.; Lange, S.; Emsley, L.; Oschkinat, H. Enhanced resolution and coherence lifetimes in the solidstate NMR spectroscopy of perdeuterated proteins under ultrafast MagicAngle Spinning; J. Chem. Phys. Lett. 2011, 2, 2205-2211.

(11) Andreas, L. B.; Jaudzems, K.; Stanek, J.; Lalli, D.; Bertarello, A.; Le Marchand, T.; De Paepe, D. C.; Kotelovica, S.; Akopjana, I.; Knott, B.; Wegner, S.; Engelke, F.; Lesage, A.; Emsley, L.; Tars, K.; Herrmann, T.; Pintacuda, G. Structure of fully protonated proteins by proton-detected magic-angle spinning NMR; Proc. Natl. Acad. Sci. USA 2016, 113, 91879192.

(12) Struppe, J.; Quinn, C. M.; Lu, M.; Wang, M.; Hou, G.; Lu, X.; Kraus, J.; Andreas, L. B.; Stanek, J.; Lalli, D.; Lesage, A.; Pintacuda, G.; Maas, W.; Gronenborn, A. M.; Polenova, T. Expanding the horizons for structural analysis of fully protonated protein assemblies by NMR spectroscopy at MAS frequencies above $100 \mathrm{kHz}$; Solid State Nucl. Magn. Reson. 2017, 87, 117-125

(13) Marchanka, A.; Stanek, J.; Pintacuda, G.; Carlomagno, T. Rapid access to RNA resonances by proton-detected solid-state NMR at $>100$ kHz MAS; Chem. Commun. 2018, 54, 8972-8975.

(14) Penzel, S.; Smith, A. A.; Agarwal, V.; Hunkeler, A.; Org, M. L.; Samoson, A.; Böckmann, A.; Ernst, M.; Meier, B. H. Protein resonance assignment at MAS frequencies approaching $100 \mathrm{kHz}$ : a quantitative comparison of J-coupling and dipolar-coupling-based transfer methods; $J$. Biomol. NMR 2015, 63, 165-186.

(15) Andreas, L. B.; Stanek, J.; Le Marchand, T.; Bertarello, A.; Paepe, D. C.; Lalli, D.; Krejcikova, M.; Doyen, C.; Oster, C.; Knott, B.; Wegner, S.; Engelke, F.; Felli, I. C.; Pierattelli, R.; Dixon, N. E.; Emsley, L.; Herrmann, T.; Pintacuda, G. Protein residue linking in a single spectrum for magic-angle spinning NMR assignment; J. Biomol. NMR 2015, 62, 253-261.

(16) Xiang, S.; Grohe, K.; Rovó, P.; Vasa, S. K.; Giller, K.; Becker, S.; Linser, R. Sequential backbone assignment based on dipolar amide-toamide correlation experiments; J. Biomol. NMR 2015, 62, 303-311.

(17) Fricke, P.; Chevelkov, V.; Zinke, M.; Giller, K.; Becker, S.; Lange, A. Backbone assignment of perdeuterated proteins by solid-state NMR using proton detection and ultrafast magic-angle spinning; Nat. Protoc. 2017, 12, 764-782

(18) Wang, S.; Munro, R. A.; Shi, L.; Kawamura, I.; Okitsu, T.; Wada, A.; Kim, S.-Y.; Jung, K.-H.; Brown, L. S.; Ladizhansky, V. Solid-state NMR spectroscopy structure determination of a lipid-embedded heptahelical membrane protein; Nat. Meth. 2013, 10, 1007-1012.

(19) Retel, J. S.; Nieuwkoop, A. J.; Hiller, M.; Higman, V. A.; BarbetMassin, E.; Stanek, J.; Andreas, L. B.; Franks, W. T.; van Rossum, B. J.; Vinothkumar, K. R.; Handel, L.; de Palma, G. G.; Bardiaux, B.; Pintacuda, G.; Emsley, L.; Kuhlbrandt, W.; Oschkinat, H. Structure of outer membrane protein G in lipid bilayers; Nat. Commun. 2017, 8, 2073.
(20) Vasa, S. K.; Singh, H.; Rovo, P.; Linser, R. Dynamics and Interactions of a $29 \mathrm{kDa}$ Human Enzyme Studied by Solid-State NMR; $J$. Phys. Chem. Lett. 2018, 9, 1307-1311.

(21) Ward, M. E.; Shi, L.; Lake, E.; Krishnamurthy, S.; Hutchins, H.; Brown, L. S.; Ladizhansky, V. Proton-detected solid-state NMR reveals intramembrane polar networks in a seven-helical transmembrane protein proteorhodopsin; J. Am. Chem. Soc. 2011, 133, 17434-17443.

(22) Gauto, D. F.; Estrozi, L. F.; Schwieters, C. D.; Effantin, G.; Macek, P.; Sounier, R.; Sivertsen, A. C.; Schmidt, E.; Kerfah, R.; Mas, G.; Colletier, J. P.; Güntert, P.; Favier, A.; Schoehn, G.; Schanda, P.; Boisbouvier, J. Integrated NMR and cryo-EM atomic-resolution structure determination of a half-megadalton enzyme complex; Nat. Commun. 2019, 10, 2697.

(23) Gupta, S.; Tycko, R. Segmental isotopic labeling of HIV-1 capsid protein assemblies for solid state NMR; J. Biomol. NMR 2018, 70, 103114.

(24) Han, Y.; Ahn, J.; Concel, J.; Byeon, I.-J. L.; Gronenborn, A. M.; Yang, J.; Polenova, T. Solid-State NMR Studies of HIV-1 Capsid Protein Assemblies; J. Am. Chem. Soc. 2010, 132, 1976-1987.

(25) Stanek, J.; Andreas, L. B.; Jaudzems, K.; Cala, D.; Lalli, D.; Bertarello, A.; Schubeis, T.; Akopjana, I.; Kotelovica, S.; Tars, K.; Pica, A.; Leone, S.; Picone, D.; Xu, Z.-Q.; Dixon, N. E.; Martinez, D.; Berbon, M.; El Mammeri, N.; Noubhani, A.; Saupe, S.; Habenstein, B.; Loquet, A.; Pintacuda, G. NMR spectroscopic assignment of backbone and sidechain protons in fully protonated proteins: microcrystals, sedimented assemblies, and amyloid fibrils; Angew. Chem. Int. Ed. 2016, 128, 1573015735 .

(26) Lalli, D.; Idso, M. N.; Andreas, L. B.; Hussain, S.; Baxter, N.; Han, S.; Chmelka, B. F.; Pintacuda, G. Proton-Based Structural Analysis of a Heptahelical Transmembrane Protein in Lipid Bilayers; J. Am. Chem. Soc. 2017, 139, 13006-13012.

(27) Malmodin, D.; Papavoine, C. H.; Billeter, M. Fully automated sequence-specific resonance assignments of hetero-nuclear protein spectra; J. Biomol. NMR 2003, 27, 69-79.

(28) Niklasson, M.; Ahlner, A.; Andresen, C.; Marsh, J. A.; Lundström, P. Fast and accurate resonance assignment of small-to-large proteins by combining automated and manual approaches; PLoS Comput. Biol. 2015, $11, \mathrm{e} 1004022$.

(29) Gopinath, T.; Veglia, G. Dual acquisition magic-angle spinning solidstate NMR-spectroscopy: simultaneous acquisition of multidimensional spectra of biomacromolecules; Angew. Chem. Int. Ed. Engl. 2012, 51, 2731-2735.

(30) Das, B. B.; Opella, S. J. Multiple acquisition/multiple observation separated local field/chemical shift correlation solid-state magic angle spinning NMR spectroscopy; J. Magn. Reson. 2014, 245, 98-104.

(31) Linser, R.; Bardiaux, B.; Higman, V.; Fink, U.; Reif, B. Structure calculation from unambiguous long-range amide and methyl $1 \mathrm{H}-1 \mathrm{H}$ distance restraints for a microcrystalline protein with MAS solid-state NMR spectroscopy; J. Am. Chem. Soc. 2011, 133, 5905-5912.

(32) Gopinath, T.; Veglia, G. Orphan spin operators enable the acquisition of multiple 2D and 3D magic angle spinning solid-state NMR spectra; $J$ Chem Phys 2013, 138, 184201.

(33) Sharma, K.; Madhu, P. K.; Mote, K. R. A suite of pulse sequences based on multiple sequential acquisitions at one and two radiofrequency channels for solid-state magic-angle spinning NMR studies of proteins; $J$. Biomol. NMR 2016, 65, 127-141.

(34) Vranken, W. F.; Boucher, W.; Stevens, T. J.; Fogh, R. H.; Pajon, A.; Llinas, M.; Ulrich, E. L.; Markley, J. L.; Ionides, J.; Laue, E. D. The CCPN data model for NMR spectroscopy: development of a software pipeline; Proteins 2005, 59, 687-696.

(35) Schmidt, E.; Güntert, P. A new algorithm for reliable and general NMR resonance assignment; J. Am. Chem. Soc. 2012, 134, 12817-12829. (36) Schmidt, E.; Gath, J.; Habenstein, B.; Ravotti, F.; Székely, K.; Huber, M.; Buchner, L.; Böckmann, A.; Meier, B. H.; Güntert, P. Automated solid-state NMR resonance assignment of protein microcrystals and amyloids; J. Biomol. NMR 2013, 56, 243-254.

(37) Pritišanac, I.; Würz, J. M.; Alderson, T. R.; Güntert, P. Automatic structure-based NMR methyl resonance assignment in large proteins; Nat. Commun. 2019, 10, 4922.

(38) Barbet-Massin, E.; Pell, A. J.; Jaudzems, K.; Franks, W. T.; Retel, J. S.; Kotelovica, S.; Akopjana, I.; Tars, K.; Emsley, L.; Oschkinat, H.; Lesage, A.; Pintacuda, G. Out-and-back 13C-13C scalar transfers in protein resonance assignment by proton-detected solid-state NMR under ultra-fast MAS; J. Biomol. NMR 2013, 56, 379-386. 
(39) Shen, Y.; Bax, A. Protein backbone and sidechain torsion angles predicted from NMR chemical shifts using artificial neural networks; $J$. Biomol. NMR 2013, 56, 227-241.

(40) Salzmann, M.; Pervushin, K.; Wider, G.; Senn, H.; Wüthrich, K. TROSY in triple-resonance experiments: new perspectives for sequential NMR assignment of large proteins; Proc. Natl. Acad. Sci. U. S. A. 1998, $95,13585-13590$.

(41) Bertini, I.; Engelke, F.; Gonnelli, L.; Knott, B.; Luchinat, C.; Osen, D.; Ravera, E. On the use of ultracentrifugal devices for sedimented solute NMR; J. Biomol. NMR 2012, 54, 123-127.
(42) Delaglio, F.; Grzesiek, S.; Vuister, G. W.; Zhu, G.; Pfeifer, J.; Bax, A. NMRPipe: a multidimensional spectral processing system based on UNIX pipes; J. Biomol. NMR 1995, 6, 277-293.

(43) Bak, M.; Rasmussen, J. T.; Nielsen, N. C. SIMPSON: a general simulation program for solid-state NMR spectroscopy; J. Magn. Reson. 2000, 147, 296-330.

(44) Bak, M.; Nielsen, N. C. REPULSION, A Novel Approach to Efficient Powder Averaging in Solid-State NMR; J. Magn. Reson. 1997, $125,132-139$ 


\section{Supporting Information}

\section{Automated backbone NMR resonance assignment of large proteins using redundant linking from a single simulta- neous acquisition}

Jan Stanek, $\#, \|, \sharp$ Tobias Schubeis, ${ }^{\#, \ddagger}$ Piotr Paluch, $\|$ Peter Güntert, ${ }^{\&, \S,=}$ Loren B Andreas,,,+ and Guido Pintacuda ${ }^{\#, *}$

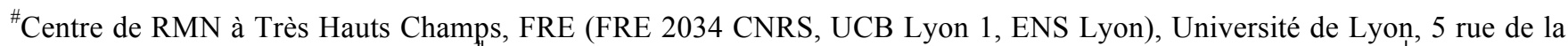
Doua, 69100 Villeurbanne, France; ${ }^{\|}$Faculty of Chemistry, University of Warsaw, 02089 Warsaw, Poland; ${ }^{\perp}$ Max Planck Institute for Biophysical Chemistry, Am Fassberg 11, D-37077 Göttingen, Germany, ${ }^{\&}$ Physical Chemistry, Eidgenössische Technische Hochschule Zurich, Zurich, Switzerland; ${ }^{\S}$ Center for Biomolecular Magnetic Resonance, Institute of Biophysical Chemistry, Goethe University Frankfurt, Frankfurt, Germany; 'Department of Chemistry, Tokyo Metropolitan University, Hachioji, Japan

CONTENTS

A. SIMULTANEOUS CP UNDER ULTRAFAST MAS 2

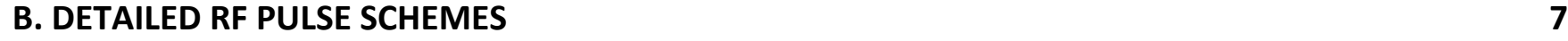

$\begin{array}{lr}\text { C. NMR DATA ACQUISITION PARAMETERS } & 10\end{array}$

D. SENSITIVITY OF RAVASSA PATHWAYS 13

$\begin{array}{lr}\text { E. NMR DATA PROCESSING } & 15\end{array}$

F. JOINT MANUAL ANALYSIS OF INTRA AND INTERRESIDUE HN AND HA-DETECTED SPECTRA 17

$\begin{array}{lr}\text { G. DETAILS OF AUTOMATED ASSIGNMENT } & 17\end{array}$

$\begin{array}{lr}\text { H. CHEMICAL SHIFTS OF MBP IN THE SOLID-STATE VERSUS IN SOLUTION } & 20\end{array}$

$\begin{array}{lr}\text { I. EXTENSIONS OF THE FLYA LIBRARY } & 21\end{array}$

$\begin{array}{lr}\text { J. PULSE PROGRAMS IN BRUKER CODE } & 22\end{array}$

$\begin{array}{lr}\text { K. REFERENCES } & 41\end{array}$ 


\section{A. Simultaneous CP under ultrafast MAS}

The contribution of amide and aliphatic proton to ${ }^{15} \mathrm{~N}$ and ${ }^{13} \mathrm{C}$ pathways in conventional ${ }^{15} \mathrm{~N}$ - and ${ }^{13} \mathrm{C}-\mathrm{CP}-\mathrm{HSQC}$ experiments is tracked in Figure S1 by frequency encoding the source proton. It can be seen that the two ${ }^{1} \mathrm{H}^{\mathrm{N}} \rightarrow{ }^{15} \mathrm{~N}$ and ${ }^{1} \mathrm{H} \alpha \rightarrow{ }^{13} \mathrm{C} \alpha$ paths are nearly independent, with for example only about 7 percent of the signal in Fig S1B originating from amide protons (Box B4). In S1A, box $\mathrm{A} 1$ and $\mathrm{A} 2$, it can be seen that about 13 percent of the signal in the $\mathrm{H}-\mathrm{N}-\mathrm{H}$ transfer pathway originates from aliphatic protons and about 5 percent from alpha protons. Lost magnetization in the final CP (Boxes A4 and B1) is also minimal, and is not included in the determination of total signal. Note that this magnetization leak occurs irrespective of whether conventional or simultaneous $\mathrm{CP}$ is performed, and is generally related to the "cross-talk" between pathways (i.e. ${ }^{15} \mathrm{~N} \rightarrow{ }^{1}$ Haliphatic and ${ }^{13} \mathrm{C} \alpha \rightarrow{ }^{1} \mathrm{H}^{\mathrm{N}}$ transfers).

At $100 \mathrm{kHz}$ MAS, we observed a 6 and 16\% loss, respectively, in the simultaneous experiments as compared with conventional ${ }^{13} \mathrm{C}$ - and ${ }^{15} \mathrm{~N}-\mathrm{CP}$-HSQC spectra recorded separately (Figure S3). The negligible loss for the ${ }^{13} \mathrm{C}$ pathway, and the larger loss for ${ }^{15} \mathrm{~N}$ are in full agreement with previous reports for SIM-CP with heteronuclear detection at slow MAS. ${ }^{1}$ A somewhat larger impact of SIM-CP for ${ }^{15} \mathrm{~N}$ is fully confirmed by quantum-mechanical simulations ${ }^{2}$ on a system of 7 spins (Figure S2). These simulations highlight that the ${ }^{15} \mathrm{~N}$ spins are sensitive to drainage of ${ }^{1} \mathrm{H} \alpha$ (and other aliphatic) polarization during concurrent ${ }^{1} \mathrm{H}-{ }^{13} \mathrm{C} \mathrm{CP}$, while for ${ }^{13} \mathrm{C} \alpha$, abundant remote side-chain protons constitute a better polarization reservoir.

Figure S4 shows the performance of ${ }^{1} \mathrm{H}-{ }^{13} \mathrm{C}$ and ${ }^{1} \mathrm{H}-{ }^{15} \mathrm{~N}$ (independent) $\mathrm{CP}$ transfers measured as the largest magnitude in ${ }^{13} \mathrm{C}$ - and ${ }^{15} \mathrm{~N}$-CP-HSQC 1D experiments as a function of ${ }^{1} \mathrm{H}$ and ${ }^{13} \mathrm{C}$, or ${ }^{1} \mathrm{H}$ and ${ }^{15} \mathrm{~N}$ RF strengths, respectively. This proves that both CPs exhibit optimal efficiency for analogous conditions, and simultaneous ${ }^{1} \mathrm{H}-{ }^{13} \mathrm{C},{ }^{15} \mathrm{~N} \mathrm{CP}$, which requires a common ${ }^{1} \mathrm{H}$ RF field strength for both transfers, does not compromise their efficiency.
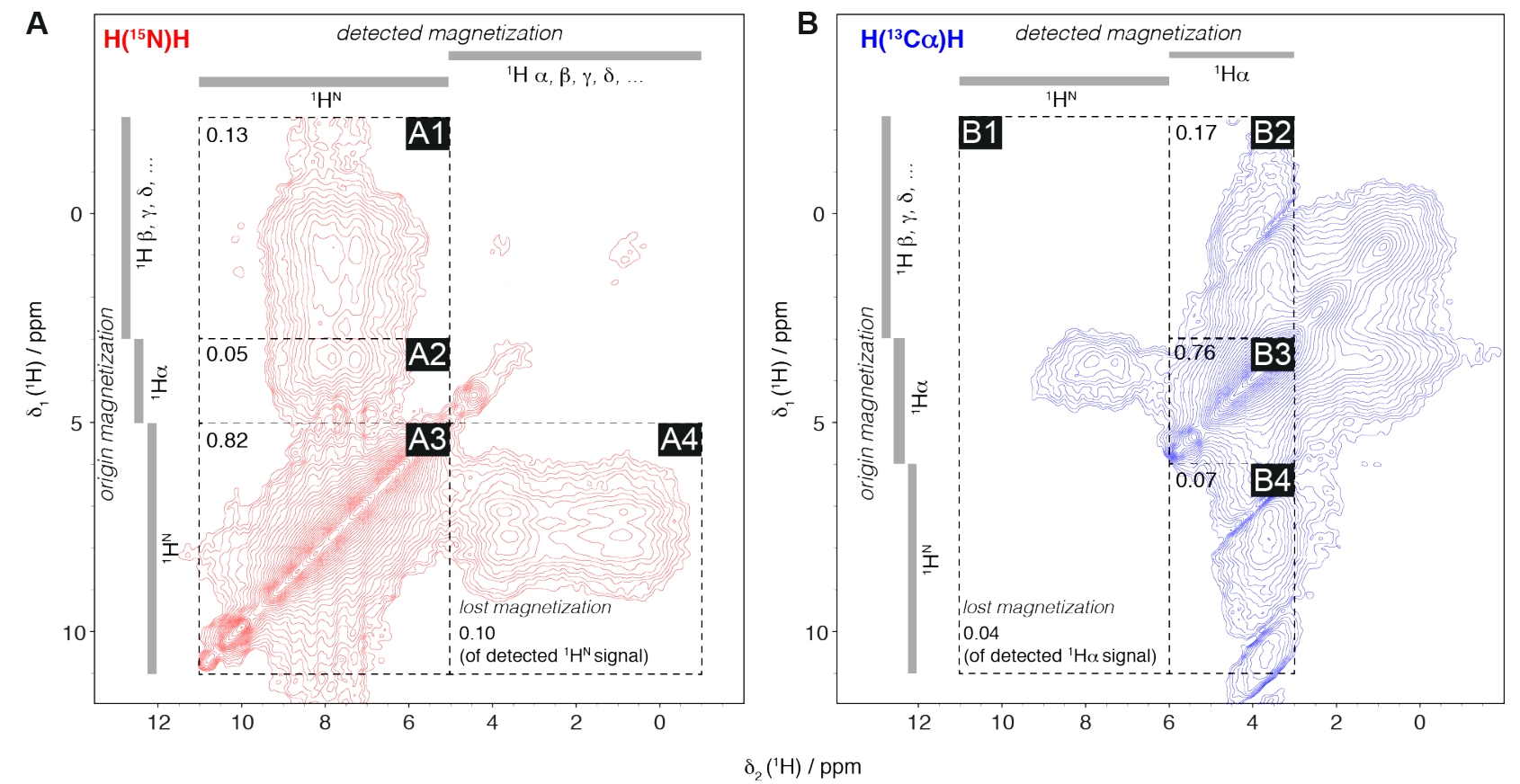

Figure S1. Investigation of the degree of independence and interference during simultaneous $\mathrm{CP}$ by recording the source proton in normally acquired $2 \mathrm{D} \mathrm{H}(\mathrm{N}) \mathrm{H}$ and $\mathrm{H}(\mathrm{C}) \mathrm{H}$ spectra. Optimized contact times of forward $\mathrm{CP}$ were $1100 \mu \mathrm{s}\left({ }^{1} \mathrm{H} \rightarrow{ }^{15} \mathrm{~N}\right)$ and $400 \mu \mathrm{s}$ $\left({ }^{1} \mathrm{H} \rightarrow{ }^{13} \mathrm{C}\right)$, and of backward $\mathrm{CP}$ were $900 \mu \mathrm{s}\left({ }^{15} \mathrm{~N} \rightarrow{ }^{1} \mathrm{H}\right)$ and $200 \mu \mathrm{s}\left({ }^{13} \mathrm{C} \rightarrow{ }^{1} \mathrm{H}\right)$ were used. 


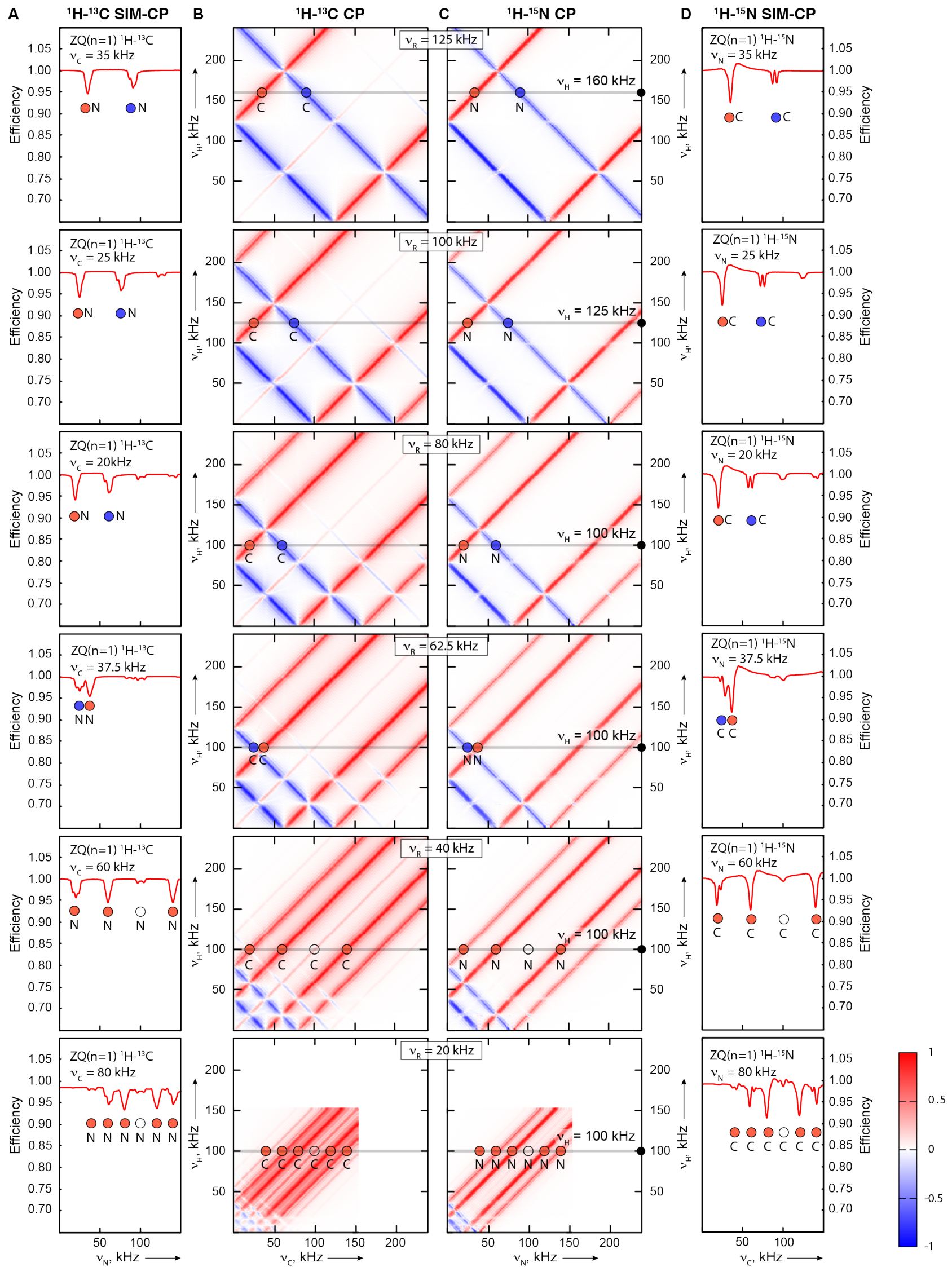

Figure S2. SIMPSON simulations that characterize interference occurring during simultaneous CP, leading to minor loss of transfer efficiency. The simulations were performed for ${ }^{1} \mathrm{H}-{ }^{13} \mathrm{C}(\mathrm{A}, \mathrm{B})$ and ${ }^{1} \mathrm{H}-{ }^{15} \mathrm{~N} \mathrm{CP}(\mathrm{C}, \mathrm{D})$ with ${ }^{13} \mathrm{C}$ or ${ }^{15} \mathrm{~N}$ detection. Simulation of ${ }^{1} \mathrm{H}-{ }^{13} \mathrm{C}$ or ${ }^{15} \mathrm{~N} \mathrm{CP}$ transfer efficiency is shown in various conditions of different spinning frequencies $\left(v_{R}\right)$ equal to $125,100,80,62.5,40,20 \mathrm{kHz}$. In the case of simulation at $v_{R}=20 \mathrm{kHz}$, an RF field of up to only $160 \mathrm{kHz}$ was considered due to general probe limitation when operating typical devices that spin at this frequency. A) Simultaneous ${ }^{1} \mathrm{H}-{ }^{13} \mathrm{C} /{ }^{1} \mathrm{H}_{-}{ }^{15} \mathrm{~N} \mathrm{CP}$ with ${ }^{13} \mathrm{C}$ detection as a function of $v_{15 \mathrm{~N}}$ and constant $v_{1 \mathrm{H}}$ and $v_{13 \mathrm{C}}$, B) 
Dual channel (conventional) ${ }^{1} \mathrm{H}_{-}{ }^{13} \mathrm{C} \mathrm{CP}$ as a function of $v_{1 \mathrm{H}}$ and $v_{13 \mathrm{C}}, \mathrm{C}$ ) Dual channel ${ }^{1} \mathrm{H}_{-}{ }^{15} \mathrm{~N} \mathrm{CP}$ as function of $v_{1 \mathrm{H}}$ and $v_{15 \mathrm{~N}}$, D) Simultaneous ${ }^{1} \mathrm{H}-{ }^{13} \mathrm{C} /{ }^{1} \mathrm{H}-{ }^{15} \mathrm{~N}$ CP with ${ }^{15} \mathrm{~N}$ detection as a function of $v_{13 \mathrm{C}}$ and constant $v_{1 \mathrm{H}}$ and $v_{15 \mathrm{~N}}$. In A) and D), a slight decrease (up to $8 \%$ ) in transfer efficiency is observed when the ${ }^{15} \mathrm{~N}$ or ${ }^{13} \mathrm{C}$ RF reaches an effective simultaneous $\mathrm{CP}$ matching condition with the proton RF. These conditions are indicated with red and blue dots, according to whether the simultaneous $\mathrm{CP}$ is a zero- or double-quantum condition, and labeled with the nucleus name ("C" or "N").

Listing 1. Sample SIMPSON input for simulation of simultaneous CP (SIM-CP).

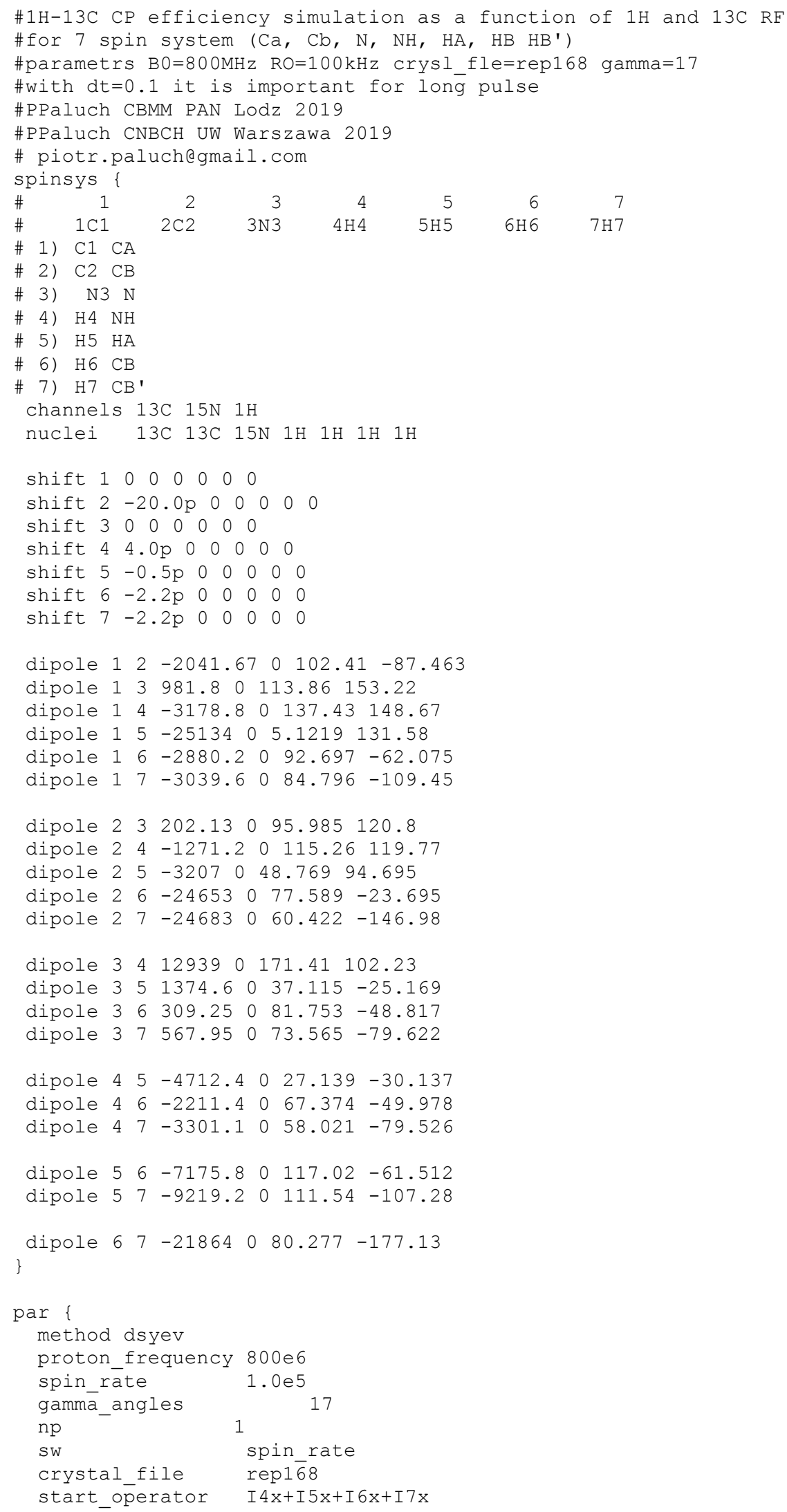




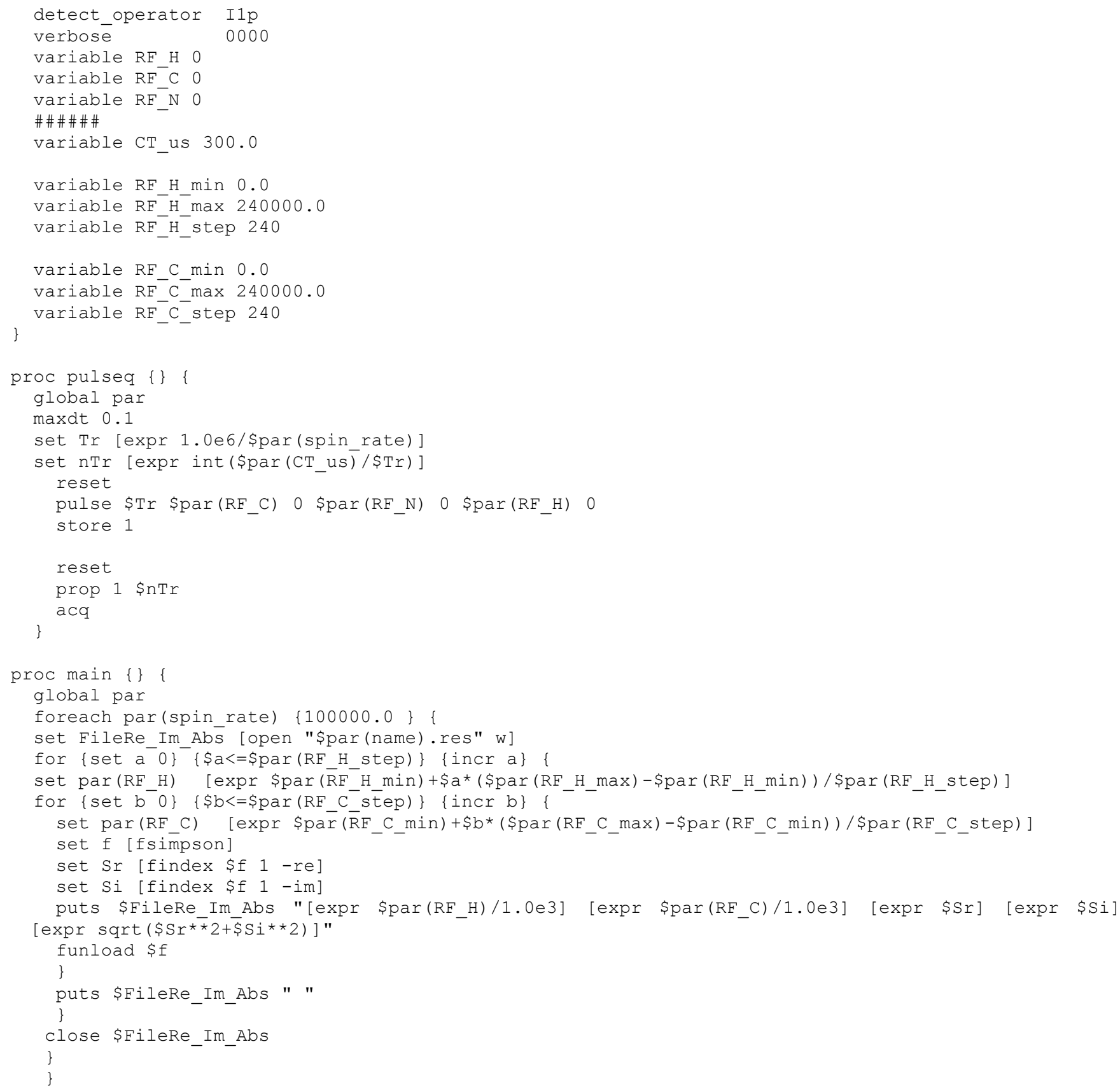



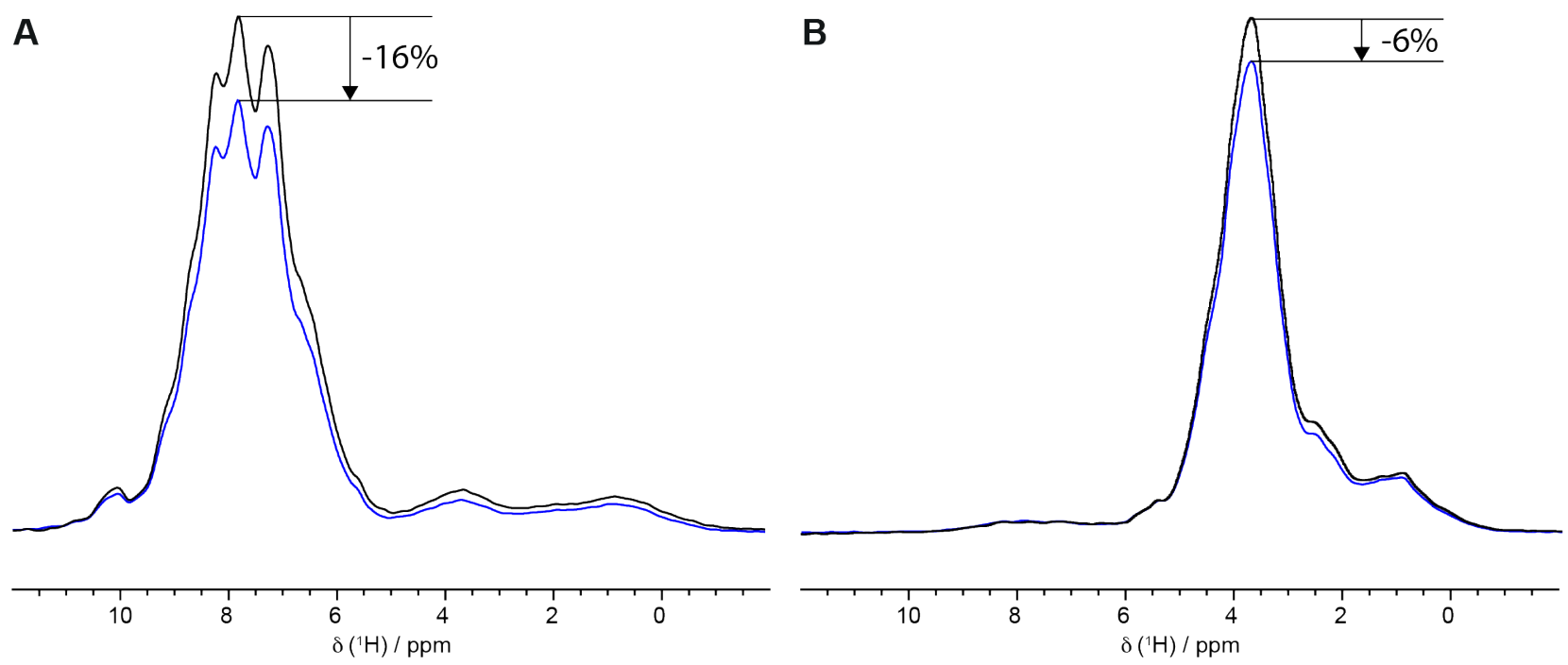

Figure S3. Quantification of interference between ${ }^{1} \mathrm{H} \rightarrow{ }^{15} \mathrm{~N}$ and ${ }^{1} \mathrm{H} \rightarrow{ }^{13} \mathrm{C} \mathrm{CP}$ at $107 \mathrm{kHz}$ MAS on a sample of uniformly ${ }^{13} \mathrm{C},{ }^{15} \mathrm{~N}-$ labeled maltose binding protein. (A) $1 \mathrm{D}(\mathrm{H}) \mathrm{NH}$ experiment recorded with (in blue) and without (in black) simultaneous irradiation of ${ }^{13} \mathrm{C}$ nuclei. (B) $1 \mathrm{D}(\mathrm{H}) \mathrm{CH}$ experiment with a ${ }^{13} \mathrm{C} \alpha$-selective refocusing pulse recorded with (in blue) and without (in black) simultaneous irradiation of ${ }^{15} \mathrm{~N}$ nuclei. ${ }^{15} \mathrm{~N}$ and ${ }^{13} \mathrm{C}$ RF irradiation was applied for the same time in all cases (800 $\left.\mu \mathrm{s}\right)$.
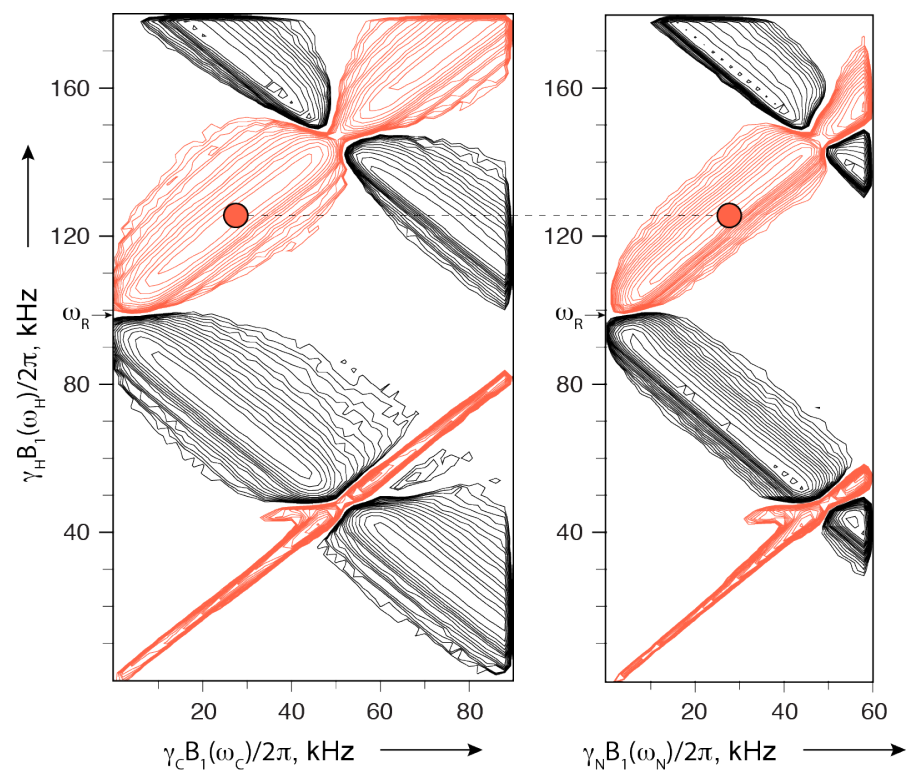

Figure S4. Standard (sequential) $\mathrm{CP}$ conditions for ${ }^{1} \mathrm{H}_{-}{ }^{13} \mathrm{C}$ (left) and ${ }^{1} \mathrm{H}^{-15} \mathrm{~N} \mathrm{CP}$ (right) at $107 \mathrm{kHz}$ MAS in a 0.7 mm Bruker HCN probe on a $800 \mathrm{MHz}$ spectrometer. Signal intensity was evaluated by stepwise variation of ${ }^{1} \mathrm{H}$ and either ${ }^{13} \mathrm{C}$ or ${ }^{15} \mathrm{~N}$ RF strength during a fixed contact time $\mathrm{CP}$ following the first ${ }^{1} \mathrm{H}$ pulse in a $1 \mathrm{D}(\mathrm{H}) \mathrm{CH}$ or $(\mathrm{H}) \mathrm{NH}$ experiment ("first FID"). The intensities along detected ${ }^{1} \mathrm{H}$ dimension were summed over the aliphatic or amide ${ }^{1} \mathrm{H}$ range. Zero-quantum (ZQ) and double-quantum (DQ) CP show opposite signs and are shown in red and black, respectively. Red disks connected by a horizontal dashed line (i.e. at common ${ }^{1} \mathrm{H}$ RF strength) indicate the optimal $\mathrm{CP}$ conditions for both sequential transfers, which are chosen here for the simultaneous CP (SIM-CP). 


\section{B. Detailed RF pulse schemes}

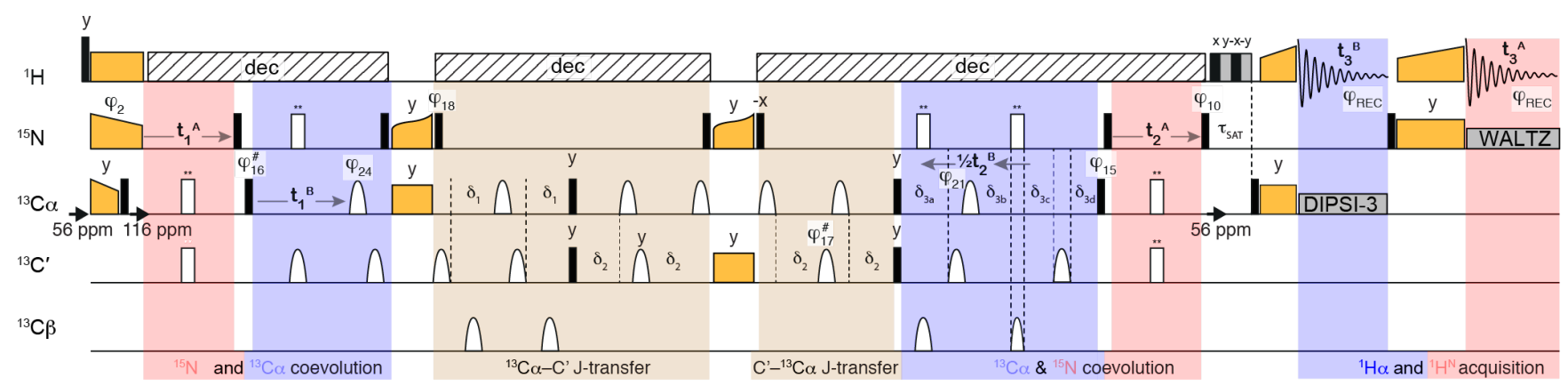

Figure S5. Radiofrequency (RF) pulse scheme for the "8-in-1" experiment. Heteronuclear cross-polarization (CP) transfers are shown as either wide rectangular, trapezoid or tangential orange shapes simultaneously on two or three RF channels. RF strength, duration and detailed shapes for CP transfers are provided in Table S2. Solid and open pulses represent high-power $90^{\circ}$ and $180^{\circ}$ pulses, respectively. Open pulses marked with double star $\left(^{* *}\right)$ denote composite $180^{\circ}$ pulses $90_{x}^{\circ} 180_{y}{ }^{\circ} 90_{x}^{\circ}$, which were used to minimize signal losses on the pathways other than the decoupled one. In our implementation (see Section J) these pulses are optional, and can be skipped for short evolution times. Open bell shapes on ${ }^{13} \mathrm{C}$ channels represent $\mathrm{Q} 3{ }^{3}$ (for ${ }^{13} \mathrm{C} \alpha$ and ${ }^{13} \mathrm{C}^{\prime}$ ) and ReBURP ${ }^{4}$ (for ${ }^{13} \mathrm{C} \beta$ ) selective pulses. Pulse durations and peak RF strength were $161.5,178.5$ and $960.9 \mu$ s and $20.43,18.49$ and $6.52 \mathrm{kHz}$ for ${ }^{13} \mathrm{C} \alpha,{ }^{13} \mathrm{C}^{\prime}$ and ${ }^{13} \mathrm{C} \beta$ pulses respectively. Note that the moderately selective ${ }^{13} \mathrm{C} \alpha$ pulses affect both ${ }^{13} \mathrm{C} \alpha$ and ${ }^{13} \mathrm{C} \beta$ spins. Heteronuclear ${ }^{1} \mathrm{H}$ decoupling during indirect evolution or $J$-transfer periods is shown in hatched grey. Swept-TPPM ${ }^{5-6}{ }^{1} \mathrm{H}$ decoupling with RF field of $10 \mathrm{kHz}$ and pulse length of $25 \mu \mathrm{s}$ was used. WALTZ-16 ${ }^{7}$ and DISPI- $3^{8}$ with RF strength of 10 and $20 \mathrm{kHz}$, and pulse lengths of 25 and $12.5 \mu \mathrm{s}$, were used for ${ }^{15} \mathrm{~N}$ and ${ }^{13} \mathrm{C}$ decoupling during signal acquisition, respectively. The MISSISSIPPI water suppression, ${ }^{9}$ with duration $\tau_{\mathrm{SAT}}$ of $200 \mathrm{~ms}$ and RF strength of $25.4 \mathrm{kHz}$, is shown as a composite block of four solid and grey pulses. Relaxation-optimized ${ }^{13} \mathrm{C} \alpha-{ }^{13} \mathrm{C}^{\prime} J$-transfer delays $\delta_{1}$ and $\delta_{2}$ were 4.2 and $4.3 \mathrm{~ms}$, respectively. They were derived from the formula: $\delta=1 / 2 \tan ^{-1}\left(\pi J T_{2}{ }^{\prime}\right) /(\pi J)$, where $T_{2}^{\prime}$ denotes either the ${ }^{13} \mathrm{C} \alpha$ or $\mathrm{C}^{\prime}$ refocused coherence lifetime (estimated to 48 and $70 \mathrm{~ms}$, respectively). ${ }^{13} \mathrm{C} \alpha-{ }^{13} \mathrm{C}^{\prime} J$-coupling constant of $55 \mathrm{~Hz}$ was assumed. ${ }^{13} \mathrm{C} \alpha$ evolution in $t_{2}\left(\right.$ denoted $t_{2 \mathrm{~B}}$ ) was performed in constant- or real-time, depending on whether $t_{2 \mathrm{~B}}$ exceeded the relaxation-optimized transfer delay $\delta_{1}$ or the maximum transfer time $\delta^{*}=1 / 2(2 J)^{-1}$. Namely, the delays $\delta_{3 \mathrm{a}}, \delta_{3 \mathrm{~b}}, \delta_{3 \mathrm{c}}, \delta_{3 \mathrm{~d}}$ were set to respectively $\delta_{1}-1 / 2 t_{2 \mathrm{~B}}, 1 / 4 t_{2 \mathrm{~B}}+1 / 2\left(\delta_{1}-p w^{\mathrm{CB}}\right), 1 / 4 t_{2 \mathrm{~B}}+1 / 2\left(\delta_{1}-p w^{\mathrm{CB}}\right)$ and 0 if $t_{2 \mathrm{~B}}<2\left(\delta_{1}-p w^{\mathrm{CB}}\right)$; to respectively $p w^{\mathrm{CB}}, 1 / 2 t_{2 \mathrm{~B}}, 1 / 2 t_{2 \mathrm{~B}}$ and 0 if $2\left(\delta_{1}-p w^{\mathrm{CB}}\right) \leq t_{2 \mathrm{~B}}<2\left(\delta^{*}-p w^{\mathrm{CB}}\right)$; and to respectively $p w^{\mathrm{CB}}, 1 / 2 t_{2 \mathrm{~B}}, \delta^{*}-$ $p w^{\mathrm{CB}}$ and $1 / 2 t_{2 \mathrm{~B}}-\left(\delta^{*}-p w^{\mathrm{CB}}\right)$ for $t_{2 \mathrm{~B}} \geq 2\left(\delta^{*}-p w^{\mathrm{CB}}\right)$, where $p w^{\mathrm{CB}}$ stands for the duration of ${ }^{13} \mathrm{C} \beta$-selective pulse. All pulses have phase $x$ unless indicated. The phase cycle was (for convenience the numbering of phases is consistent with pulse sequence code provided below): $\phi_{2}=\{y,-y\}, \phi_{10}=\{x, x,-x,-x\}, \phi_{15}=\{x, x,-x,-x\}, \phi_{16}=\{x,-x\}, \phi_{17}=y, \phi_{18}=x, \phi_{21}=x, \phi_{24}=x$, and $\phi_{\text {rec }}=\{y,-y,-y, y\}$. Quadrature detection in the indirect dimensions was accomplished using the States-TPPI ${ }^{10}$ method by incrementing $\phi_{2}$ and $\phi_{16}$ (in $t_{1}$ ) and decrementing $\phi_{10}$ and $\phi_{15}$ (in $t_{2}$ ), independently from $t_{1}$ and $t_{2}$ time incrementation. Additionally, a quarter spectral window upfield and downfield shift for respectively ${ }^{15} \mathrm{~N}$ and ${ }^{13} \mathrm{C} \alpha$ resonances, was implemented by incrementing $\phi_{2}$ and $\phi_{16}$ in synchrony with $t_{1}$ time incrementation, i.e. $\phi_{2}=\{y$, $y\}+90^{\circ} \times\left(\left(t_{1} s w_{1}\right) \bmod 4\right)$. The ${ }^{15} \mathrm{~N}$ offset was set to $117.5 \mathrm{ppm}$ while the ${ }^{1} \mathrm{H}$ offset was set on resonance with the $\mathrm{H}_{2} \mathrm{O}$ line $($ approx. 4.8 ppm). The ${ }^{13} \mathrm{C}$ offset was set to the center of the ${ }^{13} \mathrm{C} \alpha$ band $(56.4 \mathrm{ppm})$ for the first and last $\mathrm{CP}$ transfer, and in-between the ${ }^{13} \mathrm{C} \alpha$ and ${ }^{13} \mathrm{C}^{\prime}$ regions (116.4 ppm) for the rest of the sequence (as indicated by horizontal arrows). Effectively, both $t_{1}$ and $t_{2}{ }^{13} \mathrm{C} \alpha$ evolution is performed off-resonance, and the extra acquired phase is compensated by the time-proportional phase incrementation on refocusing pulses with phases $\phi_{21}$ and $\phi_{24}: \phi_{21}=\{x\}+180 * \Delta \Omega * t_{2}, \phi_{24}=\{x\}+180 * \Delta \Omega * t_{1}$ (in degrees), where $\Delta \Omega=\Omega_{\mathrm{C} \alpha}-\Omega_{0}$ (in hertz). Also, all shaped ${ }^{13} \mathrm{C}$ pulses are performed off-resonance by a stepwise phase modulation with respective offset difference $\Omega_{\mathrm{C} \alpha}-\Omega_{0}=-60$ ppm, $\Omega_{\mathrm{C}}{ }^{\prime}-\Omega_{0}=60$ ppm or $\Omega_{\mathrm{C} \beta}-\Omega_{0}=-91 \mathrm{ppm}$ (where $\Omega_{0}$ stands for the carrier offset). The ${ }^{13} \mathrm{C}$ pulses for ${ }^{15} \mathrm{~N}-{ }^{13} \mathrm{C} \alpha$ and ${ }^{15} \mathrm{~N}-{ }^{13} \mathrm{C}^{\prime} \mathrm{CP}$ transfers are performed with relative offsets $\Omega_{\mathrm{C} \alpha}-\Omega_{0}-60 \mathrm{ppm}=-120 \mathrm{ppm}$ and $\Omega_{\mathrm{C}}{ }^{\prime}-\Omega_{0}+60 \mathrm{ppm}=+120 \mathrm{ppm}$, respectively. The additional $\pm 60 \mathrm{ppm}$ offset is to minimize undesired ${ }^{15} \mathrm{~N}-{ }^{13} \mathrm{C}^{\prime}$ and ${ }^{15} \mathrm{~N}-{ }^{13} \mathrm{C} \alpha$ transfers during these $\mathrm{CP}$ transfers (these lossy transfers arise due to the direction of the ${ }^{15} \mathrm{~N}$ ramp enforced by other pathways). Zero phase alignment for the ${ }^{13} \mathrm{C}$ pulses during ${ }^{15} \mathrm{~N}-{ }^{13} \mathrm{C} \alpha$ and ${ }^{15} \mathrm{~N}-{ }^{13} \mathrm{C}^{\prime} \mathrm{CP}$ transfers was enforced at the end and the beginning of the pulse, respectively. While this ensures the phase agreement for ${ }^{13} \mathrm{C}$ pulses between these two $\mathrm{CP}$ transfers, a constant phase difference with respect to the $90^{\circ}$ pulse before ${ }^{15} \mathrm{~N}-{ }^{13} \mathrm{C} \alpha \mathrm{CP}$ (causing a zero-order phase for ${ }^{13} \mathrm{C} \alpha$ in $\omega_{1}$ ), and with respect to the $90^{\circ}$ pulse after ${ }^{15} \mathrm{~N}-{ }^{13} \mathrm{C}^{\prime} \mathrm{CP}$ is generated (leading to the loss of signal). It is thus necessary to correct these phase shifts, e.g. by empirically optimizing the phases $\phi_{16}$ and $\phi_{17}$, while a single pathway is selected (see Section J). In our experiment, the best values of $310^{\circ}$ and $75^{\circ}$ were found for $\phi_{16}$ and $\phi_{17}$, respectively. Additionally, as shown in Figure S6, among 8 recorded types of correlations there are four pairs sharing the same frequency regions in $\omega_{1}, \omega_{2}$ and $\omega_{3}$ dimensions $\left(\right.$ e.g. ${ }^{13} \mathrm{C} \alpha(i-1)-{ }^{15} \mathrm{~N}(i)-{ }^{1} \mathrm{H}^{\mathrm{N}}(i)$ and $\left.{ }^{13} \mathrm{C} \alpha(i)-{ }^{15} \mathrm{~N}(i)-{ }^{1} \mathrm{H}^{\mathrm{N}}(i)\right)$. They can be discriminated based on which term, i.e. either ${ }^{15} \mathrm{~N}$ or ${ }^{13} \mathrm{C}$, is present between the ${ }^{15} \mathrm{~N}-{ }^{13} \mathrm{C} \alpha$ and ${ }^{15} \mathrm{~N}-{ }^{13} \mathrm{C}^{\prime} \mathrm{CP}$ transfers. Here, an extra $1800^{\circ}$ incrementation of phase $\phi_{18}$ is introduced as the innermost loop, and the interleaved data requires a linear combination (addition and subtraction) during signal processing as described in section $\mathrm{E}$. 
a)

$(\mathrm{H}) \mathrm{N}(\mathrm{CA})(\mathrm{CO}) \mathrm{NH}+(\mathrm{H}) \mathrm{CA}(\mathrm{N})(\mathrm{CO}) \mathrm{CAHA}$

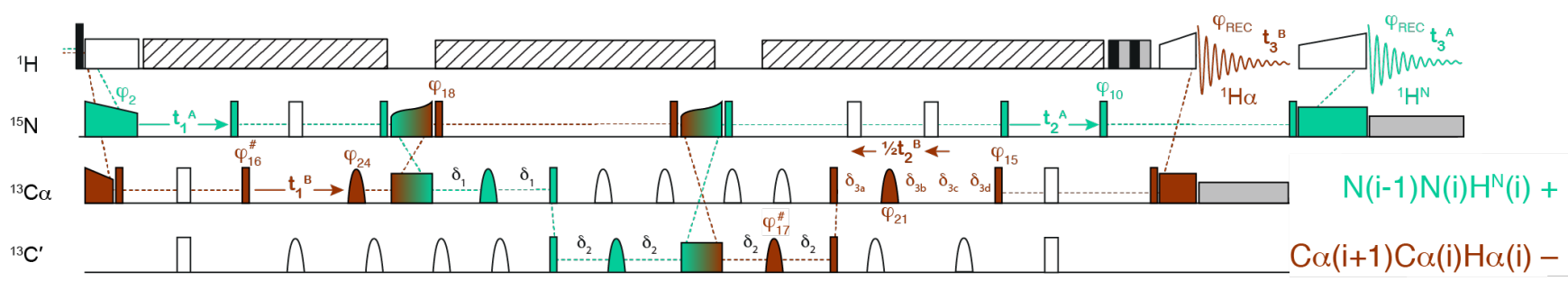

b) $(\mathrm{H}) \mathrm{N}(\mathrm{CA})(\mathrm{CO}) \mathrm{CAHA}+(\mathrm{H}) \mathrm{CANH}$

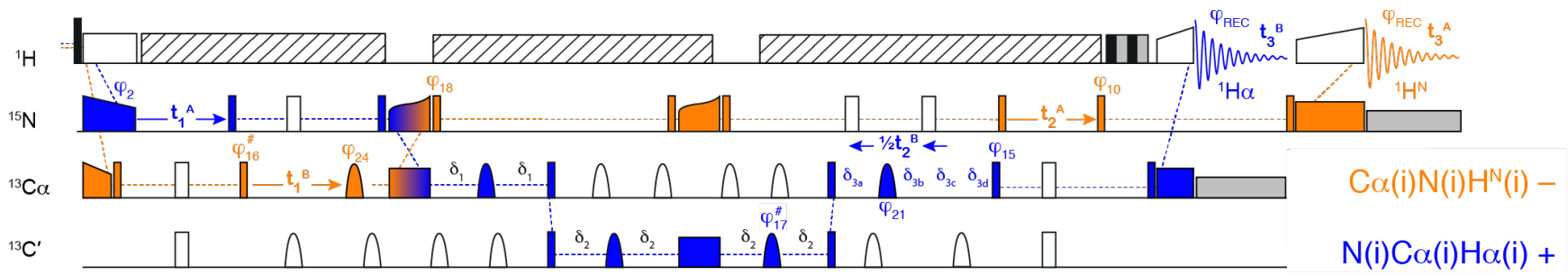

c) $(\mathrm{H}) \mathrm{N}(\mathrm{CO}) \mathrm{CAHA}+(\mathrm{H}) \mathrm{CA}(\mathrm{CO}) \mathrm{NH}$

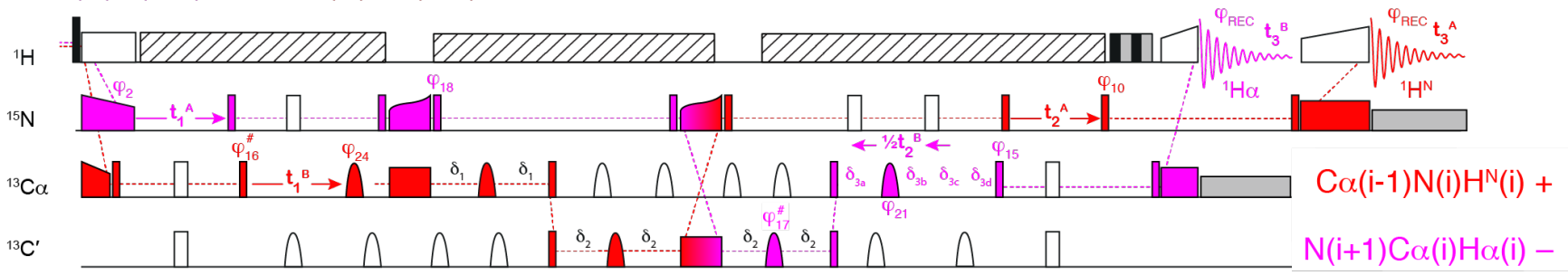

d) $(\mathrm{H}) \mathrm{NNH}+(\mathrm{H}) \mathrm{CA}(\mathrm{CO}) \mathrm{CAHA}$

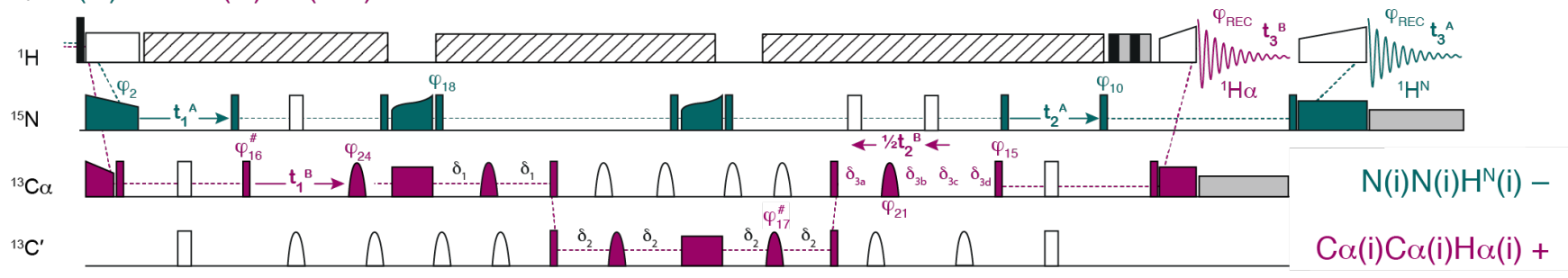

Figure S6. Scheme of 8 independent coherence transfer pathways recorded using the experiment described in Figure S5. Pathways are illustrated as dashed lines superimposed onto a simplified pulse sequence scheme from Figure S5. For clarity, the scheme was separated into 4 classes of pathways with respect to coherence response to the ${ }^{15} \mathrm{~N}-{ }^{13} \mathrm{C} \alpha$ and ${ }^{15} \mathrm{~N}-{ }^{13} \mathrm{C}^{\prime} \mathrm{CP}$ transfers: (a) coherence transferred in both CP steps; (b) coherence transferred only in ${ }^{15} \mathrm{~N}-{ }^{13} \mathrm{C} \alpha \mathrm{CP}$, orphan coherence utilized after ${ }^{15} \mathrm{~N}-{ }^{13} \mathrm{C}^{\prime} \mathrm{CP}$; (c) orphan coherence utilized after ${ }^{15} \mathrm{~N}-{ }^{13} \mathrm{C} \alpha \mathrm{CP}$, transferred coherence during ${ }^{15} \mathrm{~N}-{ }^{13} \mathrm{C}^{\prime} \mathrm{CP}$; (d) orphan terms from both ${ }^{15} \mathrm{~N}-{ }^{13} \mathrm{C} \alpha$ and ${ }^{15} \mathrm{~N}-{ }^{13} \mathrm{C}^{\prime}$ CPs used. The types of obtained correlations are provided in bottom-right corner of each panel. "-“" and "+" signs denote whether the particular correlation is observed in the "difference" or "sum" data set after a linear combination of interleaved FIDs. The "+" pathways are present as ${ }^{13} \mathrm{C} \alpha$ coherence just after ${ }^{15} \mathrm{~N}-{ }^{13} \mathrm{C} \alpha \mathrm{CP}$ and insensitive to ${ }^{15} \mathrm{~N} 90^{\circ}$ pulse phase $\phi_{18}$, while "-_" pathways are stored as ${ }^{15} \mathrm{~N}$ coherence at this point, thus undergo a phase change according to $\phi_{18}$. Direct interresidue ${ }^{1} \mathrm{H}^{\mathrm{N}}$-to- ${ }^{1} \mathrm{H}^{\mathrm{N}}$ and ${ }^{1} \mathrm{H} \alpha$-to- ${ }^{1} \mathrm{H} \alpha$ correlations (class "a") utilize the best possible signal, while intraresidue (class " $\mathrm{b}$ ") and interresidue (class " $\mathrm{c}$ ") ${ }^{15} \mathrm{~N}-{ }^{13} \mathrm{C} \alpha-{ }^{1} \mathrm{H} \alpha$ and ${ }^{13} \mathrm{C} \alpha-{ }^{15} \mathrm{~N}-{ }^{1} \mathrm{H}^{\mathrm{N}}$ pathways make use of residual signal in one of ${ }^{15} \mathrm{~N}-{ }^{13} \mathrm{C} \mathrm{CP}$. Class " $\mathrm{d}$ " pathways are doubly attenuated, however, these pathways are not useful for sequential assignment (byproducts). 


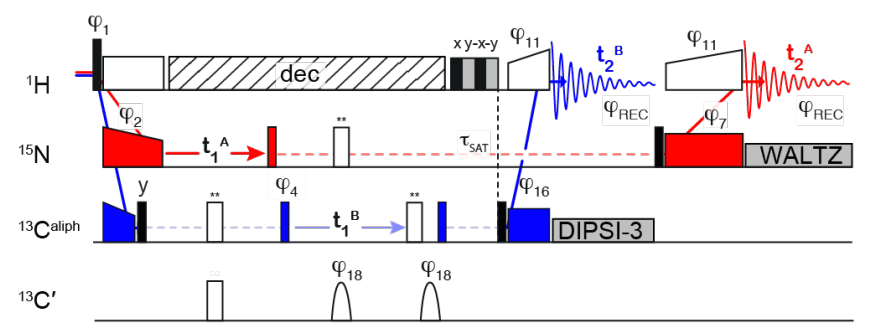

Figure S7. RF pulse scheme for the simultaneous dipolar ${ }^{13} \mathrm{C},{ }^{15} \mathrm{~N}-\mathrm{HSQC}$ experiment. The same convention for pulses and $\mathrm{CP}$ steps as in Figure S5 is used. RF strength, duration and detailed shapes for CP transfers are provided in Table S2. The phase cycle was: $\phi_{1}=\{4(y)$, 4($y)\}, \phi_{2}=\{y, y,-y,-y\}, \phi_{4}=\{x, x,-x,-x\}, \phi_{7}=\{y,-y\}, \phi_{11}=\{8(y), 8(-y)\}, \phi_{16}=\{x,-x\}, \phi_{17}=y, \phi_{18}=x, \phi_{21}=x, \phi_{24}=x$, and $\phi_{\text {rec }}=\{y,-y,-y$, $y$ \}. Quadrature detection in the indirect dimension $t_{1}\left(t_{1}{ }^{A}\right.$ for ${ }^{15} \mathrm{~N}$ and $t_{1}{ }^{\mathrm{B}}$ for $\left.{ }^{13} \mathrm{C}\right)$ was accomplished using States-TPPI ${ }^{10}$ method by simultaneous incrementation of $\phi_{2}$ and $\phi_{4}$. Offsets for ${ }^{13} \mathrm{C}$ and ${ }^{15} \mathrm{~N}$ channels were set to 40.0 and $117.5 \mathrm{ppm}$, while ${ }^{1} \mathrm{H}$ offset was set on resonance with $\mathrm{H}_{2} \mathrm{O}$ line (approx. $4.8 \mathrm{ppm}$ ). Open bell shapes on ${ }^{13} \mathrm{C}$ channels represent $\mathrm{Q} 3{ }^{3}{ }^{13} \mathrm{C}^{\prime}$-selective pulses of $178.5 \mu$ s duration and peak RF strength of $18.49 \mathrm{kHz}$.

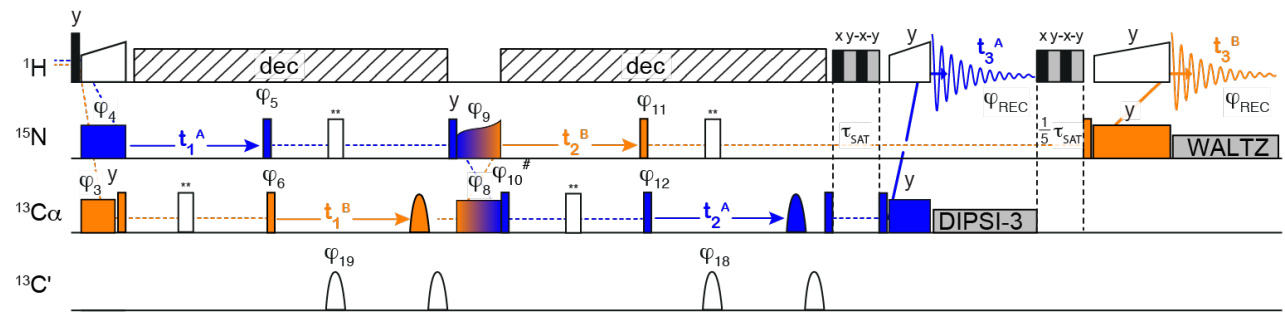

Figure S8. RF pulse scheme for the simultaneous (H)CANH and (H)NCAHA experiment ("intra-2in1"). The same convention for pulses and CP steps as in Figure S5 is used. Coherence transfer pathway is shown as dashed orange (for (H)CANH) or blue lines (for (H)NCAHA), and $\mathrm{CP}$ and $90^{\circ}$ and $180^{\circ}$ pulses are colored accordingly. RF strength, duration and detailed shapes for CP transfers are provided in Table S2. All pulses have phase $x$ unless indicated. The phase cycle was: $\phi_{3}=\{x,-x\}, \phi_{4}=\{y,-y\}, \phi_{5}=x, \phi_{6}=y, \phi_{8}=\{x, x,-x$, $-x\}, \phi_{9}=\{4(x), 4(-x)\}, \phi_{10}=y, \phi_{11}=y, \phi_{12}=x, \phi_{18}=\{x, y\}, \phi_{19}=\{x, x, y, y\}$ and $\phi_{\mathrm{rec}}=\{2(y,-y,-y, y)\}$. The minimum phase cycle length is 4 scans. Quadrature detection in the indirect dimensions $t_{1}\left(t_{1}{ }^{\mathrm{A}}\right.$ for ${ }^{15} \mathrm{~N}$ and $t_{1}{ }^{\mathrm{B}}$ for $\left.{ }^{13} \mathrm{C}\right)$ and $t_{2}\left(t_{2}{ }^{\mathrm{B}}\right.$ for ${ }^{15} \mathrm{~N}$ and $t_{2}{ }^{\mathrm{A}}$ for $\left.{ }^{13} \mathrm{C}\right)$ was accomplished using States-TPPI ${ }^{10}$ method by simultaneous decrementation of $\phi_{5}$ and incrementation of $\phi_{6}$ (in $t_{1}$ ) and by simultaneous decrementation of $\phi_{11}$ and incrementation of $\phi_{12}$ (in $t_{2}$ ). Offsets for ${ }^{13} \mathrm{C}$ and ${ }^{15} \mathrm{~N}$ channels were set to 56.4 (center of ${ }^{13} \mathrm{C} \alpha$ region) and $117.5 \mathrm{ppm}$, while ${ }^{1} \mathrm{H}$ offset was set on resonance with $\mathrm{H}_{2} \mathrm{O}$ line (approx. $4.8 \mathrm{ppm}$ ). Open bell shapes on ${ }^{13} \mathrm{C}$ channels represent $\mathrm{Q} 3^{3}{ }^{13} \mathrm{C} \alpha$ and ${ }^{13} \mathrm{C}^{\prime}$-selective pulses of durations of were 161.5 and $178.5 \mu$ s and peak RF strength of 20.43 and $18.49 \mathrm{kHz}$ for ${ }^{13} \mathrm{C} \alpha$ and ${ }^{13} \mathrm{C}^{\prime}$ pulses respectively. ${ }^{13} \mathrm{C}^{\prime}$ selective pulses were performed off-resonance by phase modulation corresponding to $+120 \mathrm{ppm}$ with respect to ${ }^{13} \mathrm{C}$ offset. ${ }^{13} \mathrm{C}$ pulse during ${ }^{13} \mathrm{C} \alpha-{ }^{15} \mathrm{~N}$ CP can be performed on-resonance (with no phase modulation), however, a better selectivity of ${ }^{15} \mathrm{~N} \rightarrow{ }^{13} \mathrm{C} \alpha$ transfer is achieved (for (H)NCAHA pathway) if additional $-60{ }^{13} \mathrm{C}$ ppm offset is applied (effectively, the pulse is performed at $56.4-60=-3.6 \mathrm{ppm}$ ). While it minimizes the competitive ${ }^{15} \mathrm{~N} \rightarrow{ }^{13} \mathrm{C}^{\prime}$ transfer, a constant phase difference acquired over this pulse (w.r.t. the enforced zero phase at the beginning of this pulse) must be compensated by $\phi_{20}$. Empirically, in our conditions we found the best value of $325^{\circ}$. 


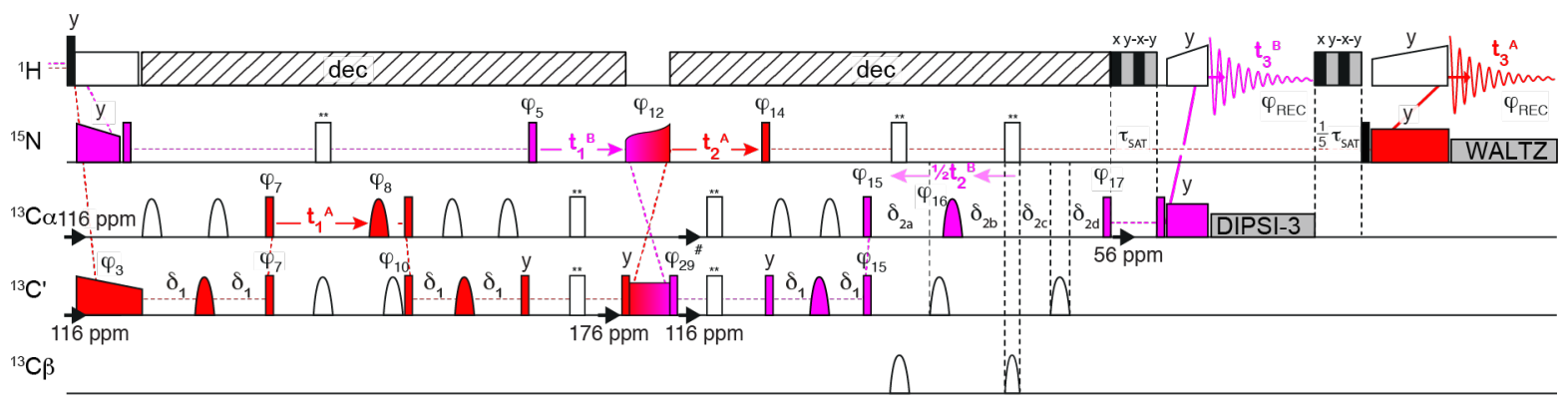

Figure S9. RF pulse scheme for the simultaneous $(\mathrm{H}) \mathrm{CA}(\mathrm{CO}) \mathrm{NH}$ and $(\mathrm{H}) \mathrm{N}(\mathrm{CO}) \mathrm{CAHA}$ experiment ("inter-2in1"). The same convention for pulses and CP steps as in Figure S5 is used. Coherence transfer pathway is shown as dashed red (for $(\mathrm{H}) \mathrm{CA}(\mathrm{CO}) \mathrm{NH})$ or magenta lines (for $(\mathrm{H}) \mathrm{N}(\mathrm{CO}) \mathrm{CAHA}$ ), and $\mathrm{CP}$ and $90^{\circ}$ and $180^{\circ}$ pulses colored accordingly. RF strength, duration and detailed shapes for $\mathrm{CP}$ transfers are provided in Table S2. Open bell shapes on ${ }^{13} \mathrm{C}$ channels represent $\mathrm{Q} 3{ }^{3}$ (for ${ }^{13} \mathrm{C} \alpha$ and ${ }^{13} \mathrm{C}^{\prime}$ ) and ReBURP ${ }^{4}$ (for ${ }^{13} \mathrm{C} \beta$ ) selective pulses. Pulse durations and peak RF strength were $161.5,178.5$ and $960.9 \mu$ s and $20.43,18.49$ and $6.52 \mathrm{kHz}$ for ${ }^{13} \mathrm{C} \alpha,{ }^{13} \mathrm{C}^{\prime}$ and ${ }^{13} \mathrm{C} \beta$ pulses respectively. Relaxation-optimized ${ }^{13} \mathrm{C} \alpha-{ }^{13} \mathrm{C}^{\prime} J$-transfer delays $\delta_{1}$ and $\delta_{2}$ were 4.3 and $4.2 \mathrm{~ms}$, respectively. They were derived from the formula: $\delta=1 / 2$ $\tan ^{-1}\left(\pi J T_{2}^{\prime}\right) /(\pi J)$, where $T_{2}$ ' denotes either the ${ }^{13} \mathrm{C} \alpha$ or $\mathrm{C}^{\prime}$ refocused coherence lifetime (estimated to 48 and $70 \mathrm{~ms}$, respectively). ${ }^{13} \mathrm{C} \alpha-$ ${ }^{13} \mathrm{C}^{\prime} J$-coupling constant of $55 \mathrm{~Hz}$ was assumed. ${ }^{13} \mathrm{C} \alpha$ evolution in $t_{2}$ (denoted $t_{2 \mathrm{~B}}$ ) was performed in constant- or real-time, depending on whether $t_{2 \mathrm{~B}}$ exceeded the relaxation-optimized transfer delay $\delta_{2}$ or the maximum transfer time $\delta^{*}=1 / 2(2 J)^{-1}$. Namely, the delays $\delta_{2 \mathrm{a}}$, $\delta_{2 \mathrm{~b}}, \delta_{2 \mathrm{c}}$, $\delta_{2 \mathrm{~d}}$ were set to respectively $\delta_{2}-1 / 2 t_{2 \mathrm{~B}}, 1 / 4 t_{2 \mathrm{~B}}+1 / 2\left(\delta_{2}-p w^{\mathrm{CB}}\right), 1 / 4 t_{2 \mathrm{~B}}+1 / 2\left(\delta_{2}-p w^{\mathrm{CB}}\right)$ and 0 if $t_{2 \mathrm{~B}}<2\left(\delta_{2}-p w^{\mathrm{CB}}\right)$; to respectively $p w^{\mathrm{CB}}, 1 / 2 t_{2 \mathrm{~B}}$, $1 / 2 t_{2 \mathrm{~B}}$ and 0 if $2\left(\delta_{2}-p w^{\mathrm{CB}}\right) \leq t_{2 \mathrm{~B}}<2\left(\delta^{*}-p w^{\mathrm{CB}}\right)$; and to respectively $p w^{\mathrm{CB}}, 1 / 2 t_{2 \mathrm{~B}}, \delta^{*}-p w^{\mathrm{CB}}$ and $1 / 2 t_{2 \mathrm{~B}}-\left(\delta^{*}-p w^{\mathrm{CB}}\right)$ for $t_{2 \mathrm{~B}} \geq 2\left(\delta^{*}-p w^{\mathrm{C}}\right)$, where $p w^{\mathrm{CB}}$ stands for the duration of ${ }^{13} \mathrm{C} \beta$-selective pulse. All pulses have phase $x$ unless indicated. The phase cycle was: $\phi_{3}=\{x,-x\}, \phi_{5}$ $=\{y,-y\}, \phi_{7}=x, \phi_{8}=x, \phi_{10}=\{x, y\}, \phi_{12}=\{x, x,-x,-x,-x,-x, x, x\}, \phi_{14}=y, \phi_{15}=\{x, x,-x,-x\}, \phi_{16}=x, \phi_{17}=-y, \phi_{29}=y$, and $\phi_{\text {rec }}=\{y,-y,-y$, $y,-y, y, y,-y\}$. The minimum phase cycle length is 4 scans. Quadrature detection in the indirect dimensions $t_{1}\left(t_{1}^{\mathrm{A}}\right.$ for ${ }^{13} \mathrm{C} \alpha$ and $t_{1}{ }^{\mathrm{B}}$ for $\left.{ }^{15} \mathrm{~N}\right)$ and $t_{2}\left(t_{2}{ }^{\mathrm{A}}\right.$ for ${ }^{15} \mathrm{~N}$ and $t_{2}{ }^{\mathrm{B}}$ for $\left.{ }^{13} \mathrm{C} \alpha\right)$ was accomplished using States-TPPI ${ }^{10}$ method by the simultaneous incrementation of $\phi_{5}$ and $\phi_{7}$ and decrementation of $\phi_{3}$ (in $t_{1}$ ) and by the simultaneous decrementation of $\phi_{14}$ and $\phi_{17}\left(\right.$ in $\left.t_{2}\right)$. ${ }^{15} \mathrm{~N}$ offset was set to 117.5 ppm while ${ }^{1} \mathrm{H}$ offset was set on resonance with $\mathrm{H}_{2} \mathrm{O}$ line (approx. $\left.4.8 \mathrm{ppm}\right) .{ }^{13} \mathrm{C}$ offset was set to in-between of ${ }^{13} \mathrm{C} \alpha$ and ${ }^{13} \mathrm{C}^{\prime}$ regions $(116.4 \mathrm{ppm})$ for the entire experiment except the $\mathrm{C}^{\prime}-{ }^{15} \mathrm{~N} \mathrm{CP}$ where it was on-resonance with $\mathrm{C}^{\prime}(176.4 \mathrm{ppm})$ and the final ${ }^{13} \mathrm{C} \alpha-{ }^{1} \mathrm{H} \alpha \mathrm{CP}$ where it was at the center of ${ }^{13} \mathrm{C} \alpha$ band (56.4 ppm) (offset changes on the ${ }^{13} \mathrm{C}$ channel are indicated by horizontal arrows). Effectively, both $t_{1}$ and $t_{2}{ }^{13} \mathrm{C} \alpha$ evolution is performed off-resonance, and the extra acquired phase is compensated by the time-proportional phase incrementation on refocusing pulses with phases $\phi_{8}$ and $\phi_{16}: \phi_{8}=\{x\}-180 * \Delta \Omega * t_{1}, \phi_{16}=\{x\}-180 * \Delta \Omega * t_{2}$ (in degrees), where $\Delta \Omega=\Omega_{\mathrm{C} \alpha}-\Omega_{0}$ (in hertz). Also, all shaped ${ }^{13} \mathrm{C}$ pulses are performed off-resonance by a stepwise phase modulation with respective offset difference $\Omega_{\mathrm{C} \alpha}-\Omega_{0}=-60 \mathrm{ppm}$, $\Omega_{\mathrm{C}}{ }^{\prime}-\Omega_{0}=$ $60 \mathrm{ppm}$ or $\Omega_{\mathrm{C} \beta}-\Omega_{0}=-91 \mathrm{ppm}$ (where $\Omega_{0}$ stands for the carrier offset at $116.4 \mathrm{ppm}$ ). ${ }^{13} \mathrm{C}$ pulse during ${ }^{1} \mathrm{H}-{ }^{13} \mathrm{C}^{\prime} \mathrm{CP}$ is performed offresonance with respective phase modulation, and zero phase alignment at the end of the pulse is enforced. ${ }^{13} \mathrm{C}$ pulse during ${ }^{13} \mathrm{C}^{\prime}-{ }^{15} \mathrm{~N} \mathrm{CP}$ can be performed on-resonance (with no phase modulation), however, a better selectivity of ${ }^{15} \mathrm{~N} \rightarrow{ }^{13} \mathrm{C}^{\prime}$ transfer is achieved (for (H)N(CO)CAHA pathway) if additional $\sim 60{ }^{13} \mathrm{C}$ ppm offset is applied (effectively, the pulse is performed at $176.4+60=236.4$ ppm). While it minimizes the competitive ${ }^{15} \mathrm{~N} \rightarrow{ }^{13} \mathrm{C} \alpha$ transfer, a constant phase difference acquired over this pulse (w.r.t. the enforced zero phase at the beginning of this pulse) must be compensated by $\phi_{29}$. Empirically, in our conditions we found the best value of $50^{\circ}$.

\section{NMR data acquisition parameters}

All spectra were acquired at the static field of $18.8 \mathrm{~T}\left(800 \mathrm{MHz}{ }^{1} \mathrm{H}\right)$. A four-channel (HCND) 0.7 mm Bruker MAS probe was used. High-power pulse durations were 2.5, 3.5 and $4.5 \mu$ s for ${ }^{1} \mathrm{H},{ }^{13} \mathrm{C}$ and ${ }^{15} \mathrm{~N}$, respectively. The sample was spun at $107 \mathrm{kHz}$, and the temperature was maintained at using a Bruker cooling unit (BCU III) with a regulated dry $\mathrm{N}_{2}$ gas directed at the rotor. The temperature detected by the sensor $(260 \mathrm{~K})$ at the point where bearing, drive and VT gases are mixed, corresponds to roughly $285 \pm 5 \mathrm{~K}$ inside the $0.7 \mathrm{~mm}$ rotor. Note that in all experiments, ${ }^{15} \mathrm{~N}$ and ${ }^{13} \mathrm{C}$ chemical shifts were co-evolved with time increments bound by the ration of gyromagnetic ratios: $\Delta_{N}=\frac{\gamma_{C}}{\gamma_{N}} \Delta_{C}$. Although not mandatory, this choice simplifies the immediate interpretation of chemical shifts since 1 ppm of ${ }^{15} \mathrm{~N}$ and ${ }^{13} \mathrm{C}$ appear equal (e.g. ${ }^{15} \mathrm{~N}$ frequencies seem scaled up if interpreted for ${ }^{13} \mathrm{C}$ evolution). The summary of acquisition parameters for multidimensional spectra of MBP can be found in Table S1. 
Table S1. Acquisition parameters for multidimensional spectra acquired for the sample of $\mathrm{U}_{-}{ }^{13} \mathrm{C},{ }^{15} \mathrm{~N}-\mathrm{labelled} \mathrm{MBP}$.

\begin{tabular}{|c|c|c|c|c|c|c|c|c|c|c|c|c|}
\hline \multirow[t]{2}{*}{ Spectrum } & \multicolumn{3}{|c|}{ Max evolution time, $\mathrm{ms}$} & \multicolumn{3}{|c|}{$\begin{array}{l}\text { Number of com- } \\
\text { plex points }\end{array}$} & \multicolumn{3}{|c|}{$\begin{array}{l}\text { Spectral window } \\
(\mathrm{Hz} / \mathrm{ppm})^{a}\end{array}$} & \multirow[t]{2}{*}{$\left|\begin{array}{l}\text { Scans } \\
\text { per } \\
\text { point }\end{array}\right|$} & \multirow[t]{2}{*}{$\begin{array}{l}\text { Inter- } \\
\text { scan } \\
\text { delay, s }\end{array}$} & \multirow[t]{2}{*}{$\begin{array}{l}\text { Exper- } \\
\text { imental } \\
\text { time, h }\end{array}$} \\
\hline & $\omega_{1}$ & $\omega_{2}$ & $\omega_{3}$ & $t_{1}$ & $t_{2}$ & $t_{3}$ & $\omega_{1}$ & $\omega_{2}$ & $\omega_{3}$ & & & \\
\hline$(\mathrm{H}) \mathrm{CH}+(\mathrm{H}) \mathrm{NH}$ & $\begin{array}{l}37.1 \\
\left({ }^{15} \mathrm{~N}\right) \\
15.0 \\
\left({ }^{13} \mathrm{C}\right)\end{array}$ & $\begin{array}{l}24.0 \\
(8.0)^{b}\end{array}$ & & 211 & $\begin{array}{l}768^{a} \\
(256)\end{array}$ & & $\begin{array}{l}5679 / 70.0 \\
\left({ }^{15} \mathrm{~N}\right) \\
14085 / 70.0 \\
\left({ }^{13} \mathrm{C}\right)\end{array}$ & $\begin{array}{l}32051 / \\
40.1 \\
\left({ }^{1} \mathrm{H}\right)\end{array}$ & & 8 & 1.0 & $1 \mathrm{~h}$ \\
\hline 8-in-1 & $\begin{array}{l}12.4 \\
\left({ }^{15} \mathrm{~N}\right) \\
6.6 \\
\left({ }^{13} \mathrm{C} \alpha\right)\end{array}$ & $\begin{array}{l}12.4 \\
\left({ }^{15} \mathrm{~N}\right) \\
6.6 \\
\left({ }^{13} \mathrm{C} \alpha\right)\end{array}$ & $\begin{array}{l}24.0 \\
(8.0)^{b}\end{array}$ & 106 & $53^{c}$ & $\begin{array}{l}768^{a} \\
(256)\end{array}$ & $\begin{array}{l}6482 / 79.9 \\
\left({ }^{15} \mathrm{~N}\right)^{d} \\
16077 / 79.9 \\
\left({ }^{13} \mathrm{C} \alpha\right)^{d}\end{array}$ & $\begin{array}{l}3246 / 40.0 \\
\left({ }^{15} \mathrm{~N}\right) \\
8051 / 40.0 \\
\left({ }^{13} \mathrm{C} \alpha\right)\end{array}$ & $\begin{array}{l}32051 / \\
40.1 \\
\left({ }^{1} \mathrm{H}\right)\end{array}$ & $8 \times 2^{c}$ & 0.82 & $\begin{array}{l}118 \mathrm{~h} \\
(4 \mathrm{~d} \\
22 \mathrm{~h})\end{array}$ \\
\hline$(\mathrm{H})(\mathrm{CA}) \mathrm{CBCAH}$ & $\begin{array}{l}6.4 \\
\left({ }^{13} \mathrm{C} \beta\right)\end{array}$ & $\begin{array}{l}6.8 \\
\left({ }^{13} \mathrm{C} \alpha\right)\end{array}$ & $\begin{array}{l}24.0 \\
(8.0)^{b}\end{array}$ & 84 & 44 & $\begin{array}{l}768^{a} \\
(256)\end{array}$ & $\begin{array}{l}13089 / 65.0 \\
\left({ }^{13} \mathrm{C} \beta\right)\end{array}$ & $\begin{array}{l}6435 / 32.0 \\
\left({ }^{13} \mathrm{C} \alpha\right)\end{array}$ & $\begin{array}{l}32051 / \\
40.1 \\
\left({ }^{1} \mathrm{H}\right)\end{array}$ & 4 & 1.0 & $21 \mathrm{~h}$ \\
\hline$(\mathrm{H})(\mathrm{CA}) \mathrm{CB}(\mathrm{CA}) \mathrm{NH}$ & $\begin{array}{l}4.0 \\
\left({ }^{13} \mathrm{C} \beta\right)\end{array}$ & $\begin{array}{l}10.4 \\
\left({ }^{15} \mathrm{~N}\right)\end{array}$ & $\begin{array}{l}20.0 \\
(8.0)^{b}\end{array}$ & 142 & 72 & \begin{tabular}{|l|}
1994 \\
$(798)$
\end{tabular} & $\begin{array}{l}17607 / 70 \\
\left({ }^{13} \mathrm{C} \beta\right)\end{array}$ & $\begin{array}{l}3446 / 34 \\
\left({ }^{15} \mathrm{~N}\right)\end{array}$ & $\begin{array}{l}100000 \\
/ 100\end{array}$ & 8 & 1.15 & 26 \\
\hline $\begin{array}{l}\text { (H)NCAHA }+ \\
(\mathrm{H}) \mathrm{CANH}\end{array}$ & $\begin{array}{l}23.1 \\
\left({ }^{15} \mathrm{~N}\right) \\
9.3 \\
\left({ }^{13} \mathrm{C} \alpha\right)\end{array}$ & $\begin{array}{l}23.1 \\
\left({ }^{15} \mathrm{~N}\right) \\
9.3 \\
\left({ }^{13} \mathrm{C} \alpha\right)\end{array}$ & $\begin{array}{l}24.0 \\
(8.0)^{b}\end{array}$ & 75 & 75 & \begin{tabular}{|l|}
$768^{a}$ \\
$(256)$
\end{tabular} & $\begin{array}{l}3246 / 40.0 \\
\left({ }^{15} \mathrm{~N}\right) \\
8052 / 40.0 \\
\left({ }^{13} \mathrm{C} \alpha\right)\end{array}$ & $\begin{array}{l}3246 / 40.0 \\
\left({ }^{15} \mathrm{~N}\right) \\
8052 / 40.0 \\
\left({ }^{13} \mathrm{C} \alpha\right)\end{array}$ & \begin{tabular}{|l|}
$32051 /$ \\
40.1 \\
$\left({ }^{1} \mathrm{H}\right)$
\end{tabular} & 4 & 0.8 & 27 \\
\hline $\begin{array}{l}(\mathrm{H}) \mathrm{N}(\mathrm{CO}) \mathrm{CAHA}+ \\
(\mathrm{H}) \mathrm{CA}(\mathrm{CO}) \mathrm{NH}\end{array}$ & $\begin{array}{l}23.1 \\
\left({ }^{15} \mathrm{~N}\right) \\
9.3 \\
\left({ }^{13} \mathrm{C} \alpha\right)\end{array}$ & $\begin{array}{l}23.1 \\
\left({ }^{15} \mathrm{~N}\right) \\
9.3 \\
\left({ }^{13} \mathrm{C} \alpha\right)\end{array}$ & $\begin{array}{l}24.0 \\
(8.0)^{b}\end{array}$ & 75 & 75 & $\begin{array}{l}768^{a} \\
(256)\end{array}$ & $\begin{array}{l}3246 / 40.0 \\
\left({ }^{15} \mathrm{~N}\right) \\
8052 / 40.0 \\
\left({ }^{13} \mathrm{C} \alpha\right)\end{array}$ & $\begin{array}{l}3246 / 40.0 \\
\left({ }^{15} \mathrm{~N}\right) \\
8052 / 40.0 \\
\left({ }^{13} \mathrm{C} \alpha\right)\end{array}$ & \begin{tabular}{|l|}
$32051 /$ \\
40.1 \\
$\left({ }^{1} \mathrm{H}\right)$
\end{tabular} & 8 & 0.8 & 60 \\
\hline
\end{tabular}

${ }^{a}$ At the static field used $(18.8 \mathrm{~T}) 1 \mathrm{ppm}{ }^{1} \mathrm{H}=800.2 \mathrm{~Hz}, 1 \mathrm{ppm}{ }^{13} \mathrm{C}=201.2 \mathrm{~Hz}$, and $1 \mathrm{ppm}{ }^{15} \mathrm{~N}=81.1 \mathrm{~Hz}$

${ }^{b}$ Signal truncated to $1 / 3(8.0 \mathrm{~ms})$ during signal processing

${ }^{c}$ Separation of the pathways requires an additional two-step phase-cycling on ${ }^{15} \mathrm{~N}$ pulse (phase $\varphi_{18}$ ) as described in the caption to Figure S5. This was implemented here as an extra loop in $\omega_{2}$ dimension, which thus requires a double number of complex points (106 instead of 53)

${ }^{d}$ Useful window is a half of the given value, since ${ }^{15} \mathrm{~N}$ and ${ }^{13} \mathrm{C} \alpha$ resonances are shifted a quarter of spectral window upfield and downfield, respectively

Table S2. Details of cross polarization transfer

\begin{tabular}{|c|c|c|c|}
\hline CP transfer no & Parameter & Value & $\begin{array}{l}\text { Parameter } \\
\text { name }\end{array}$ \\
\hline \multicolumn{4}{|l|}{ 8-in-1 } \\
\hline \multirow{7}{*}{$\begin{array}{l}1 \\
\left({ }^{1} \mathrm{H} \rightarrow{ }^{15} \mathrm{~N},\right. \\
\left.{ }^{1} \mathrm{H} \rightarrow{ }^{13} \mathrm{C} \alpha\right)\end{array}$} & " contact time $\mathrm{H}-\mathrm{C}, \mathrm{ms}$ & 4.0 & p29 \\
\hline & contact time $\mathrm{H}-\mathrm{N}, \mathrm{ms}$ & 4.1 & p15 \\
\hline & ${ }^{1} \mathrm{H}$ r.f. field (const), $\mathrm{kHz}$ & 139 & spw6 \\
\hline & ${ }^{15} \mathrm{~N}$ r.f. max. field, $\mathrm{kHz}$ & 43.7 & spw4 \\
\hline & ${ }^{13} \mathrm{C}$ r.f. max. field, $\mathrm{kHz}$ & 50.2 & spw29 \\
\hline & ${ }^{15} \mathrm{~N}$ r.f. amplitude ramp ${ }^{a}$ & $67 \% \quad \downarrow$ & spnam4 \\
\hline & ${ }^{13} \mathrm{C}$ r.f. amplitude ramp ${ }^{a}$ & $75 \% \quad \downarrow$ & spnam29 \\
\hline \multirow[t]{6}{*}{$2\left({ }^{15} \mathrm{~N} \leftrightarrow{ }^{13} \mathrm{C} \alpha\right)$} & contact time, $\mathrm{ms}$ & 20.0 & p27 \\
\hline & ${ }^{15} \mathrm{~N}$ r.f. max. field, $\mathrm{kHz}{ }^{b}$ & 45.6 & spw3 \\
\hline & ${ }^{15} \mathrm{~N}$ r.f. average field, $\mathrm{kHz}^{b}$ & 41.5 & \multirow{3}{*}{ spnam 3} \\
\hline & ${ }^{15} \mathrm{~N}$ r.f. modulation depth, $\mathrm{kHz}^{b}$ & -4.1 & \\
\hline & ${ }^{15} \mathrm{~N}$ r.f. effective coupling, $\mathrm{Hz}^{b}$ & 1509 & \\
\hline & ${ }^{13} \mathrm{C} \alpha$ r.f. field (const), $\mathrm{kHz}$ & 60.0 & spw9 \\
\hline
\end{tabular}




\begin{tabular}{|c|c|c|c|}
\hline \multirow[t]{6}{*}{$3\left({ }^{13} \mathrm{C}^{\prime} \leftrightarrow{ }^{15} \mathrm{~N}\right)$} & contact time, $\mathrm{ms}$ & 18.0 & p26 \\
\hline & ${ }^{13} \mathrm{C}^{\prime}$ r.f. field (const), $\mathrm{kHz}$ & 60.0 & spw8 \\
\hline & ${ }^{15} \mathrm{~N}$ r.f. max. field, $\mathrm{kHz}{ }^{b}$ & 43.7 & spw2 \\
\hline & ${ }^{15} \mathrm{~N}$ r.f. average field, $\mathrm{kHz}^{b}$ & 39.8 & \multirow{3}{*}{ spnam2 } \\
\hline & ${ }^{15} \mathrm{~N}$ r.f. modulation depth, $\mathrm{kHz}^{b}$ & -4.0 & \\
\hline & ${ }^{15} \mathrm{~N}$ r.f. effective coupling, $\mathrm{Hz}^{b}$ & 1447 & \\
\hline \multirow[t]{4}{*}{$4\left({ }^{1} \mathrm{H} \leftarrow{ }^{13} \mathrm{C} \alpha\right)$} & contact time, $\mathrm{ms}$ & 0.2 & p30 \\
\hline & ${ }^{13} \mathrm{C}$ r.f. field (const), $\mathrm{kHz}$ & 28.0 & spw30 \\
\hline & ${ }^{1} \mathrm{H}$ r.f. max. field, $\mathrm{kHz}$ & 139 & spw7 \\
\hline & ${ }^{1} \mathrm{H}$ r.f. amplitude ramp ${ }^{a}$ & $20 \% \uparrow$ & spnam7 \\
\hline \multirow[t]{4}{*}{$4^{\prime}\left({ }^{1} \mathrm{H} \leftarrow{ }^{15} \mathrm{~N}\right)$} & contact time, $\mathrm{ms}$ & 0.9 & p17 \\
\hline & ${ }^{15} \mathrm{~N}$ r.f. field (const), $\mathrm{kHz}$ & 27.9 & spw5 \\
\hline & ${ }^{1} \mathrm{H}$ r.f. max. field, $\mathrm{kHz}$ & 139 & spw10 \\
\hline & ${ }^{1}$ H r.f. amplitude ramp ${ }^{a}$ & $20 \% \uparrow$ & spnam 10 \\
\hline \multicolumn{4}{|l|}{${ }^{13} \mathrm{C},{ }^{15} \mathrm{~N}-\mathrm{HSQC}$} \\
\hline \multirow{7}{*}{$\begin{array}{l}1 \\
\left({ }^{1} \mathrm{H} \rightarrow{ }^{15} \mathrm{~N},\right. \\
\left.{ }^{1} \mathrm{H} \rightarrow{ }^{13} \mathrm{C} \alpha\right)\end{array}$} & contact time $\mathrm{H}-\mathrm{C}, \mathrm{ms}$ & 0.5 & p29 \\
\hline & contact time $\mathrm{H}-\mathrm{N}, \mathrm{ms}$ & 1.0 & p15 \\
\hline & ${ }^{1} \mathrm{H}$ r.f. field (const), $\mathrm{kHz}$ & 159 & spw6 \\
\hline & ${ }^{15} \mathrm{~N}$ r.f. max. field, $\mathrm{kHz}$ & 45.4 & spw2 \\
\hline & ${ }^{13} \mathrm{C}$ r.f. max. field, $\mathrm{kHz}$ & 68.9 & spw29 \\
\hline & ${ }^{15} \mathrm{~N}$ r.f. amplitude ramp ${ }^{a}$ & $54 \% \downarrow$ & spnam2 \\
\hline & ${ }^{13} \mathrm{C}$ r.f. amplitude ramp ${ }^{a}$ & $54 \% \downarrow$ & spnam 28 \\
\hline \multirow[t]{4}{*}{$2\left({ }^{1} \mathrm{H} \leftarrow{ }^{13} \mathrm{C} \alpha\right)$} & contact time, $\mathrm{ms}$ & 0.2 & $\mathrm{p} 30$ \\
\hline & ${ }^{13} \mathrm{C}$ r.f. field (const), $\mathrm{kHz}$ & 26.8 & spw30 \\
\hline & ${ }^{1} \mathrm{H}$ r.f. max. field, $\mathrm{kHz}$ & 153 & spw7 \\
\hline & ${ }^{1} \mathrm{H}$ r.f. amplitude ramp ${ }^{a}$ & $20 \% \uparrow$ & spnam7 \\
\hline \multirow[t]{4}{*}{$2^{\prime}\left({ }^{1} \mathrm{H} \leftarrow{ }^{15} \mathrm{~N}\right)$} & contact time, $\mathrm{ms}$ & 0.9 & p17 \\
\hline & ${ }^{15} \mathrm{~N}$ r.f. field (const), $\mathrm{kHz}$ & 25.6 & spw20 \\
\hline & ${ }^{1} \mathrm{H}$ r.f. max. field, $\mathrm{kHz}$ & 151 & spw10 \\
\hline & ${ }^{1} \mathrm{H}$ r.f. amplitude ramp ${ }^{a}$ & $20 \% \uparrow$ & spnam 10 \\
\hline \multicolumn{4}{|c|}{ SIM-(H)CANH,(H)NCAHA } \\
\hline \multirow{6}{*}{$\begin{array}{l}1 \\
\left({ }^{1} \mathrm{H} \rightarrow{ }^{15} \mathrm{~N},\right. \\
\left.{ }^{1} \mathrm{H} \rightarrow{ }^{13} \mathrm{C} \alpha\right)\end{array}$} & contact time $\mathrm{H}-\mathrm{C}, \mathrm{ms}$ & 1.09 & p29 \\
\hline & contact time $\mathrm{H}-\mathrm{N}, \mathrm{ms}$ & 1.1 & $\mathrm{p} 15$ \\
\hline & ${ }^{1} \mathrm{H}$ r.f. max. field, $\mathrm{kHz}$ & 141 & spw6 \\
\hline & ${ }^{15} \mathrm{~N}$ r.f. max. field (const), $\mathrm{kHz}$ & 27.5 & spw2 \\
\hline & ${ }^{13} \mathrm{C}$ r.f. max. field (const), $\mathrm{kHz}$ & 26.8 & spw29 \\
\hline & ${ }^{1} \mathrm{H}$ r.f. amplitude ramp ${ }^{a}$ & $20 \% \downarrow$ & spnam6 \\
\hline \multirow[t]{6}{*}{$2\left({ }^{15} \mathrm{~N} \leftrightarrow{ }^{13} \mathrm{C} \alpha\right)$} & contact time, $\mathrm{ms}$ & 20.0 & p16 \\
\hline & ${ }^{15} \mathrm{~N}$ r.f. max. field, $\mathrm{kHz}^{b}$ & 44.8 & spw3 \\
\hline & ${ }^{15} \mathrm{~N}$ r.f. average field, $\mathrm{kHz}^{b}$ & 40.7 & \multirow{3}{*}{ spnam3 } \\
\hline & ${ }^{15} \mathrm{~N}$ r.f. modulation depth, $\mathrm{kHz}^{b}$ & -4.1 & \\
\hline & ${ }^{15} \mathrm{~N}$ r.f. effective coupling, $\mathrm{Hz}^{b}$ & 1482 & \\
\hline & ${ }^{13} \mathrm{C} \alpha$ r.f. field (const), $\mathrm{kHz}$ & 60.0 & spw9 \\
\hline \multirow[t]{4}{*}{$3\left({ }^{1} \mathrm{H} \leftarrow{ }^{13} \mathrm{C} \alpha\right)$} & contact time, $\mathrm{ms}$ & 0.2 & p30 \\
\hline & ${ }^{13} \mathrm{C}$ r.f. field (const), $\mathrm{kHz}$ & 26.8 & spw30 \\
\hline & ${ }^{1} \mathrm{H}$ r.f. max. field, $\mathrm{kHz}$ & 153 & spw7 \\
\hline & ${ }^{1}$ H r.f. amplitude ramp ${ }^{a}$ & $20 \% \uparrow$ & spnam7 \\
\hline
\end{tabular}




\begin{tabular}{|c|c|c|c|}
\hline \multirow[t]{4}{*}{$3^{\prime}\left({ }^{1} \mathrm{H} \leftarrow{ }^{15} \mathrm{~N}\right)$} & contact time, $\mathrm{ms}$ & 0.9 & p17 \\
\hline & ${ }^{15} \mathrm{~N}$ r.f. field (const), $\mathrm{kHz}$ & 27.5 & spw20 \\
\hline & ${ }^{1} \mathrm{H}$ r.f. max. field, $\mathrm{kHz}$ & 150.6 & spw10 \\
\hline & ${ }^{1}$ H r.f. amplitude ramp ${ }^{a}$ & $20 \% \uparrow$ & spnam 10 \\
\hline \multicolumn{4}{|c|}{ SIM-(H)CA(CO)NH,(H)N(CO)CAHA } \\
\hline \multirow{7}{*}{$\begin{array}{l}1 \\
\left({ }^{1} \mathrm{H} \rightarrow{ }^{15} \mathrm{~N},\right. \\
\left.{ }^{1} \mathrm{H} \rightarrow{ }^{13} \mathrm{C}^{\prime}\right)\end{array}$} & contact time $\mathrm{H}-\mathrm{C}, \mathrm{ms}$ & 6.5 & $\mathrm{p} 28$ \\
\hline & contact time $\mathrm{H}-\mathrm{N}, \mathrm{ms}$ & 3.3 & $\mathrm{p} 15$ \\
\hline & ${ }^{1} \mathrm{H}$ r.f. field (const), $\mathrm{kHz}$ & 139 & spw6 \\
\hline & ${ }^{15} \mathrm{~N}$ r.f. max. field, $\mathrm{kHz}$ & 38.6 & spw2 \\
\hline & ${ }^{13} \mathrm{C}$ r.f. max. field, $\mathrm{kHz}$ & 36.9 & spw28 \\
\hline & ${ }^{15} \mathrm{~N}$ r.f. amplitude ramp ${ }^{a}$ & $67 \% \downarrow$ & spnam2 \\
\hline & ${ }^{13} \mathrm{C}$ r.f. amplitude ramp ${ }^{a}$ & $75 \% \downarrow$ & spnam 28 \\
\hline \multirow[t]{6}{*}{$2\left({ }^{13} \mathrm{C}^{\prime} \leftrightarrow{ }^{15} \mathrm{~N}\right)$} & contact time, $\mathrm{ms}$ & 20.0 & p16 \\
\hline & ${ }^{13} \mathrm{C}^{\prime}$ r.f. field (const), $\mathrm{kHz}$ & 60.9 & spw8 \\
\hline & ${ }^{15} \mathrm{~N}$ r.f. max. field, $\mathrm{kHz}{ }^{b}$ & 46.2 & spw3 \\
\hline & ${ }^{15} \mathrm{~N}$ r.f. average field, $\mathrm{kHz}^{b}$ & 42.0 & \multirow{3}{*}{ spnam3 } \\
\hline & ${ }^{15} \mathrm{~N}$ r.f. modulation depth, $\mathrm{kHz}^{b}$ & -4.2 & \\
\hline & ${ }^{15} \mathrm{~N}$ r.f. effective coupling, $\mathrm{Hz}^{b}$ & 1530 & \\
\hline \multirow[t]{4}{*}{$3\left({ }^{1} \mathrm{H} \leftarrow{ }^{13} \mathrm{C} \alpha\right)$} & contact time, $\mathrm{ms}$ & 0.2 & p30 \\
\hline & ${ }^{13} \mathrm{C}$ r.f. field (const), $\mathrm{kHz}$ & 28.4 & spw30 \\
\hline & ${ }^{1} \mathrm{H}$ r.f. max. field, $\mathrm{kHz}$ & 158 & spw7 \\
\hline & ${ }^{1}$ H r.f. amplitude ramp ${ }^{a}$ & $20 \% \uparrow$ & spnam7 \\
\hline \multirow[t]{4}{*}{$3^{\prime}\left({ }^{1} \mathrm{H} \leftarrow{ }^{15} \mathrm{~N}\right)$} & contact time, $\mathrm{ms}$ & 0.9 & $\mathrm{p} 17$ \\
\hline & ${ }^{15} \mathrm{~N}$ r.f. field (const), $\mathrm{kHz}$ & 28.0 & spw20 \\
\hline & ${ }^{1} \mathrm{H}$ r.f. max. field, $\mathrm{kHz}$ & 152 & spw10 \\
\hline & ${ }^{1}$ H r.f. amplitude ramp ${ }^{a}$ & $20 \% \uparrow$ & spnam 10 \\
\hline
\end{tabular}

${ }^{a}$ An x \% ramp means a linear amplitude modulation from (1-x/100) to 1.0 (ramp “up” $\uparrow$ ), or from 1.0 to (1-x/100) (“ramp down” $\left.\downarrow\right)$

${ }^{b}$ The tangential shapes (for adiabatic $\mathrm{CP}^{11}$ ) are defined by 4 empirical parameters: the average RF field $\omega_{\text {avg }}$ (close to the Hartmann-Hahn matching condition), the effective dipolar coupling $d^{\text {eff }}$ (averaged over crystal orientations and decreased due to internal motions), the modulation depth $\Delta$, and the contact time $\tau$, according to the following equation:

$\omega(t)=\omega_{\text {avg }}+d^{\text {eff }} \tan \left(\frac{2}{\tau} \operatorname{atan}\left(\frac{\Delta}{d_{N C}^{e f f}}\right)\left(\frac{\tau}{2}-t\right)\right)$

Negative modulation depth thus corresponds to a decreasing RF field strength during CP.

\section{Sensitivity of RAVASSA pathways}

The two primary experiments in RAVASSA approach, which provide direct connectivities between neighboring residues (dubbed $\mathrm{NNH}$ and $\mathrm{CCH}$ ) utilize the optimal coherence transfer pathway. They are only affected by a slight interference of the first crosspolarization, which is quantified in Figure S3 (approximate losses are 6 and $16 \%$ for $\mathrm{H}-\mathrm{C}$ and $\mathrm{H}-\mathrm{N}$ transfers, respectively). In contrast, the other 6 pathways rely on the orphan (untransferred) signal after one or two $\mathrm{C}-\mathrm{N}$ cross-polarizations, and are thus inevitably weaker than independently optimized single-spectra. Our rough estimations based on unresolved 1D spectra show 30-40\% relative efficiency of the relevant pathways, and larger attenuation of two redundant sub-spectra $(3 \mathrm{D}$ analogues of $(\mathrm{H}) \mathrm{NH}$ and (H)CH experiments). However, decreased efficiency of the relevant 4 pathways is, to a large extent, compensated by their higher intrinsic sensitivity. As a result, the intensity of RAVASSA subspectra is better balanced than reference (independent) experiments leading to better allocation of measurement time, as shown in Figure S10. Table S3 compares the integrals of 1D signal of all experiments presented in this work to a suite of conventional (serially acquired) ones. 
A

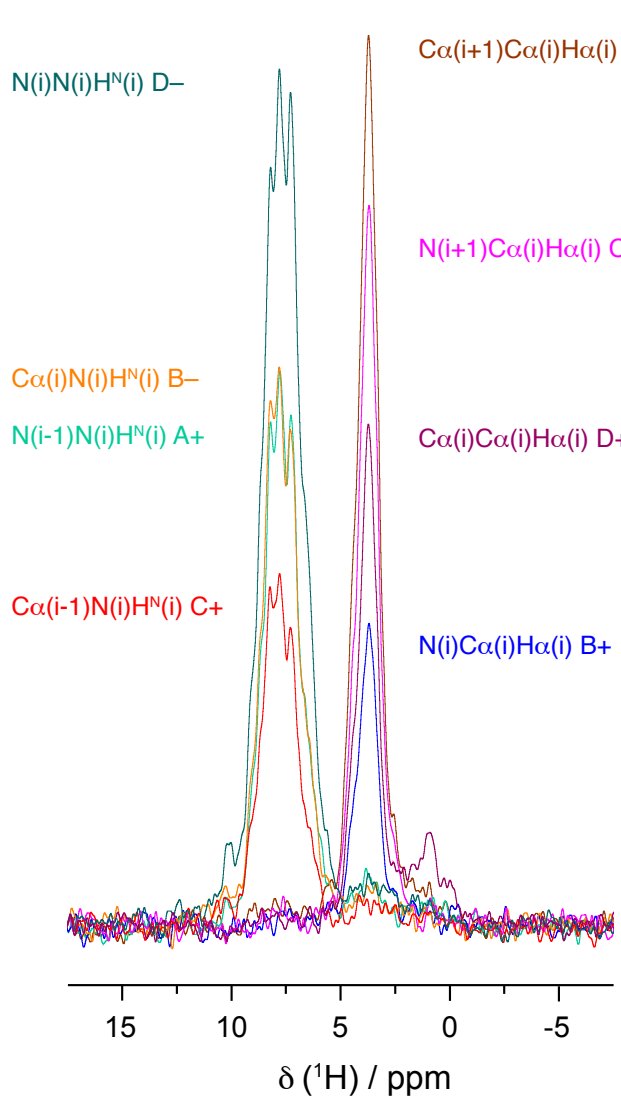

B

C

(H) NCAHA x 0.5
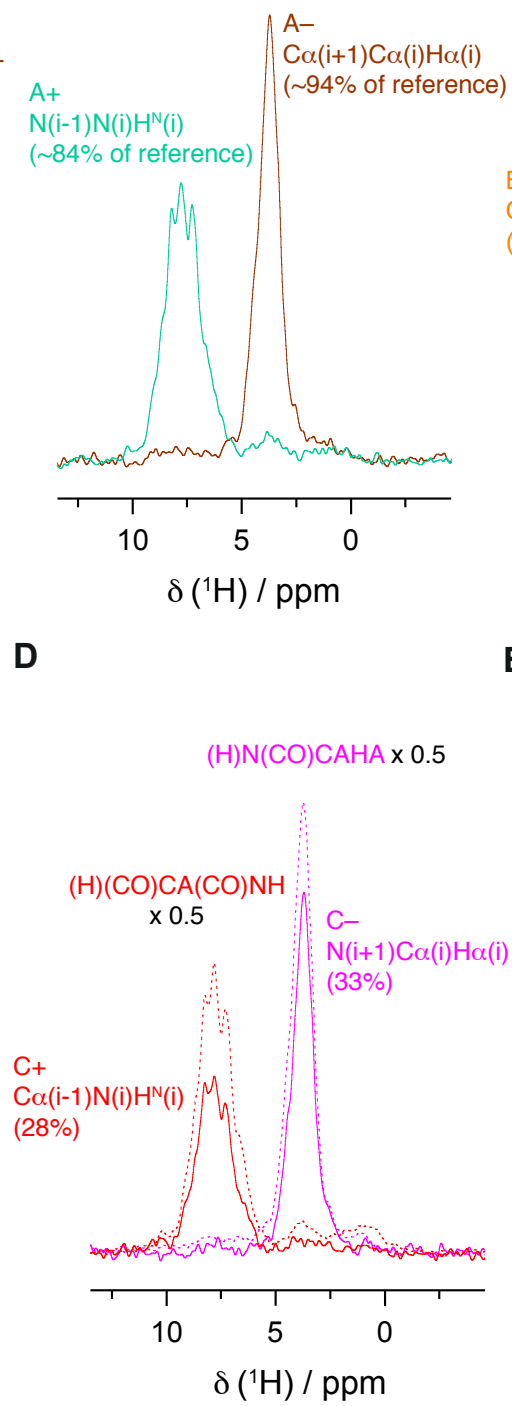

$(\mathrm{H}) \mathrm{CANH} \times 0.5$

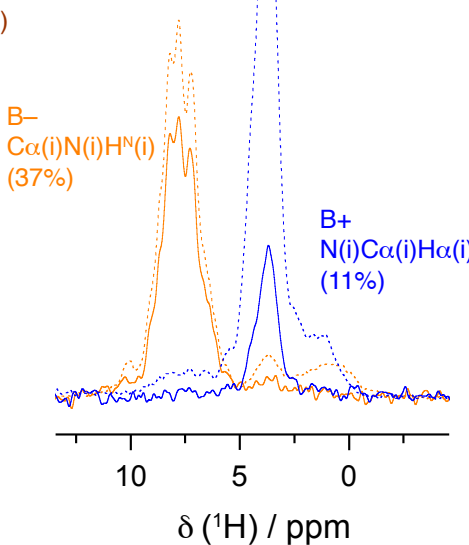

E

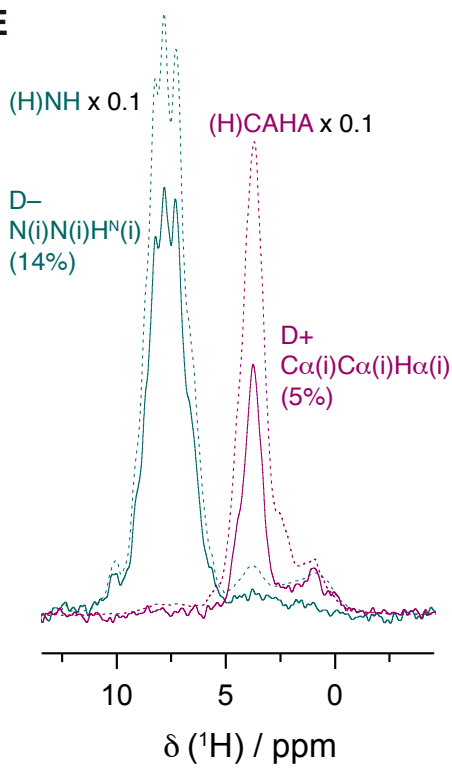

Figure S10. Relative intensities of eight RAVASSA pathways as observed in ${ }^{1} \mathrm{H}$ 1D first-FID spectra (A), color-coded and labeled "A+", "A-" etc. in agreement with pathway description in respective panels A, B, etc. of Figure S6. Selection of pathways was performed using appropriate phase cycling as described in Section J. Note that due to lack of resolution and line width differences, the intensity comparison is valid only between ${ }^{1} \mathrm{H}^{\mathrm{N}}$ - or ${ }^{1} \mathrm{H \alpha}$-detected pathways. Panels B-E show the 1D intensity comparisons of RAVASSA pathways (divided into four classes as in Figure S6) with the corresponding separately optimized serial experiments (dashed curves). Relative integral of respective 1D signals is given for every pathway. 
Table S3. Summary of sensitivity of simultaneously and serially acquired experiments on MBP

\begin{tabular}{|c|c|c|c|c|c|c|c|}
\hline \multicolumn{4}{|l|}{${ }^{1} \mathrm{H}^{\mathrm{N}}$-detected ${ }^{a}$} & \multicolumn{4}{|l|}{${ }^{1} \mathrm{H} \alpha$-detected ${ }^{b}$} \\
\hline Experiment & Mode & \multicolumn{2}{|c|}{$\begin{array}{l}\text { Relative sensitivity, }{ }^{c} \\
\%\end{array}$} & Experiment & Mode $^{c}$ & $\begin{array}{l}\text { Relative } \\
\%\end{array}$ & tivity, ${ }^{c}$ \\
\hline \multirow[t]{3}{*}{ (H)NH } & conv. $^{d}$ & $100^{e}$ & 100 & \multirow{3}{*}{ (H)CH (C $\alpha$-sel.) } & conv. $^{d, n}$ & $100^{e}$ & 100 \\
\hline & 2 -in- ${ }^{f}$ & 81 & 81 & & 2 -in- $1^{f}$ & 92 & 92 \\
\hline & 8 -in-1 ${ }^{g, h}$ & 14 & 14 & & 8 -in-1 ${ }^{g, h}$ & 4.5 & 4.5 \\
\hline \multirow[t]{3}{*}{ (H)CANH } & conv. $^{d}$ & 23 & 100 & \multirow[t]{3}{*}{ (H)NCAHA } & conv. $^{d}$ & 25 & 100 \\
\hline & 2 -in- ${ }^{i}$ & 21 & 87 & & 2 -in-1 ${ }^{i}$ & 19 & 76 \\
\hline & 8 -in- ${ }^{g}$ & 8.7 & 37 & & 8 -in- ${ }^{g, o}$ & 2.8 & 11 \\
\hline$(\mathrm{H}) \mathrm{CONH}$ & conv. $^{d}$ & 33 & - & (H)COCAHA & conv. $^{d}$ & 34 & - \\
\hline \multirow[t]{3}{*}{$(\mathrm{H})(\mathrm{CO}) \mathrm{CA}(\mathrm{CO}) \mathrm{NH}$} & conv. $^{d}$ & 19 & 100 & \multirow[t]{3}{*}{$(\mathrm{H}) \mathrm{N}(\mathrm{CO}) \mathrm{CAHA}$} & conv. $^{d}$ & 20 & 100 \\
\hline & 2 -in- ${ }^{j}$ & 19 & 99 & & 2 -in- ${ }^{j}$ & 17 & 85 \\
\hline & 8 -in-1 ${ }^{g, k}$ & 5.4 & 28 & & 8 -in-1 ${ }^{g}$ & 6.6 & 33 \\
\hline$(\mathrm{H}) \mathrm{CO}(\mathrm{CA}) \mathrm{NH}$ & conv. $^{d}$ & 8.8 & - & $(\mathrm{H}) \mathrm{CO}(\mathrm{N}) \mathrm{CAHA}$ & conv. $^{d}$ & 17 & - \\
\hline$(\mathrm{H})(\mathrm{CA}) \mathrm{CB}(\mathrm{CA}) \mathrm{NH}$ & conv. $^{d}$ & $8.1^{\prime}$ & - & $(\mathrm{H})(\mathrm{CA}) \mathrm{CBCAHA}$ & conv. $^{d}$ & $27^{\prime}$ & - \\
\hline$(\mathrm{H})(\mathrm{CA}) \mathrm{CB}(\mathrm{CA})(\mathrm{CO}) \mathrm{NH}$ & conv. $^{d}$ & $8.8^{l}$ & - & $(\mathrm{H}) \mathrm{CA}(\mathrm{N})(\mathrm{CO}) \mathrm{CAHA}$ & 8 -in- ${ }^{g}$ & 8.4 & $94^{m}$ \\
\hline$(\mathrm{H}) \mathrm{N}(\mathrm{CA})(\mathrm{CO}) \mathrm{NH}$ & 8 -in- ${ }^{g}$ & 8.4 & $84^{m}$ & & & & \\
\hline
\end{tabular}

${ }^{a}$ The table reports on sensitivity estimated as an integral of backbone amide ${ }^{1} \mathrm{H}$ signal between 11 and 5 ppm in $1 \mathrm{D} 1^{\text {st }}$ FID experiments (64 scans, $8 \mathrm{~ms}$ signal truncation, and the exponential line broadening of $100 \mathrm{~Hz}$ ).

${ }^{b}$ Similarly, but alpha ${ }^{1} \mathrm{H}$ signal was integrated between 6 and $2.5 \mathrm{ppm}$ in $1 \mathrm{D} 1^{\text {st }}$ FID experiments.

${ }^{c}$ The left column reports on sensitivity with respect to either $(\mathrm{H}) \mathrm{NH}$ or $(\mathrm{H}) \mathrm{CH}-\mathrm{C} \alpha$-selective experiment, while the values in the right column refer to the respective conventional (serially acquired) experiment in each case.

${ }^{d}$ An independently optimised conventional (serially acquired) experiment.

${ }^{e}$ The value of the signal integral was $1.2 \cdot 10^{9}$ for $(\mathrm{H}) \mathrm{NH}$, as compared to $1.17 \cdot 10^{9}$ for C $\alpha$-selective $(\mathrm{H}) \mathrm{CH}$ experiment (in arbitrary units).

${ }^{f}$ The SIM- ${ }^{13} \mathrm{C},{ }^{15} \mathrm{~N}-\mathrm{CP}-\mathrm{HSQC}$ experiments described in Figure S7.

${ }^{g}$ The 8-in-1 (RAVASSA) experiment described in Figures S5 and S6

${ }^{h}$ In the 8 -in-1 data set these pathways result in $3 \mathrm{D}$ diagonal correlations, affecting $\mathrm{S} / \mathrm{N}$ by an additional factor of $\sqrt{ } 2$ w.r.t. $2 \mathrm{D}$ spectra

${ }^{i}$ The SIM-(H)CANH,(H)NCAHA experiment described in Figure S8.

${ }^{j}$ The SIM-(H)(CO)CA(CO)NH,(H)N(CO)CAHA experiment described in Figure S9.

${ }^{k}$ In the 8-in-1 data set these correlations originate from $(\mathrm{H}) \mathrm{CA}(\mathrm{CO}) \mathrm{NH}$ pathway

${ }^{l}$ In these experiments the signal transferred from ${ }^{13} \mathrm{C} \alpha$ to ${ }^{13} \mathrm{C} \beta$ partially cancels with residual untransferred one, and with this of glycine- ${ }^{13} \mathrm{C} \alpha$. The relative sensitivity measured in $1 \mathrm{D}$ mode is thus underestimated.

${ }^{m}$ The corresponding conventional experiments were not acquired. The estimation is based on the performance of first CP (see caption to Figure S3).

${ }^{n}$ The $(\mathrm{H}) \mathrm{CH}$ experiment with an additional ${ }^{13} \mathrm{C} \alpha$-selective refocusing pulse in $t_{1}$

${ }^{o}$ In the 8-in-1 acquisition mode these correlation originate from the less sensitive $(\mathrm{H}) \mathrm{N}(\mathrm{CA})(\mathrm{CO}) \mathrm{CAHA}$ pathway.

\section{E. NMR data processing}

\section{nmrPipe processing (8-in-1 data set)}

In the first step data is imported and separated into four folders HAc, HAn, HNc, HNn, depending on the detected nucleus and signal response to phase $\phi_{18}$ (code Listing 2). Next, Fourier transformation and usual data manipulation (apodization, phasing, zero filling) is performed (code Listing 3). Finally, $\omega_{1}$ dimension is split to generate spectra with either ${ }^{13} \mathrm{C} \alpha$ or ${ }^{15} \mathrm{~N}$ shifts in $\omega_{1}$, and (optionally) converted to UCSF format. Note that resulting spectra need the adjustment of carrier frequency, offset (in ppm), and sweep widths after splitting of $\omega_{1}$ dimension if ${ }^{15} \mathrm{~N}$ chemical shifts are evolved instead of ${ }^{13} \mathrm{C}$. This was performed using ucsfdata utility from Sparky package. 
Listing 2. Data import to nmrPipe format and separation of spectra by addition/subtraction

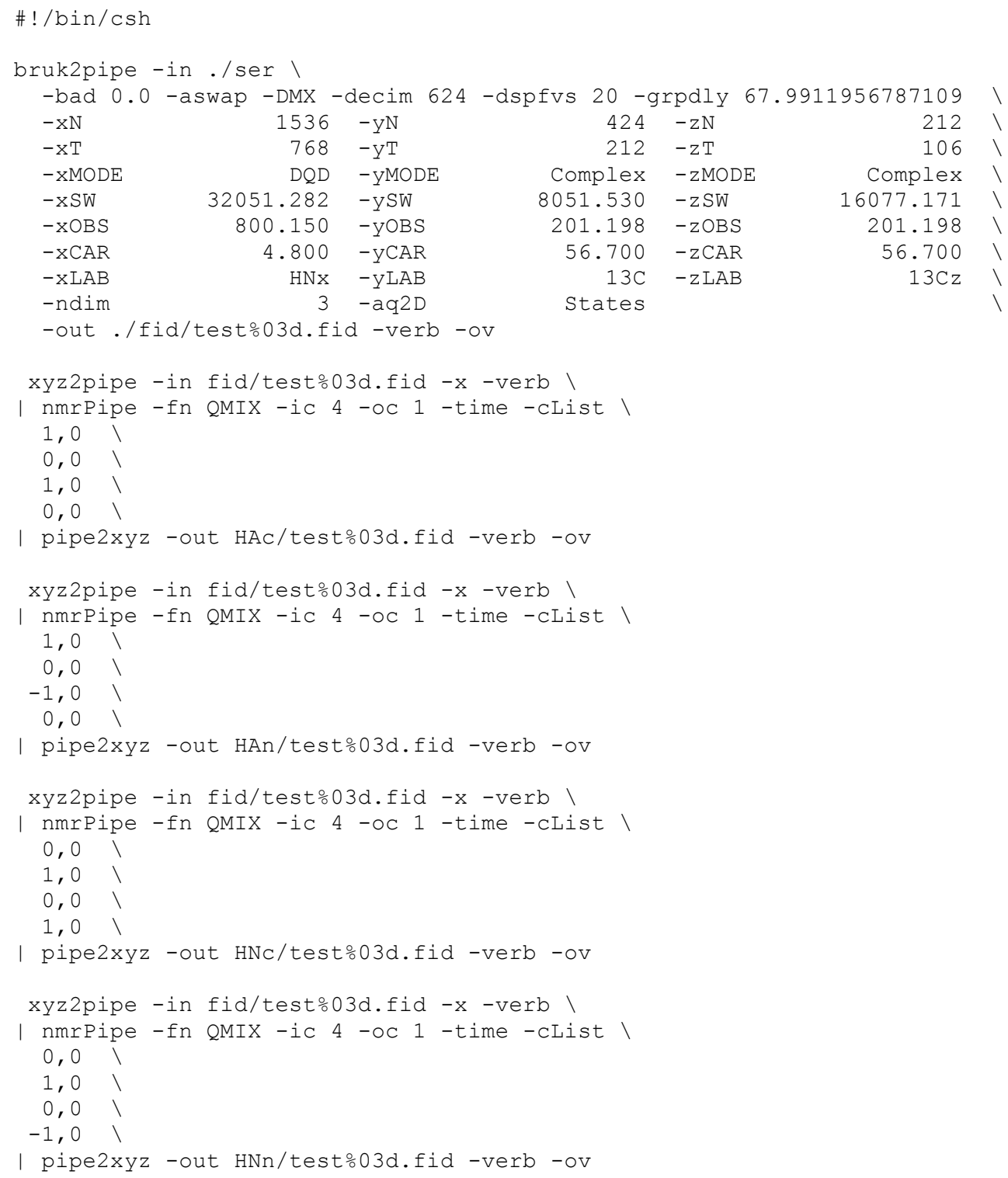

\section{Listing 3. nmrPipe Fourier processing}

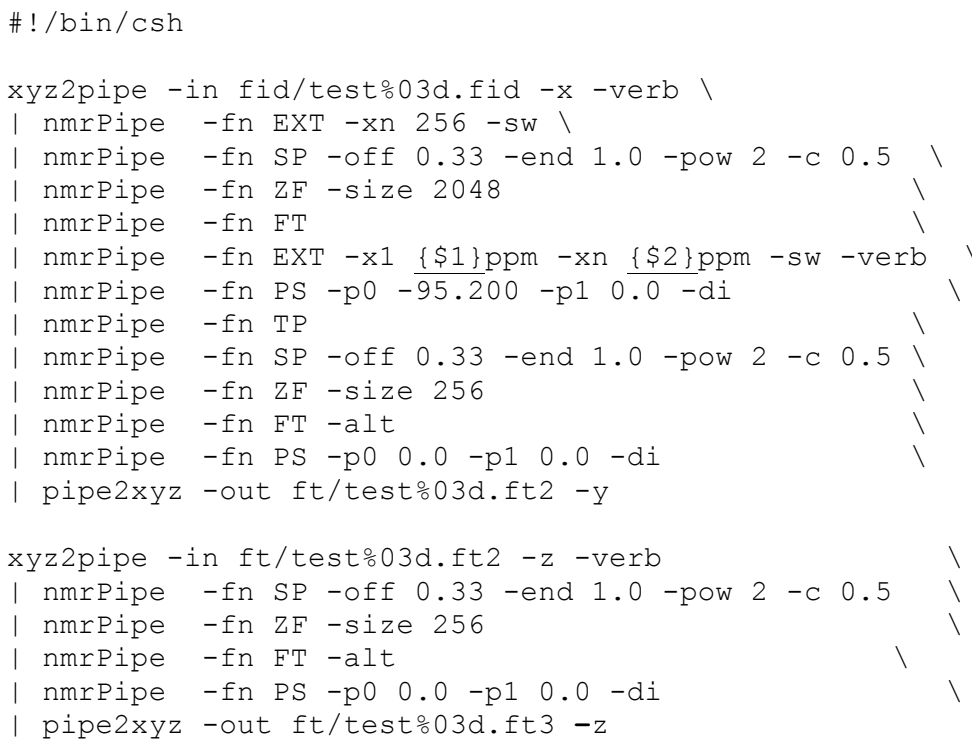




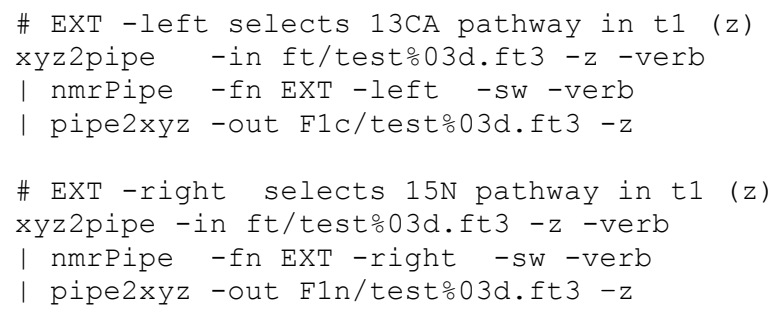

\section{F. Joint manual analysis of intra and interresidue $\mathrm{H}^{\mathrm{N}}$ and $\mathrm{Ha}$-detected spectra}

We present in Figure S11 a scheme for manual data analysis of reduced 8-in-1 data set comprising only intra- and interresidue ${ }^{1} \mathrm{H} \alpha$ and ${ }^{1} \mathrm{H}^{\mathrm{N}}$-detected ${ }^{15} \mathrm{~N}-{ }^{13} \mathrm{C} \alpha-{ }^{1} \mathrm{H}$ correlations (4 spectra). In particular, we envisage its utility for the cases of limited sample sensitivity, where the $\mathrm{NNH}$ and $\mathrm{CCH}$ pathways might not yield sufficient signals for a significant fraction of residues.

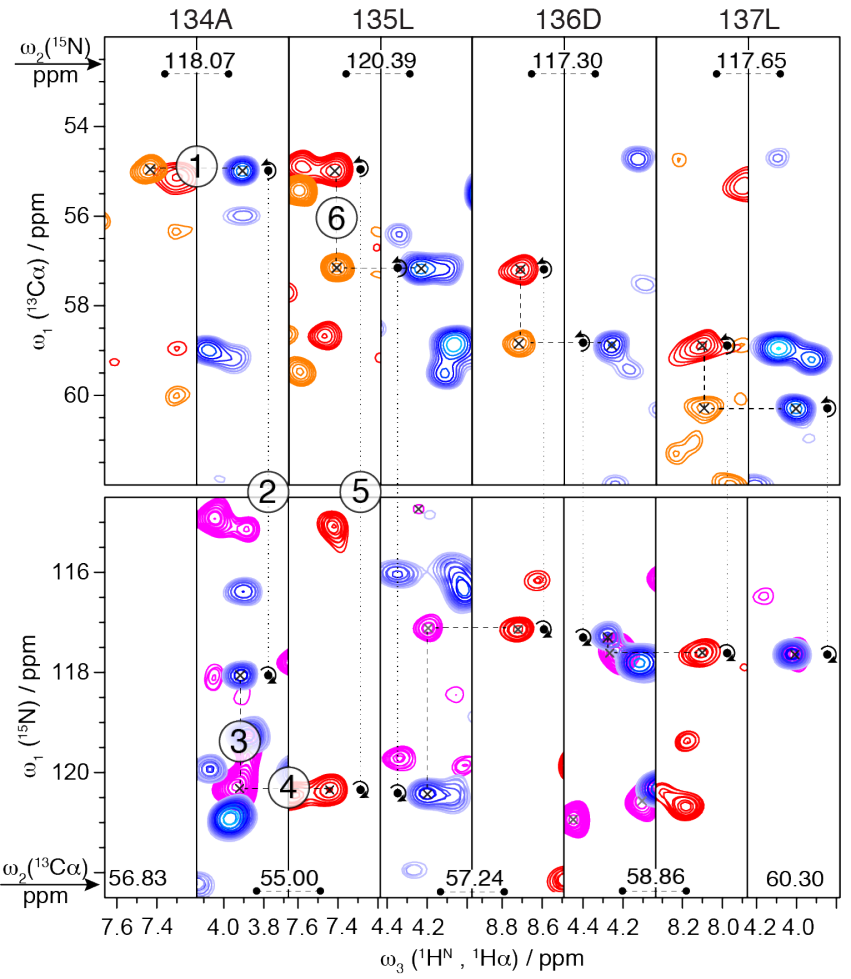

Figure S11. Strategy for sequential assignment of backbone resonances based on intra- (orange and blue contours) and interresidue correlations (red and magenta contours) recorded simultaneously in ${ }^{1} \mathrm{H}^{\mathrm{N}}$-detected (odd strips counting from left-to-right) and ${ }^{1} \mathrm{H} \alpha$ detected (even strips) experiments: (H)NCAHA (blue), (H)N(CO)CAHA (pink), (H)CANH (red), (H)CA(CO)NH (orange contours). Representative $\omega_{1}$ (either ${ }^{13} \mathrm{C} \alpha$ or $\left.{ }^{15} \mathrm{~N}\right)-\omega_{3}\left({ }^{1} \mathrm{H}\right)$ cross-sections of 3D spectra of MBP (for residues 134-137) are shown at the $\omega_{2}$ (either ${ }^{15} \mathrm{~N}$ or ${ }^{13} \mathrm{C} \alpha$ ) frequency indicated in each strip. Key steps $1,3,4$, and 6 of the process connect peaks which share two frequencies and lead to one new chemical shift, thus avoid the ambiguity encountered with conventional stripplots. Steps "2" and " 5 " represent 3D-rotations of spectra (around the peak indicated with a curling arrow) which allow to alternate between ${ }^{13} \mathrm{C} \alpha-{ }^{1} \mathrm{H}$ (top) and ${ }^{15} \mathrm{~N}-{ }^{1} \mathrm{H}$ (bottom) planes.

\section{G. Details of automated assignment}

Below we provide the batch script for CYANA program used to invoke FLYA assignment routine for MBP data (Listing S4). The outcome is summarized in Tables S4 and S5, which report on completeness of resonance assignment with respect to nuclei types and particular peak lists. Additionally, Table S6 provides evidence on the synergy between datasets comprising RAVASSA. Finally, Figure S12 illustrates the extent of assignment divided by pathway (either direct amide-to-amide (NNH), alpha-to-alpha (CCH), ${ }^{15} \mathrm{~N}$-linking with ${ }^{1} \mathrm{H} \alpha$-detection or ${ }^{1} \mathrm{H} \alpha$-linking with ${ }^{1} \mathrm{H}^{\mathrm{N}}$-detection). 


\section{Listing 4. FLYA batch script}

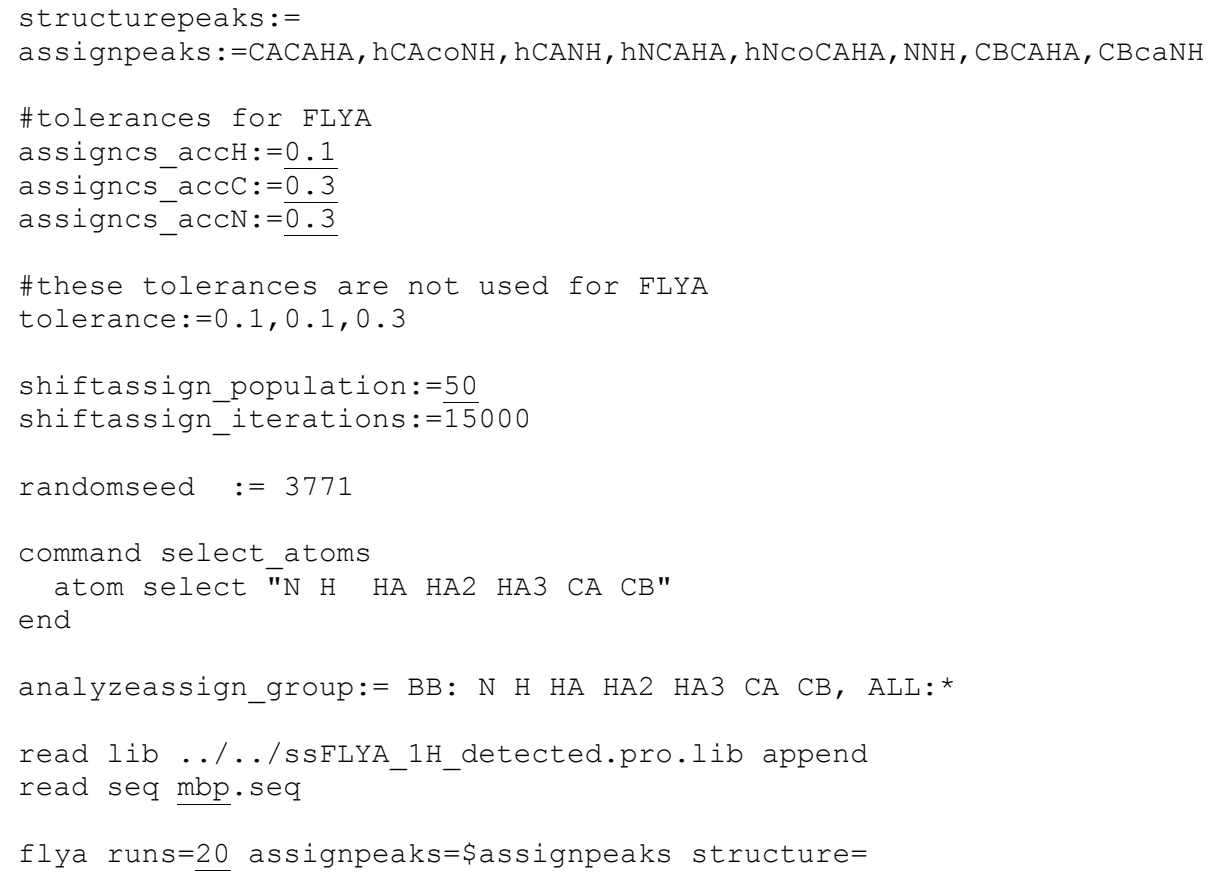

Table S4. FLYA resonance assignment summary

\begin{tabular}{|l|l|l|l|}
\hline Nucleus & Max & \multicolumn{2}{|c|}{ FLYA $^{a}$} \\
\hline${ }^{1} \mathrm{H}^{\mathrm{N}}$ & & \multicolumn{2}{|c|}{} \\
\hline${ }^{15} \mathrm{~N}$ & $349^{b}$ & 285 & 82 \\
\cline { 2 - 4 } & $341^{c}$ & 293 & 86 \\
\cline { 2 - 4 } & $21^{d}$ & 11 & 52 \\
\cline { 2 - 4 } & $371^{2}$ & 304 & 82 \\
\hline${ }^{1} \mathrm{H} \alpha$ & $371^{e}$ & 307 & 83 \\
\cline { 2 - 4 } & $384-393^{f}$ & $318^{f}$ & $81-83$ \\
\cline { 2 - 4 } & $401^{g}$ & 318 & 79 \\
\hline${ }^{13} \mathrm{C} \alpha$ & $371^{13}$ & 314 & 85 \\
\hline${ }^{13} \mathrm{C} \beta$ & $341^{2}$ & 272 & 80 \\
\hline ALL & $1803^{h}$ & 1482 & 82 \\
\hline
\end{tabular}

${ }^{a}$ Strongly assigned resonances, i.e. above and internal FLYA threshold of 0.8

${ }^{b}$ The number of amide protons, i.e. excluding proline residues and $\mathrm{N}$-terminus

${ }^{c}$ excluding proline ${ }^{15} \mathrm{~N}$ atoms

${ }^{d}$ proline ${ }^{15} \mathrm{~N}$ atoms only

${ }^{e}$ diastereotopic ${ }^{1} \mathrm{H}_{2}$ and ${ }^{1} \mathrm{H} \alpha_{3}$ atoms of 30 glycine residues treated as one entity, irrespective of their chemical shift difference

${ }^{f}$ counting diastereotopic ${ }^{1} \mathrm{H}_{2}$ and ${ }^{1} \mathrm{H} \alpha_{3}$ glycine atoms as different if assigned chemical shifts differ by at least 0.05 ppm. The maximum number of shifts is estimated based on the strongly assigned ("known") diastereotopic shifts, indistinguishable within ${ }^{1} \mathrm{H}$ linewidth (the case of 8 glycine residues)

${ }^{g}$ assuming that all diastereotopic ${ }^{1} \mathrm{H}_{2}$ and ${ }^{1} \mathrm{H} \alpha_{3}$ atoms of 30 glycine residues are distinguishable (upper limit for the number of shifts)

${ }^{h}$ given the conditions ${ }^{b}$ and ${ }^{e}$ above (all backbone ${ }^{15} \mathrm{~N}$ spins, but consolidated ${ }^{1} \mathrm{H} \alpha_{2}$ and ${ }^{1} \mathrm{H} \alpha_{3}$ glycine shifts) 
Table S5. Summary of peak lists used for automated assignment

\begin{tabular}{|l|l|l|l|}
\hline \multirow{2}{*}{ Spectrum } & \multicolumn{3}{|l|}{ Number (and percentage) of peaks $^{-}$} \\
\cline { 2 - 4 } & Expected $^{a}$ & Measured $^{b}$ & Assigned $^{c}$ \\
\hline$(\mathrm{H}) \mathrm{N}(\mathrm{CA})(\mathrm{CO}) \mathrm{NH}$ & 349 & $275(79 \%)$ & $258(94 \%)$ \\
\hline$(\mathrm{H}) \mathrm{CA}(\mathrm{N})(\mathrm{CO}) \mathrm{CAHA}$ & $400 / 370$ & $308(77 \%)$ & $268(87 \%)$ \\
\hline$(\mathrm{H}) \mathrm{CANH}$ & 349 & $302(87 \%)$ & $266(88 \%)$ \\
\hline$(\mathrm{H}) \mathrm{N}(\mathrm{CA})(\mathrm{CO}) \mathrm{CAHA}$ & $401 / 371$ & $309(77 \%)$ & $201(65 \%)$ \\
\hline$(\mathrm{H}) \mathrm{CA}(\mathrm{CO}) \mathrm{NH}$ & 349 & $294(84 \%)$ & $248(84 \%)$ \\
\hline$(\mathrm{H}) \mathrm{N}(\mathrm{CO}) \mathrm{CAHA}$ & $400 / 370$ & $282(70 \%)$ & $266(94 \%)$ \\
\hline$(\mathrm{H})(\mathrm{CA}) \mathrm{CB}(\mathrm{CA}) \mathrm{NH}$ & 320 & $243(76 \%)$ & $228(94 \%)$ \\
\hline$(\mathrm{H})(\mathrm{CA}) \mathrm{CBCAH}$ & 341 & $316(93 \%)$ & $284(89 \%)$ \\
\hline ALL & 2909 & $2329(80 \%)$ & $2019(87 \%)$ \\
\hline
\end{tabular}

${ }^{a}$ The maximum number of peaks expected from allowed magnetization pathways. For H $\alpha$-detected experiments upper and lower limits are given, depending on the feasibility to resolve correlations of diastereotopic glycine ${ }^{1} \mathrm{H} \alpha_{2}$ and ${ }^{1} \mathrm{H} \alpha_{3}$ spins

${ }^{b}$ The peaks identified in spectra and the percentage w. r. t. the number of expected peaks. Note that due to limited spectral resolution, and near-equivalent ${ }^{1} \mathrm{H}_{2}$ and ${ }^{1} \mathrm{H} \alpha_{3}$ shifts of glycine residues, some expected peaks, although detectable, may remain unresolved in the experiment (the percentage is underestimated)

${ }^{c}$ The number of measured peaks which were assigned and the percentage given w. r. t. all measured peaks

Table S6. FLYA resonance assignment summary with partial data inputs

\begin{tabular}{|c|c|c|c|c|c|c|c|c|c|}
\hline \multirow{2}{*}{$\begin{array}{l}\text { Nucleus } \\
{ }^{1} \mathrm{H}^{\mathrm{N}}\end{array}$} & \multirow{2}{*}{$\begin{array}{l}\text { Max } \\
349^{e}\end{array}$} & \multicolumn{2}{|c|}{$\begin{array}{r}\mathrm{CCH}+\mathrm{NNH}+\mathrm{CB}^{a} \\
\%\end{array}$} & \multicolumn{2}{|c|}{$\begin{array}{r}\mathrm{All}-\mathrm{CCH}-\mathrm{NNH}^{b} \\
\%\end{array}$} & \multicolumn{2}{|c|}{$\begin{array}{r}\text { Union of sets }^{c} \\
\%\end{array}$} & \multicolumn{2}{|c|}{$\begin{array}{r}\text { RAVASSA excess }^{d} \\
\%\end{array}$} \\
\hline & & 29 & 8 & 94 & 27 & 103 & 30 & 182 & 52 \\
\hline${ }^{15} \mathrm{~N}$ & $371^{f}$ & 32 & 9 & 98 & 26 & 108 & 29 & 196 & 53 \\
\hline${ }^{1} \mathrm{H} \alpha$ & $371^{g}$ & 39 & 11 & 112 & 30 & 134 & 36 & 173 & 47 \\
\hline${ }^{13} \mathrm{C} \alpha$ & 371 & 47 & 13 & 112 & 30 & 128 & 35 & 186 & 50 \\
\hline${ }^{13} \mathrm{C} \beta$ & 341 & 40 & 12 & 92 & 27 & 110 & 32 & 162 & 48 \\
\hline ALL & $1803^{h}$ & 187 & 10 & 508 & 28 & 583 & 32 & 899 & 49 \\
\hline
\end{tabular}

${ }_{a-d}$ The number of resonances strongly assigned by FLYA

${ }^{a}$ The input reduced to $(\mathrm{H}) \mathrm{CA}(\mathrm{N})(\mathrm{CO}) \mathrm{CAHA},(\mathrm{H}) \mathrm{N}(\mathrm{CA})(\mathrm{CO}) \mathrm{NH},(\mathrm{H})(\mathrm{CA}) \mathrm{CB}(\mathrm{CA}) \mathrm{NH}$ and $(\mathrm{H})(\mathrm{CA}) \mathrm{CBCAH}$ peak lists

${ }^{b}$ The input reduced to $(\mathrm{H}) \mathrm{CANH},(\mathrm{H}) \mathrm{CA}(\mathrm{CO}) \mathrm{NH},(\mathrm{H}) \mathrm{CA}(\mathrm{N})(\mathrm{CO}) \mathrm{CAHA},(\mathrm{H}) \mathrm{N}(\mathrm{CO}) \mathrm{CAHA},(\mathrm{H})(\mathrm{CA}) \mathrm{CB}(\mathrm{CA}) \mathrm{NH}$ and (H)(CA)CBCAH peak lists

${ }^{c}$ Resonance counts for the union of resonance sets of previous columns ( ${ }^{a}$ and ${ }^{b}$ )

${ }^{d}$ The synergy effect of a full RAVASSA dataset: a difference of resonance count between these given in Table S4 and the union of 2 sets for partial data input

${ }^{e}$ The number of amide protons, i.e. excluding proline residues and $\mathrm{N}$-terminus

${ }^{f}$ proline ${ }^{15} \mathrm{~N}$ atoms inclusive

${ }^{g}$ diastereotopic ${ }^{1} \mathrm{H}_{2}$ and ${ }^{1} \mathrm{H} \alpha_{3}$ atoms of 30 glycine residues treated as one entity, irrespective of their chemical shift difference

${ }^{h}$ given the conditions ${ }^{b}$ and ${ }^{e}$ above (all backbone ${ }^{15} \mathrm{~N}$ spins, but consolidated ${ }^{1} \mathrm{H} \alpha_{2}$ and ${ }^{1} \mathrm{H} \alpha_{3}$ glycine shifts) 


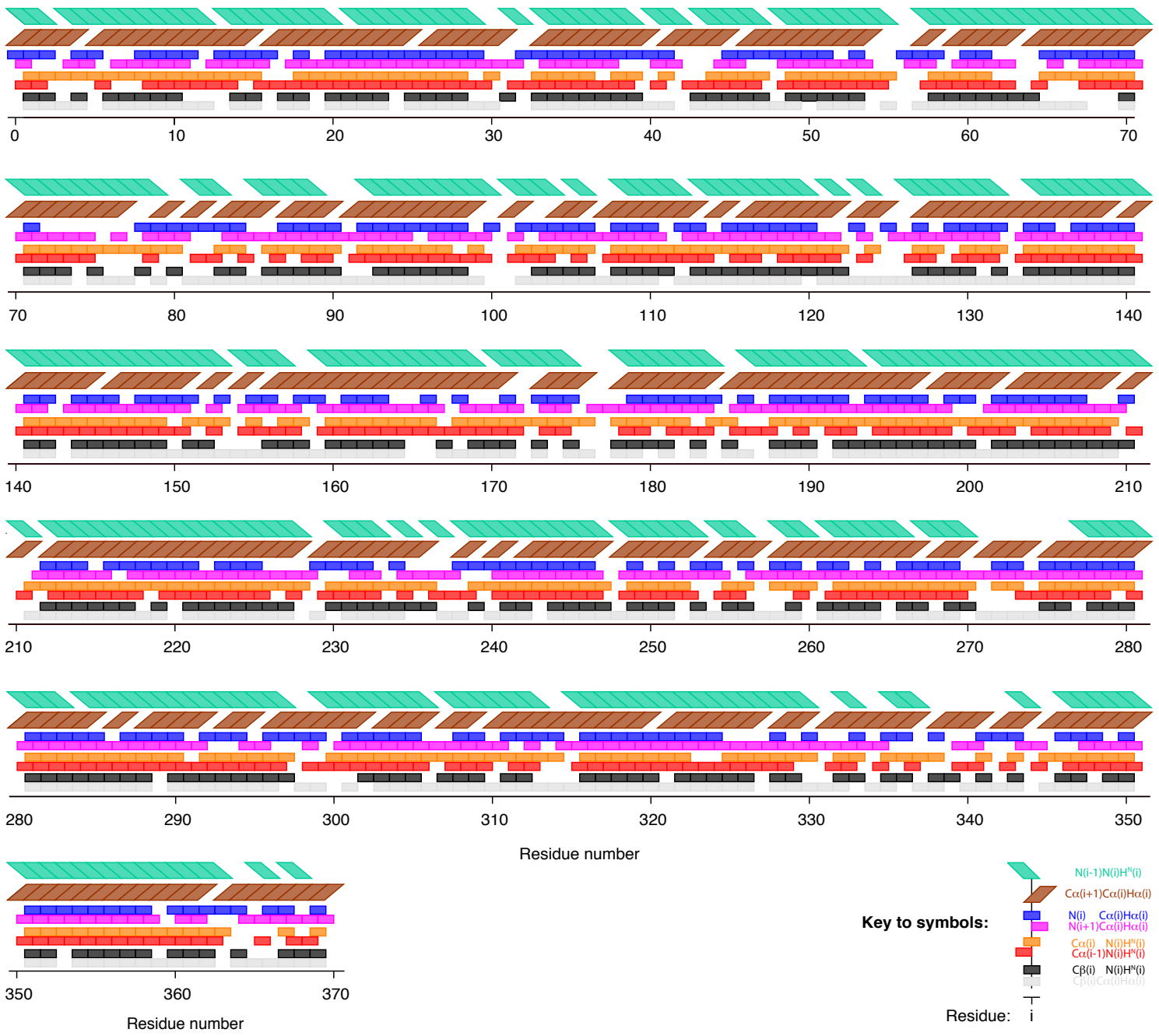

Figure S12. Extent of FLYA assignment of observed 3D resonance correlations in 6 simultaneously recorded RAVASSA subspectra and two intraresidue ${ }^{13} \mathrm{C} \beta$ correlations. The four pathways which allow (in principle independent) linking between resonances in neighboring residues are shown as boxes with the following color-coding, from top to bottom of each panel: light green $(\mathrm{N}(i-1)-$ $\mathrm{N}(i)-\mathrm{HN}(i))$; brown $(\mathrm{C} \alpha(i+1)-\mathrm{C} \alpha(i)-\mathrm{H} \alpha(i))$; blue $(\mathrm{N}(i)-\mathrm{C} \alpha(i)-\mathrm{H} \alpha(i))$ and magenta $(\mathrm{N}(i+1)-\mathrm{C} \alpha(i)-\mathrm{H} \alpha(i))$; orange $(\mathrm{C} \alpha(i)-\mathrm{N}(i)-$ $\left.\mathrm{H}^{\mathrm{N}}(i)\right)$ and red $\left(\mathrm{C} \alpha(i-1)-\mathrm{N}(i)-\mathrm{H}^{\mathrm{N}}(i)\right)$. Additionally, assigned ${ }^{13} \mathrm{C} \beta-\mathrm{N}(i)-\mathrm{H}^{\mathrm{N}}(i)$ and ${ }^{13} \mathrm{C} \beta-\mathrm{C} \alpha(i)-\mathrm{H} \alpha(i)$ correlations are shown in dark and light grey, respectively.

\section{H. Chemical shifts of MBP in the solid-state versus in solution}

The resonance chemical shifts obtained with FLYA were compared to those of maltotriose-bound MBP (in the "closed" conformation) studied in solution by Kay and co-workers ${ }^{12}$ (BMRB entry no 4987). This is the closest match among available BMRB depositions for this protein, taking the kind of ligand as a primary criterion. Since the protein in solution required extensive deuteration, ${ }^{13} \mathrm{C} \alpha$ and ${ }^{13} \mathrm{C} \beta$ shifts required a correction of ${ }^{2} \mathrm{H}$ isotope effect (using standard formulae of Venters and co-workers ${ }^{13}$ ) before a comparison to ${ }^{13} \mathrm{C},{ }^{15} \mathrm{~N}$-labelled MBP used in our study. Based on these shifts we first prepared a synthetic $2 \mathrm{D}{ }^{13} \mathrm{C}-{ }^{13} \mathrm{C}$ correlation, assuming uniform intensities and resonance line widths (94 and $59 \mathrm{~Hz}$ for ${ }^{13} \mathrm{C} \beta$ and ${ }^{13} \mathrm{C} \alpha$ respectively). Figure $\mathrm{S} 13 \mathrm{a}$ shows its superposition (black contours) with a $2 \mathrm{D} \omega_{1}-\omega_{2}$ projection of $3 \mathrm{D}(\mathrm{H})(\mathrm{CA}) \mathrm{CBCAHA}$ spectrum in the solid-state (red contours) restricted to regions of ${ }^{13} \mathrm{C} \beta-{ }^{13} \mathrm{C} \alpha$ correlations. Positions of majority of peaks agree very well between precipitated and solute MBP, and a presence of a few minor differences is in line with analogous comparisons on $\mathrm{GB} 1^{14}$ and other model proteins. In contrast, the superposition of a synthetic ${ }^{15} \mathrm{~N}-\mathrm{HSQC}$ (solution) and experimental CP- ${ }^{15} \mathrm{~N}-\mathrm{HSQC}$ (solids) in panel $b$ of Figure S13 shows significant differences for amide ${ }^{15} \mathrm{~N}$ and ${ }^{1} \mathrm{H}$ shifts. They arise most likely due to crystal ${ }^{1} \mathrm{H}-{ }^{1} \mathrm{H}$ contacts, different patterns of hydrogen bonds between the two sample formulations, conformational averaging in solution, and generally larger susceptibility of amide ${ }^{1} \mathrm{H}$ and ${ }^{15} \mathrm{~N}$ (when compared to ${ }^{13} \mathrm{C}$ ) shifts to the chemical environment, e.g. buffer $\mathrm{pH}$ (7.2 in solution vs. 8.0 in solids), ionic strength, the presence of precipitant etc. 

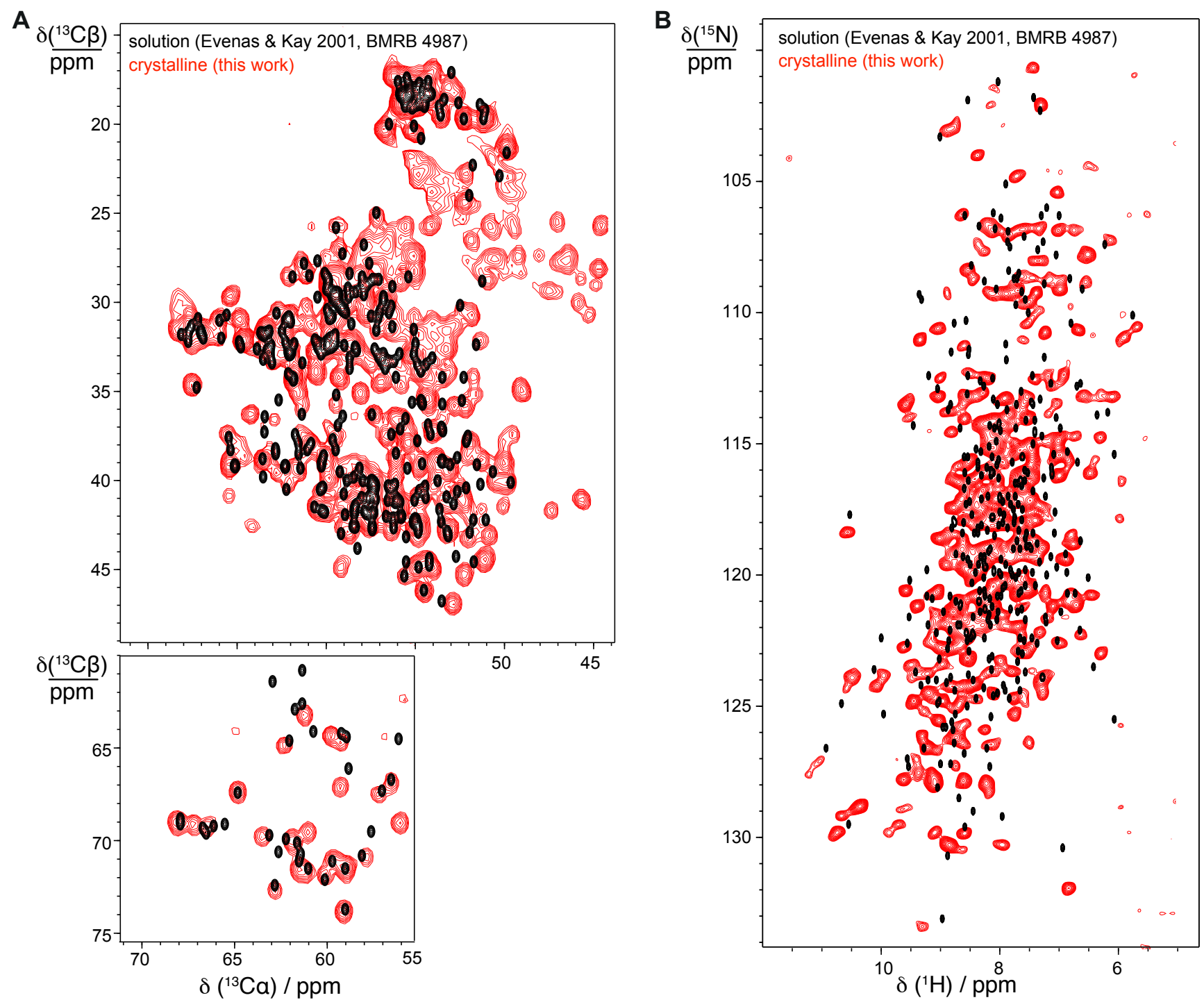

Figure S13. (A) Superposition of $2 \mathrm{D}{ }^{13} \mathrm{C} \beta-{ }^{13} \mathrm{C} \alpha$ regions of ${ }^{13} \mathrm{C}-{ }^{13} \mathrm{C}$ correlation spectrum of maltotriose-bound $\mathrm{MBP}$ in solution (black contours, synthetic - based on shifts in BMRB entry no 4987) and in the crystalline preparation (red contours). (B) Comparison of a synthetic ${ }^{15} \mathrm{~N}-\mathrm{HSQC}$ (solution, in black) and experimental $\mathrm{CP}-{ }^{15} \mathrm{~N}-\mathrm{HSQC}$ (solids, in red).

\section{Extensions of the FLYA library}

Below we provide the FLYA definitions of correlations observed in eight simultaneous experiments used in this study, and two additional ones which provide intraresidue ${ }^{13} \mathrm{C} \beta$ correlations. Note that definitions 3-6 below are also suitable to describe peaks in SIM- $(\mathrm{H}) \mathrm{CANH},(\mathrm{H}) \mathrm{NCAHA}$ and SIM-(H)(CO)CA(CO)NH,(H)N(CO)CAHA experiments.

1. $(\mathrm{H}) \mathrm{N}(\mathrm{CA})(\mathrm{CO}) \mathrm{NH}$, correlation $\mathrm{N}(i-1)-\mathrm{N}(i)-\mathrm{H}^{\mathrm{N}}(i)$

SPECTRUM SShNCaCONH N2 N1 H1

0.980 N2:N_AMI C ALI C BYL N1:N_AMI H1:H_AMI

Note that this definition allows the pathway origin at proline ${ }^{15} \mathrm{~N}$, which are usually only weakly polarized with $\mathrm{H}-\mathrm{N}$ CP. It also permits the pathways starting at $\mathrm{N}$-terminal ${ }^{15} \mathrm{~N}$-spins.

2. (H)CA(N)(CO)CAHA, correlation $\mathrm{C} \alpha(i+1)-\mathrm{C} \alpha(i)-\mathrm{H} \alpha(i)$

SPECTRUM SSCANCOCAHA C2 C1 H1

0.980 C2:C_ALI (C_BYL) N_AMI C_BYL C1:C_ALI (N_AMI) H1:H_ALI

3. (H)CANH, correlation $\mathrm{C} \alpha(i)-\mathrm{N}(i)-\mathrm{H}^{\mathrm{N}}(i)$

SPECTRUM SShCANH HN N C

0.980 HN:H AMI N:N AMI (C BYL) C:C ALI 
4. (H)N(CA)(CO)CAHA, correlation $\mathrm{N}(i)-\mathrm{C} \alpha(i)-\mathrm{H} \alpha(i)$

SPECTRUM SShNCaCOCAHA $\mathrm{N}$ C HC

$0.980 \mathrm{~N}: \mathrm{N}$ AMI C:C_ALI (C_BYL) HC:H_ALI

Note that this definition allows the pathway origin at proline ${ }^{15} \mathrm{~N}$ but excludes detection at Lys/His/Arg side-chain amide/amine protons (to distinguish from $(\mathrm{H}) \mathrm{NCAH}$ experiment where such peaks can in principle be observed).

5. (H)CA(CO)NH, correlation $\mathrm{C} \alpha(i-1)-\mathrm{N}(i)-\mathrm{H}^{\mathrm{N}}(i)$

SPECTRUM SSCACONH HN N C

0.98 HN:H_AMI N:N_AMI (C_ALI) C_BYL C:C_ALI

Note that this definition discards side-chain Asn/Gln peaks.

6. (H)N(CO)CAHA, correlation $\mathrm{N}(i+1)-\mathrm{C} \alpha(i)-\mathrm{H} \alpha(i)$

SPECTRUM SShNCOCAHA N C HC

$0.980 \mathrm{~N}: \mathrm{N} \_$AMI (C_ALI) C_BYL C:C_ALI HC:H_ALI

Note that this definition discards side-chain Asn/Gln peaks, but allows proline ${ }^{15} \mathrm{~N}$ as the origin of the pathway.

7. (H)NNH, “diagonal” correlation $\mathrm{N}(i)-\mathrm{N}(i)-\mathrm{H}^{\mathrm{N}}(i)$

SPECTRUM SShNNH N11 N1 H1

0.980 N11:N1:N_AMI (C_BYL) (C_ALI) H1:H_AMI

8. (H)CA(CO)CAHA, "diagonal" correlation $\mathrm{C} \alpha(i)-\mathrm{C} \alpha(i)-\mathrm{H} \alpha(i)$

SPECTRUM SShCACOCAHA C11 C1 H1

0.980 C11:C1:C_ALI (C_BYL) (N_AMI) H1:H_ALI

9. (H)(CA)CB(CA)NH, correlation $\mathrm{C} \beta(i)-\mathrm{N}(i)-\mathrm{H}^{\mathrm{N}}(i)$

SPECTRUM SSCBCANH HN N C

0.980 HN:H_AMI N:N_AMI (C_BYL) C_ALI C:C_ALI

Note that the N-terminal residue is excluded. Glycine residues, which give $\mathrm{C} \alpha(i)-\mathrm{N}(i)-\mathrm{H}^{\mathrm{N}}(i)$ signals of opposite signs, are not considered either.

10. (H)(CA)CBCAHA, correlation $\mathrm{C} \beta(i)-\mathrm{C} \alpha(i)-\mathrm{H} \alpha(i)$

SPECTRUM SSCBCAHA HA CA CB

0.980 HA:H_ALI CA:C_ALI (N_AMI) (C_BYL) CB:C_ALI

\section{J. Pulse programs in Bruker code}

Note that all pulse programs provided below require two memory buffers $(\mathrm{NBL}=2)$ to store separate $\mathrm{H} \alpha$ and $\mathrm{H}^{\mathrm{N}}$ signals $($ in a single scan). This enforces an additional pseudo-dimension (innermost, either F2 or F3) with $\mathrm{TD}=2$, thus experiments are acquired as $3 \mathrm{D}$ instead of 2D, and 4Ds instead of 3Ds. All programs support the disabling of inversion pulses on either ${ }^{15} \mathrm{~N}$ or ${ }^{13} \mathrm{C} \alpha$ channel during ${ }^{13} \mathrm{C} \alpha$ or ${ }^{15} \mathrm{~N}$ chemical shift evolution, respectively, via -DNOINVPUL flag in ZGOPNTS, or non-zero counter 13 (for code Listing 8). The co-evolution of ${ }^{15} \mathrm{~N}$ and ${ }^{13} \mathrm{C}$ is governed by constant 21 (cnst21), which standard value is 2.4803 (a ratio of ${ }^{13} \mathrm{C}$ and ${ }^{15} \mathrm{~N}$ gyromagnetic ratios). In the particular case of 8-in-1 experiment (Listing 8), additional counters 11, 12 and 14 are provided to allow selection of specific pathway. In such test (either 1D or 2D) experiments, a phase cycle on phase $\phi_{18}$ should be disabled using DNOSEPARATION flag. Instead of multiplexing with phase $\phi_{18}$, L2 counter allows to observe only $(+)$ pathways $(12=0)$ or $(-)$ pathways $(12=2)$ (refer to caption to Figure S6 for details). L1 counter determines whether H $\alpha$ signal only $(11=0)$, $H \alpha$ and $H^{\mathrm{N}}(11=1)$, or $\mathrm{H}^{\mathrm{N}}$ signal only $(11=2)$ is stored. Finally, counter L4 allows to select pathways regarding the magnetization behavior during ${ }^{13} \mathrm{C}$ ${ }^{15} \mathrm{~N}$ CP, and correspond to pathways shown in Figure S6a (14=2), S6b (14=3), S6c (14=4), S6d (14=5) or all of them (14=1).

Listing 5. Bruker pulse program for SIM- ${ }^{13} \mathrm{C},{ }^{15} \mathrm{~N}-\mathrm{CP}-\mathrm{HSQC}$

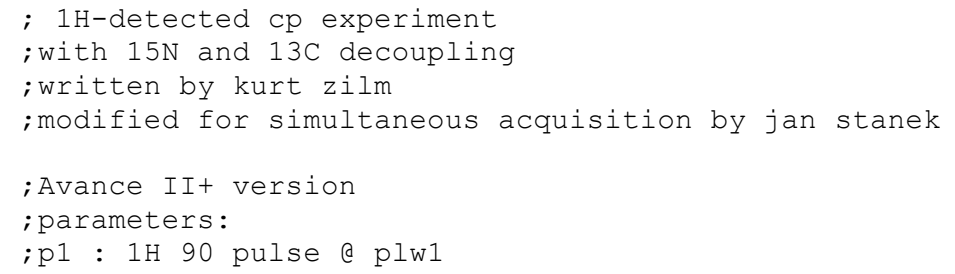




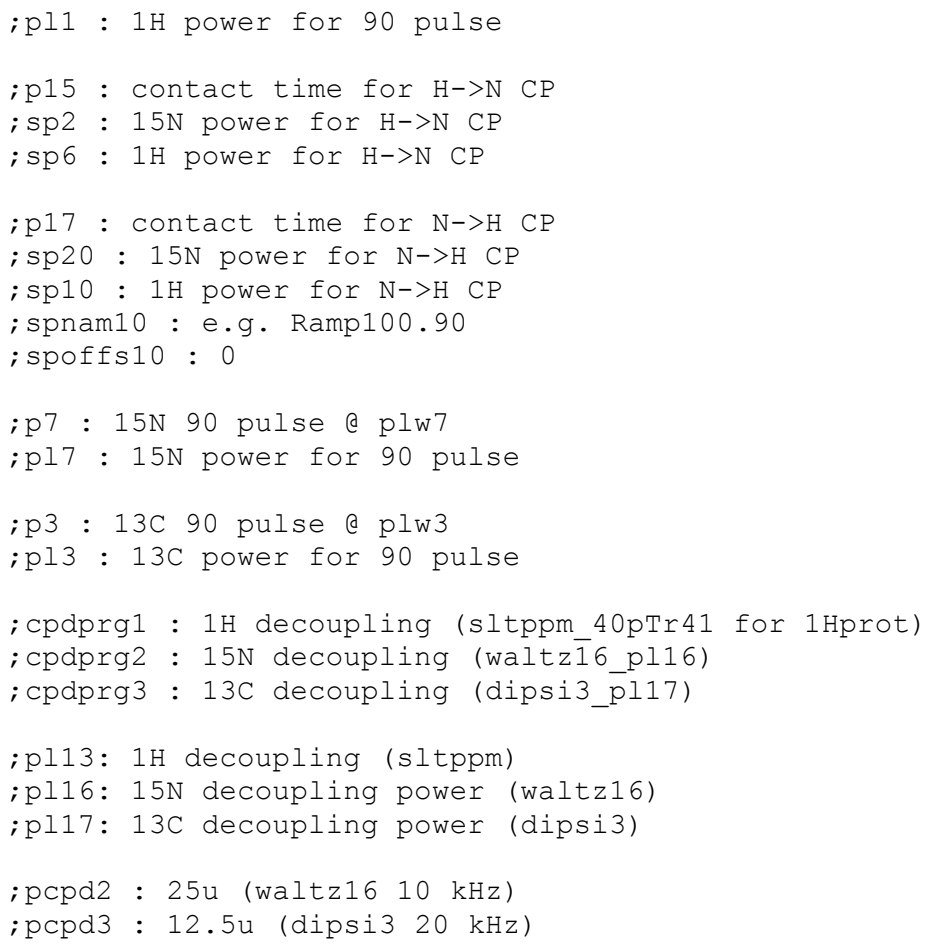




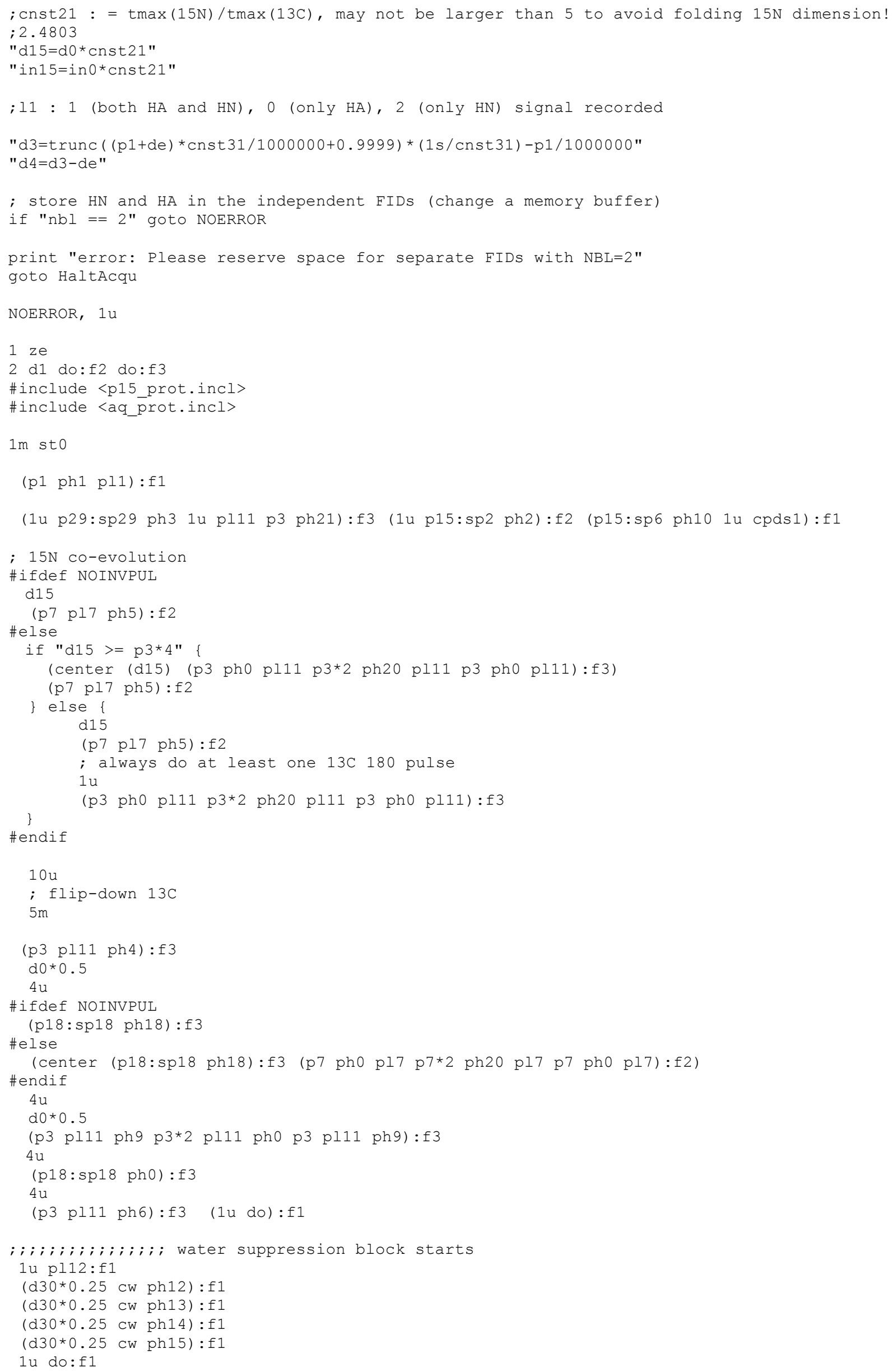




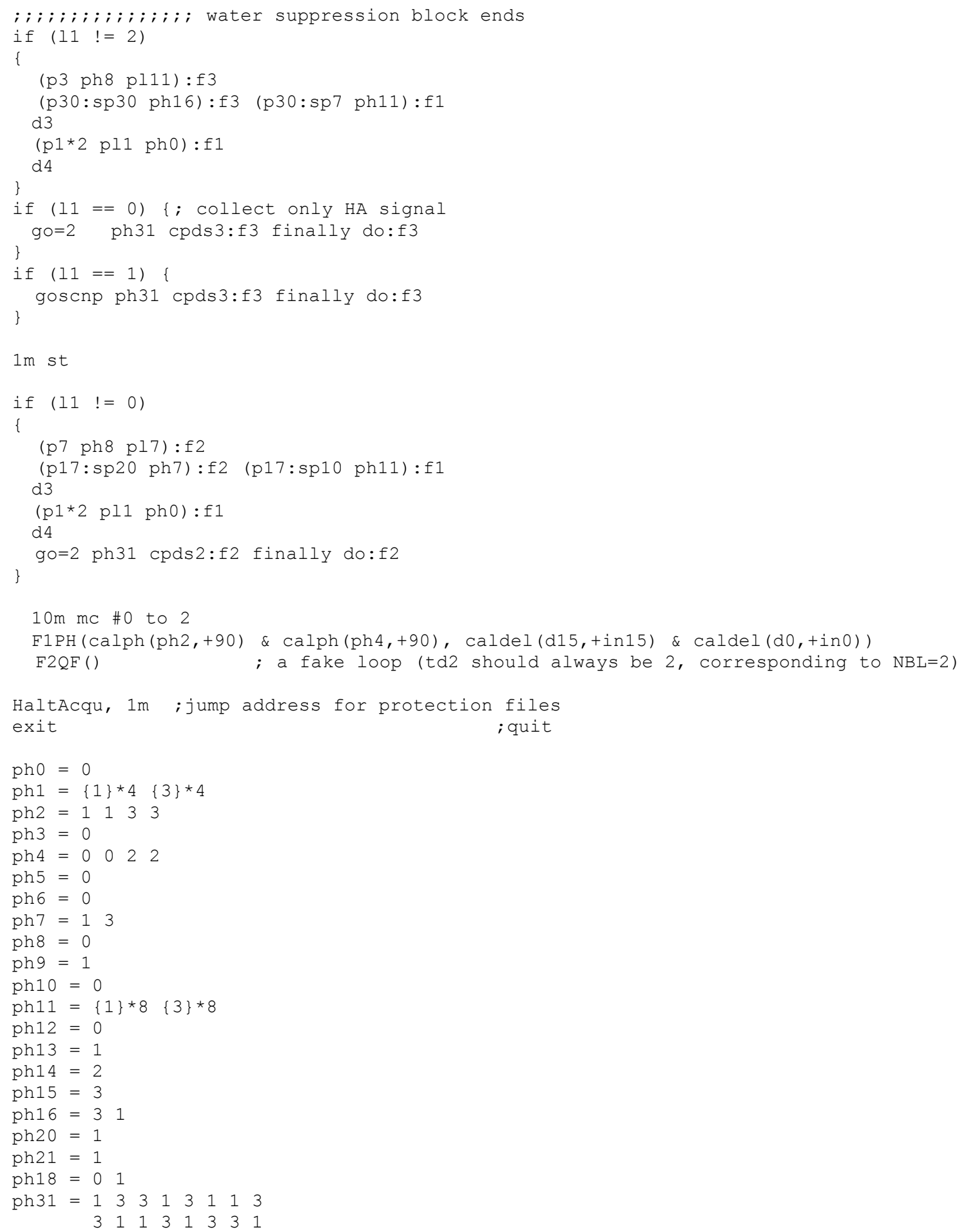

Listing 6. Bruker pulse program for SIM-(H)CANH,(H)NCAHA

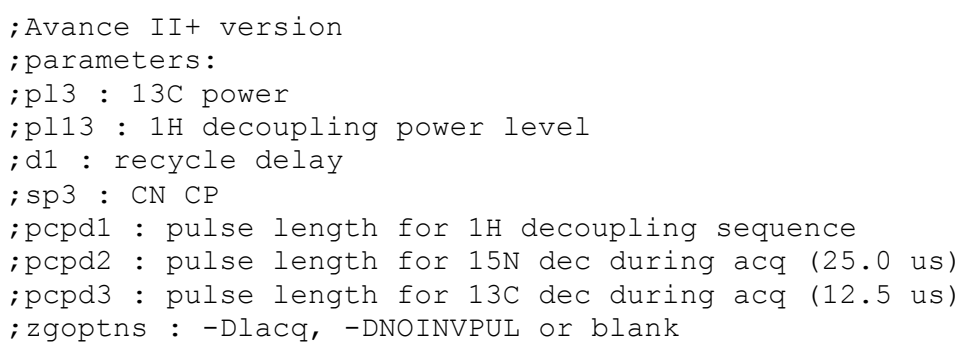




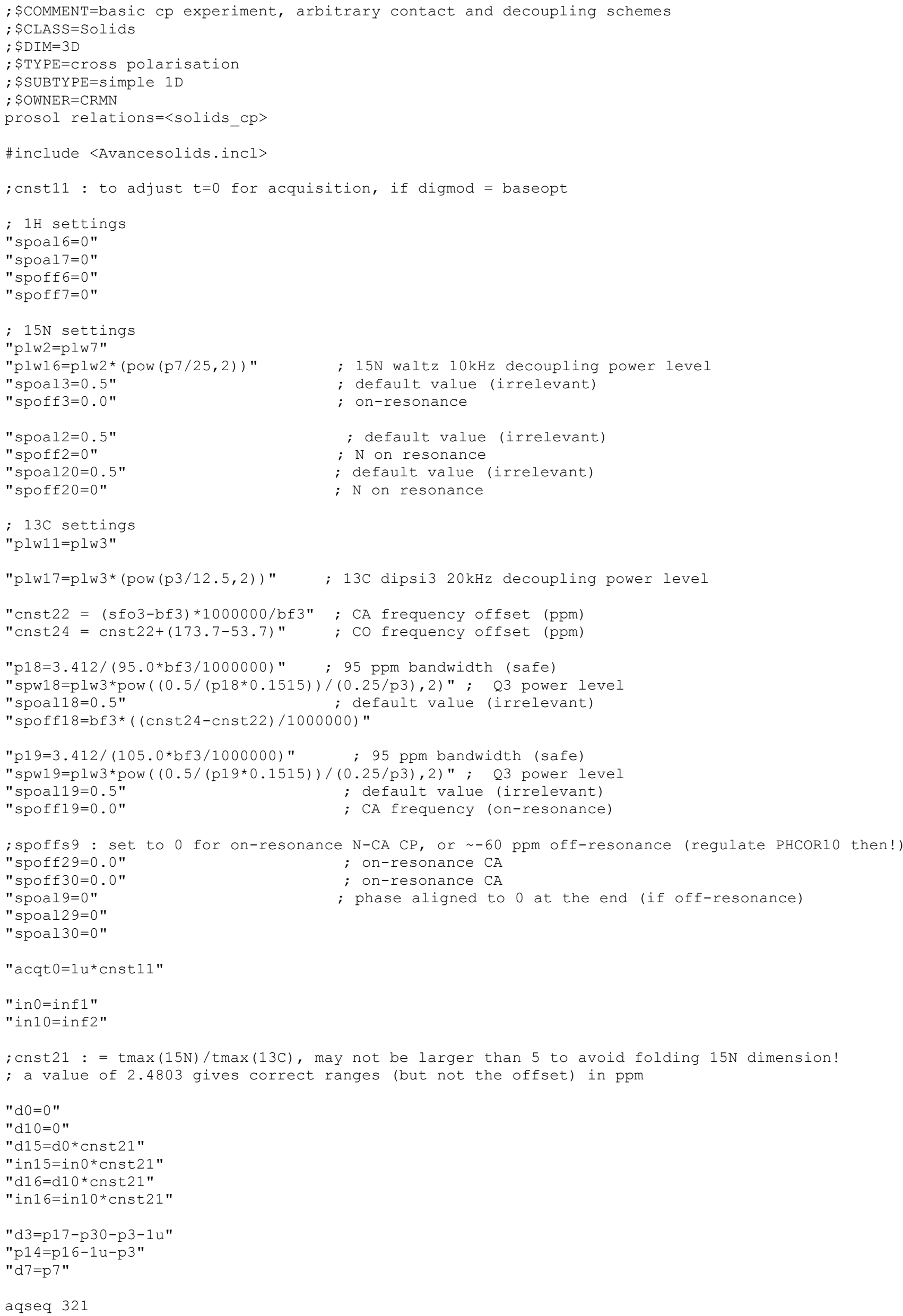




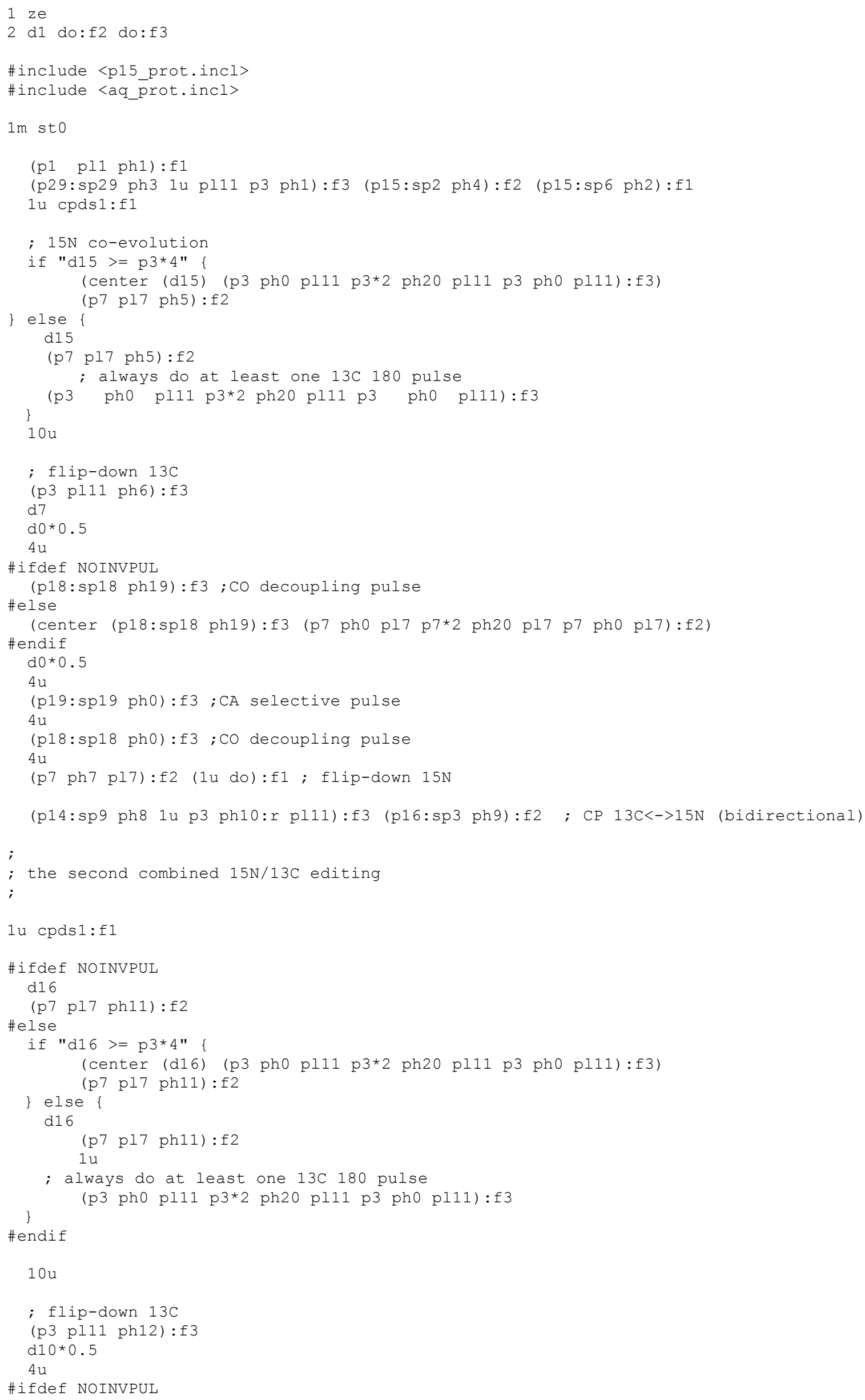




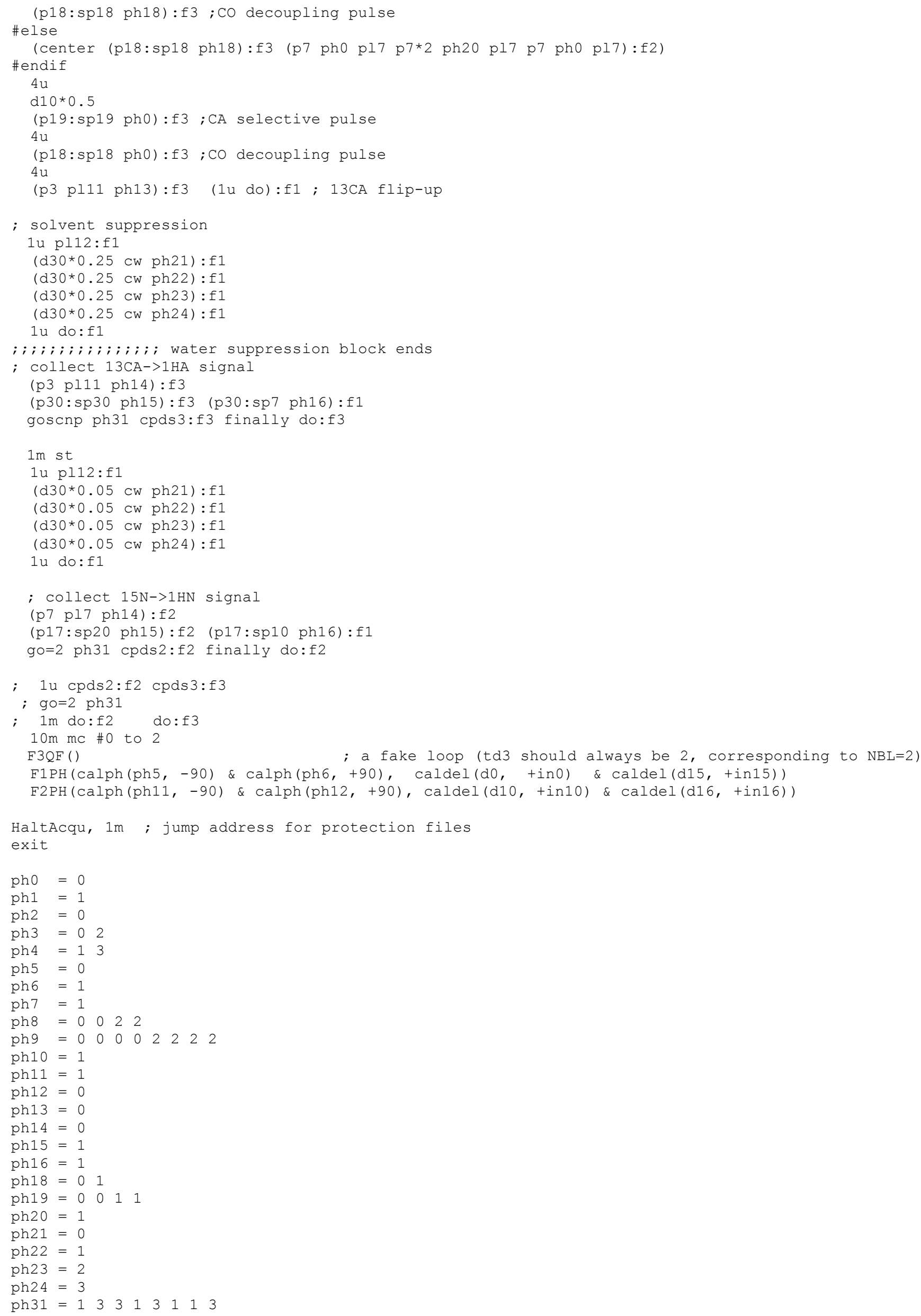


Listing 7. Bruker pulse program for SIM- $(\mathrm{H})(\mathrm{CO}) \mathrm{CA}(\mathrm{CO}) \mathrm{NH},(\mathrm{H}) \mathrm{N}(\mathrm{CO}) \mathrm{CAHA}$

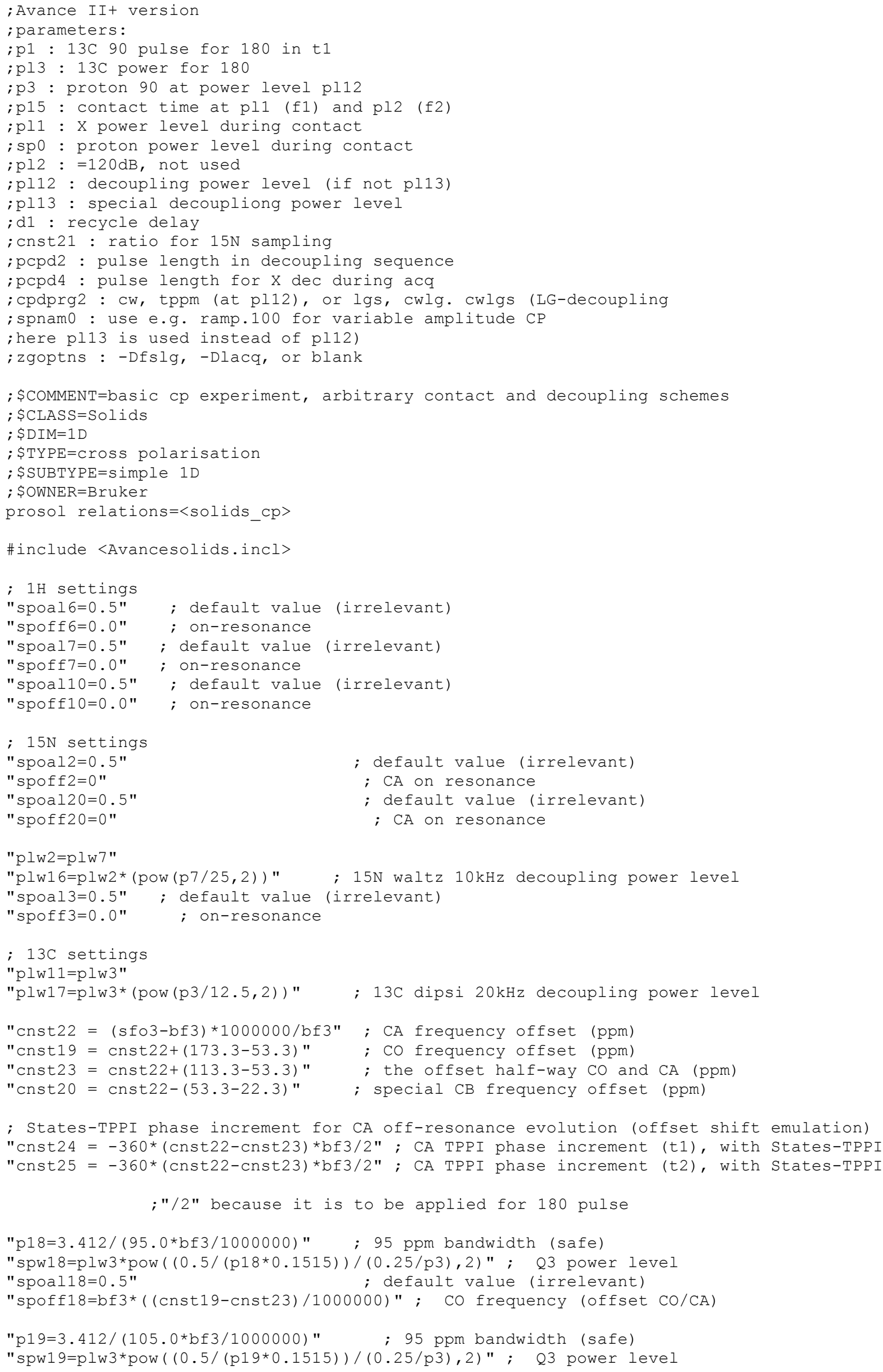




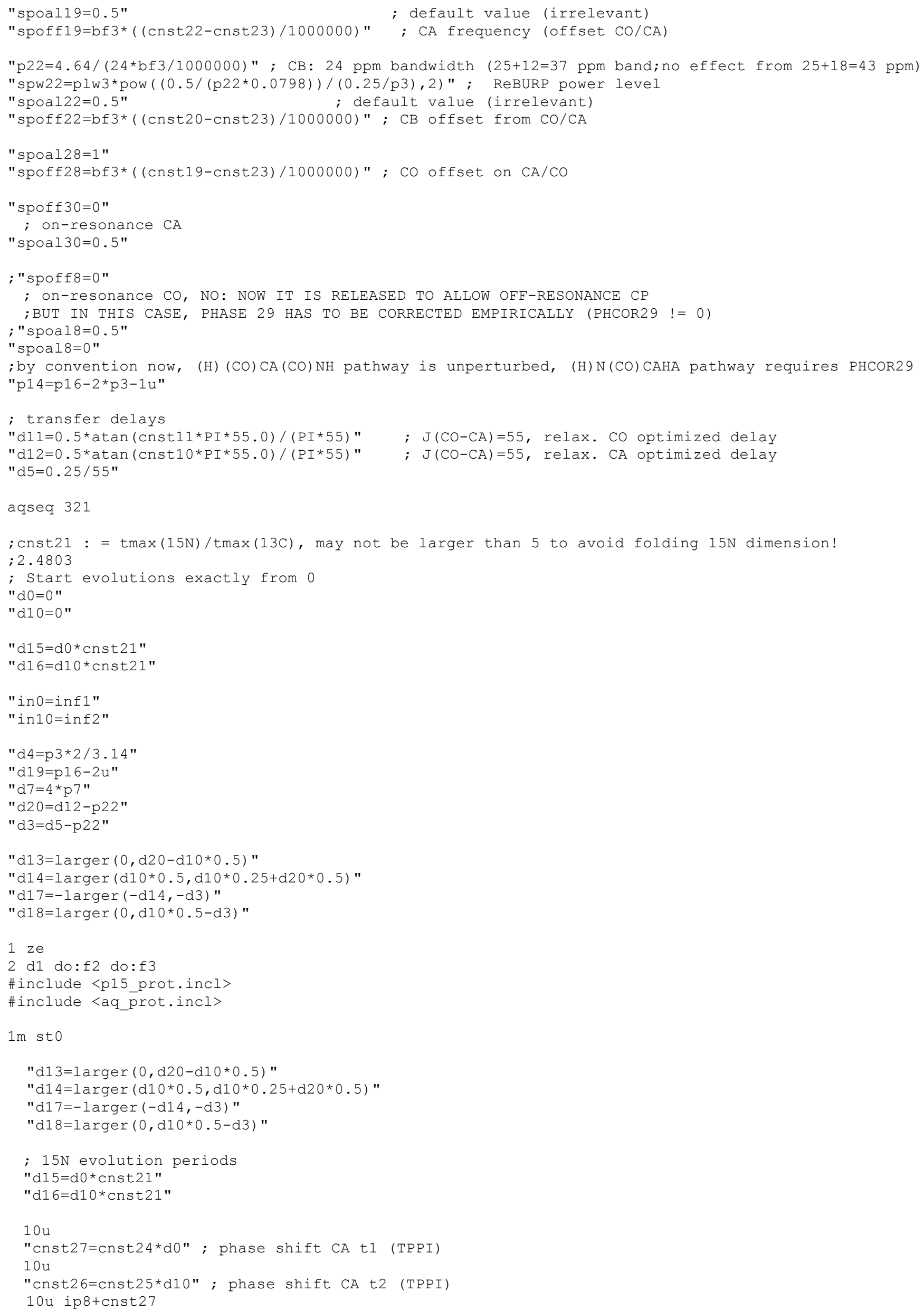




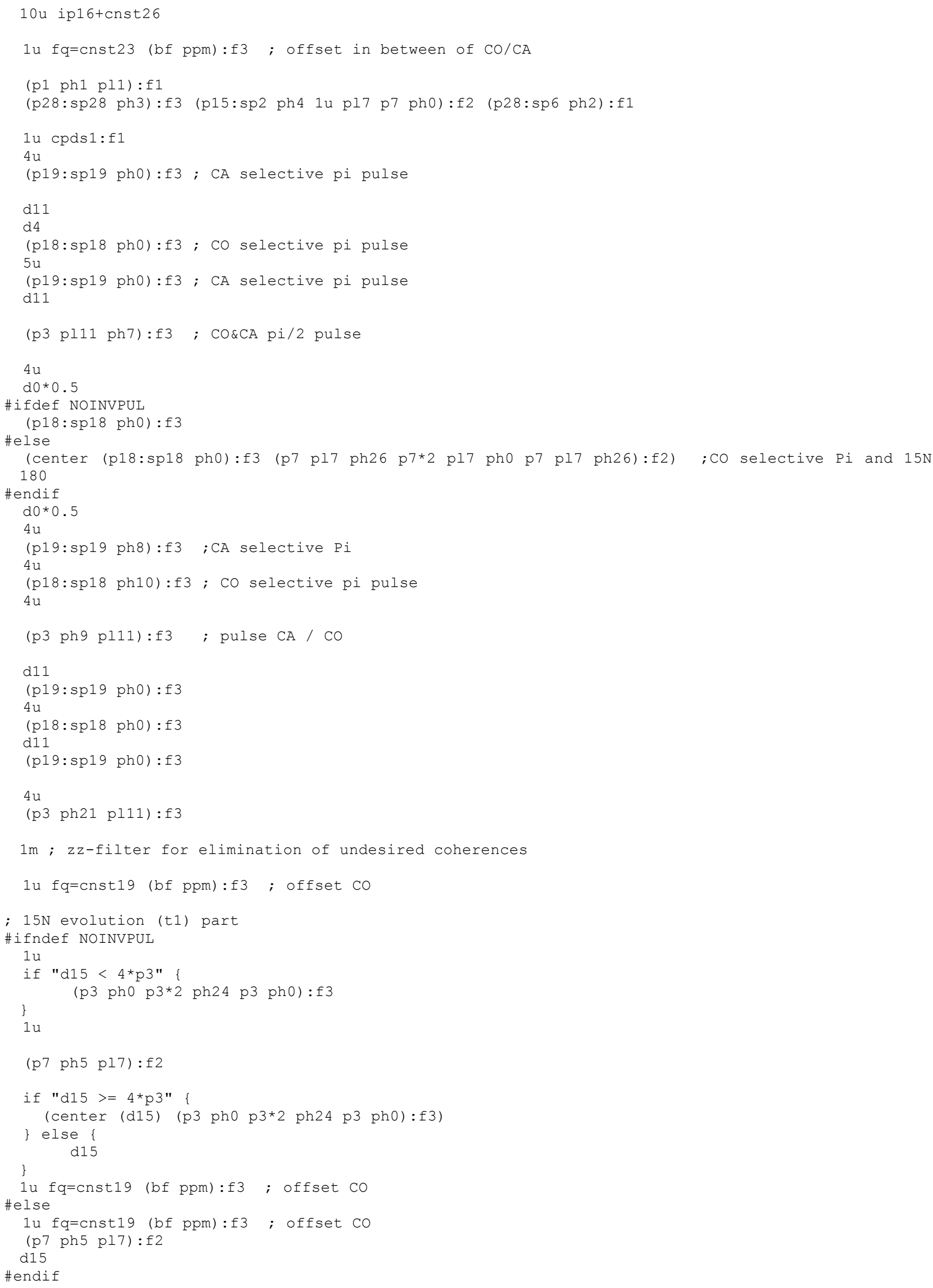




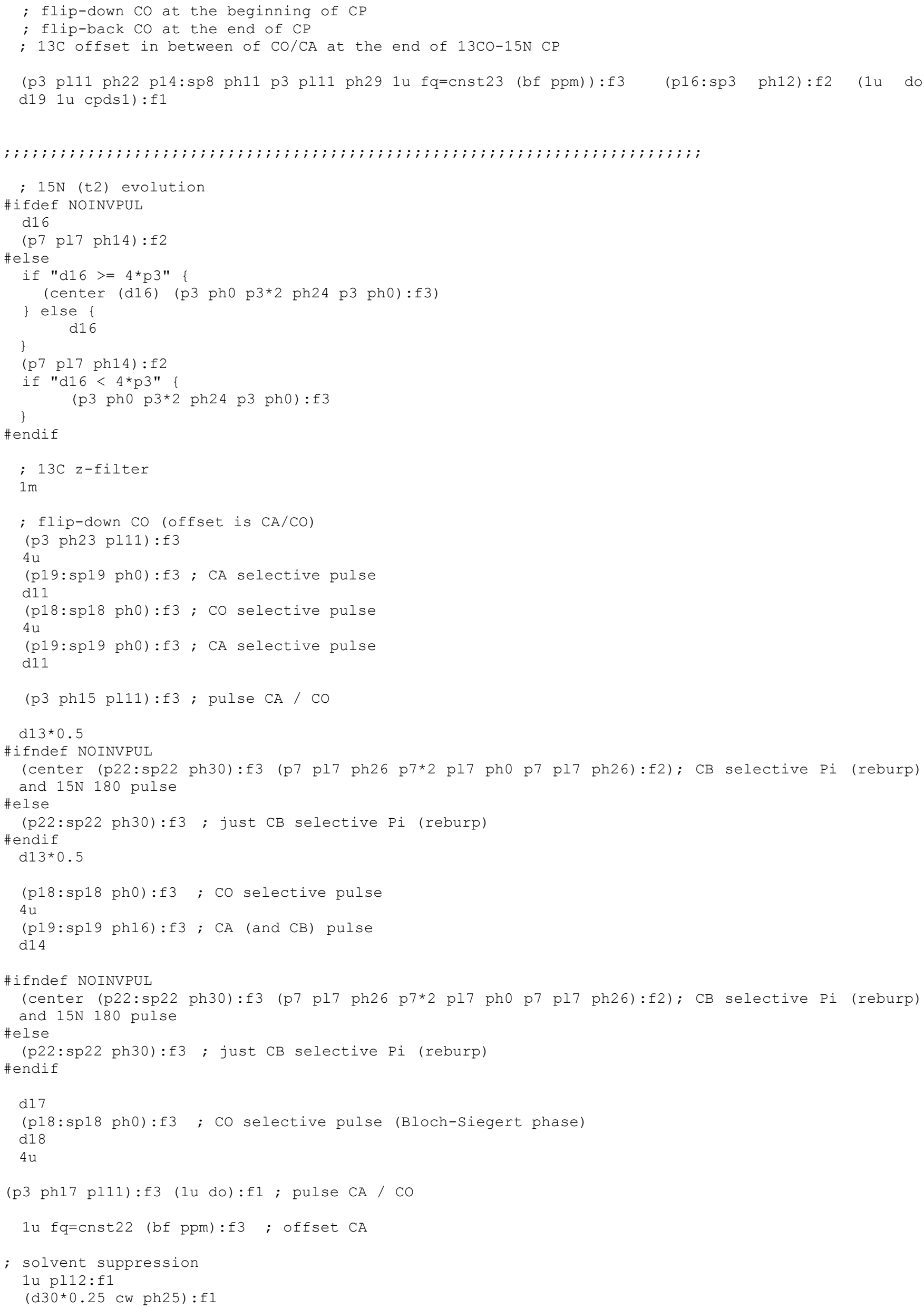




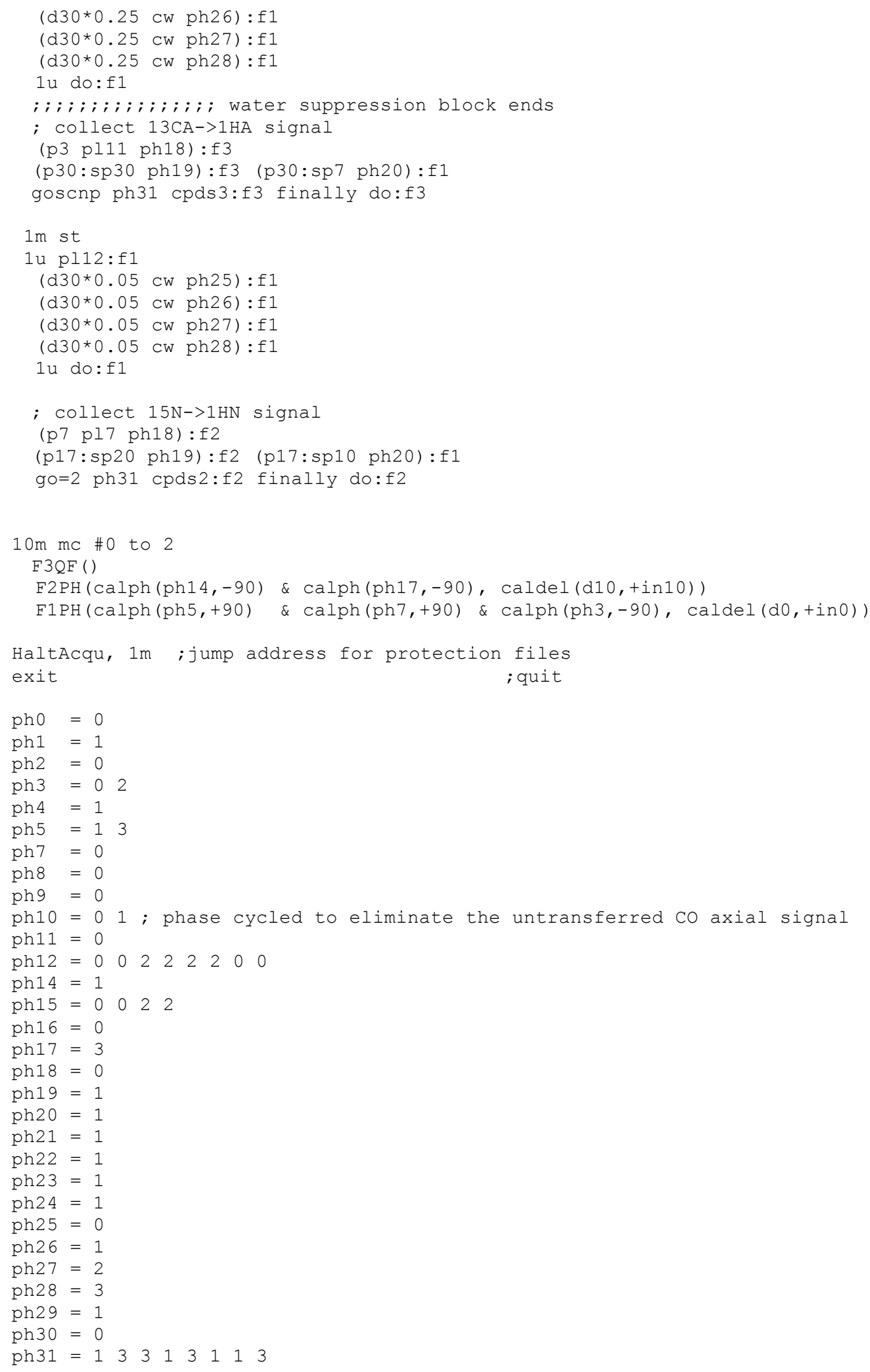


Listing 8. Bruker pulse program for SIM- $(\mathrm{H}) \mathrm{N}(\mathrm{CA})(\mathrm{CO}) \mathrm{NH},(\mathrm{H}) \mathrm{CA}(\mathrm{N})(\mathrm{CO}) \mathrm{CAHA}(8-\mathrm{in}-1)$

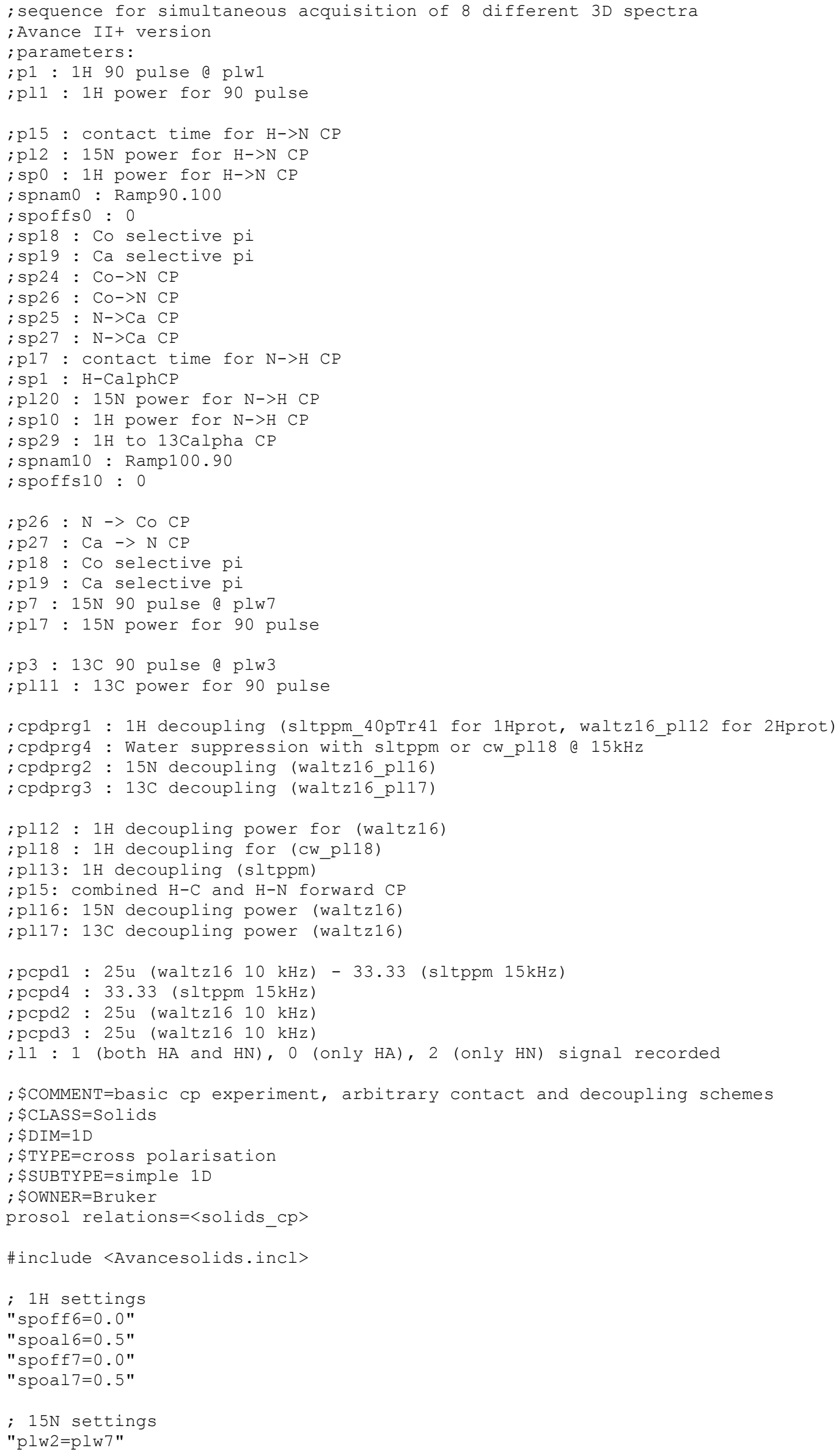




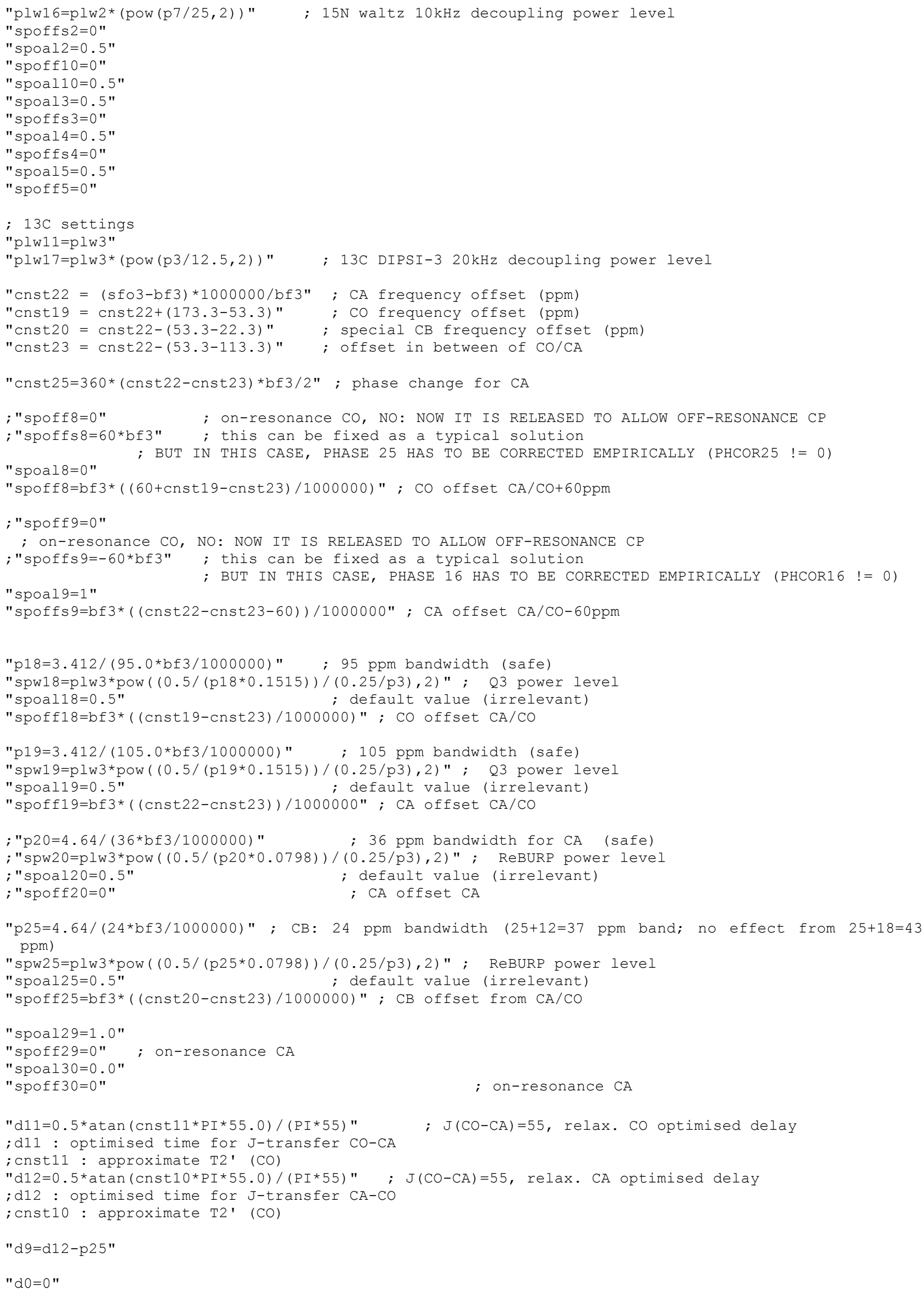




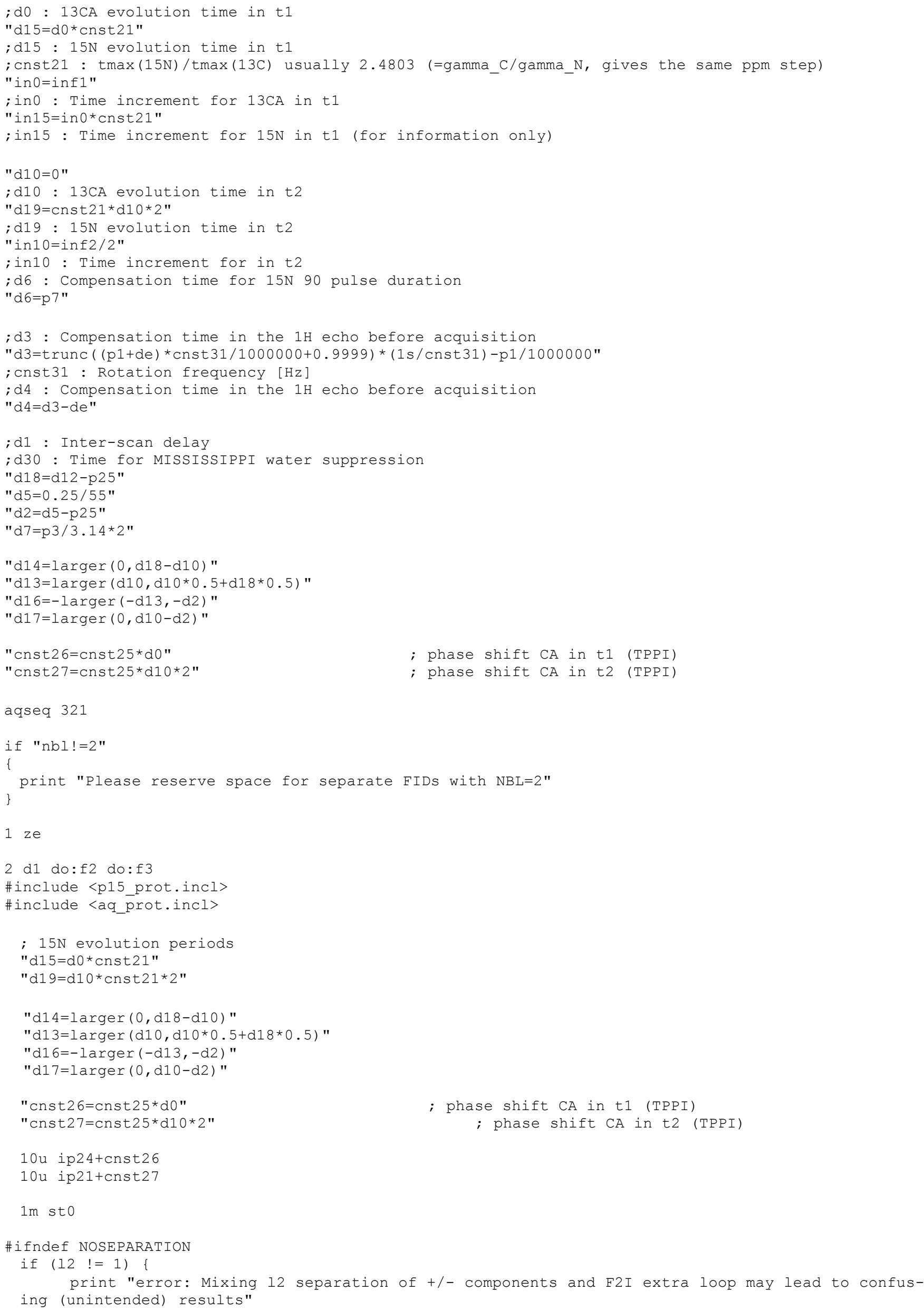




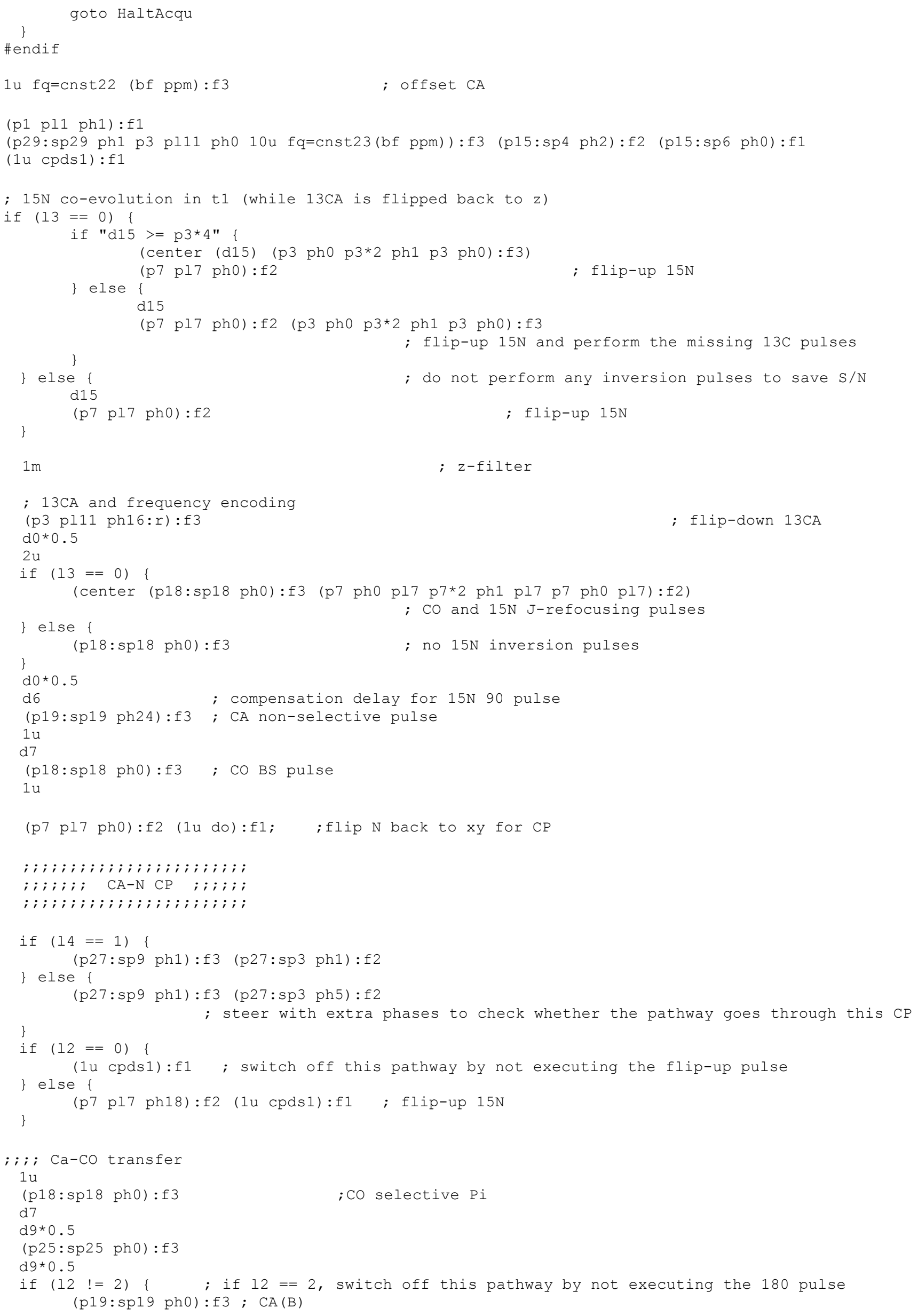




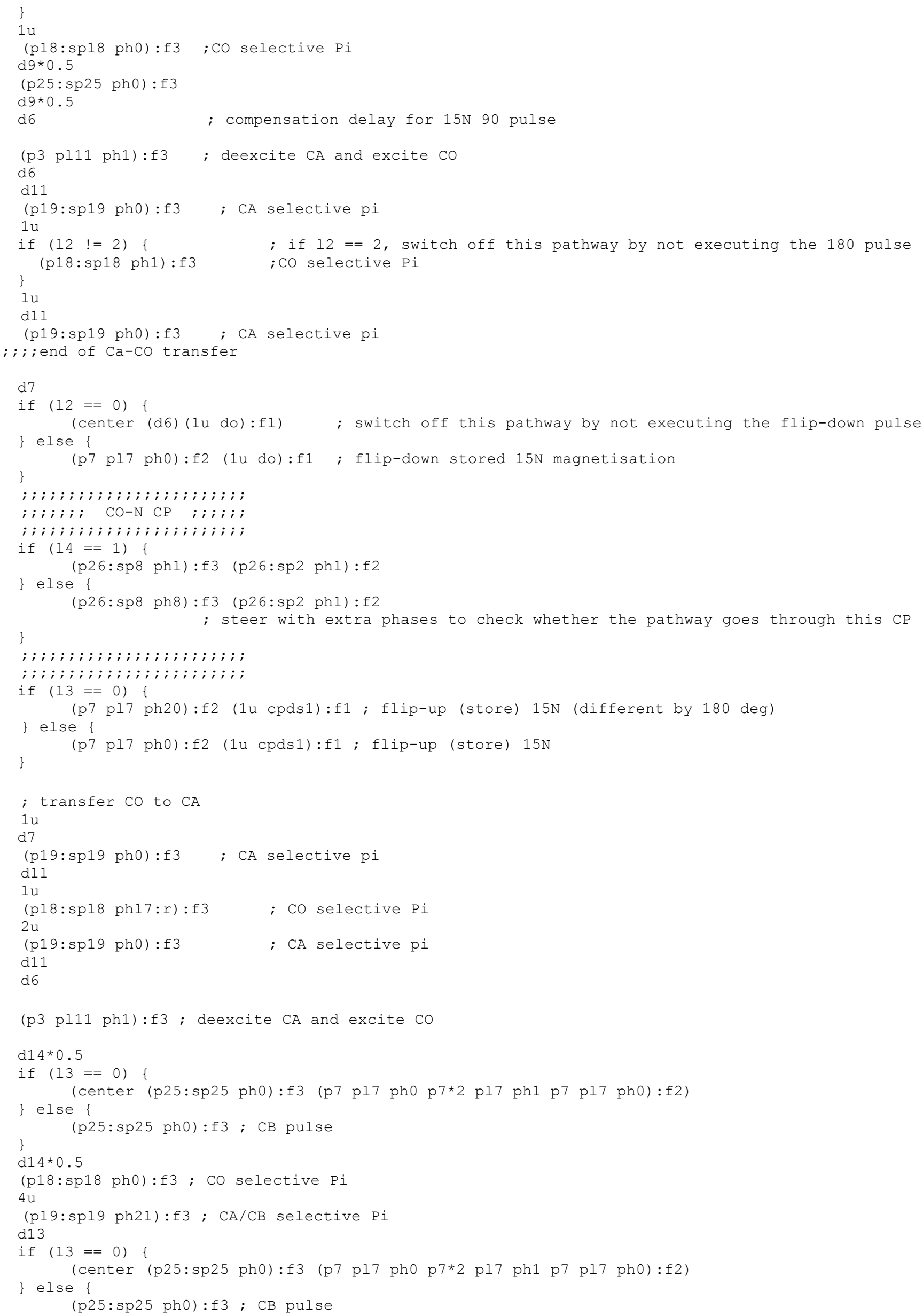




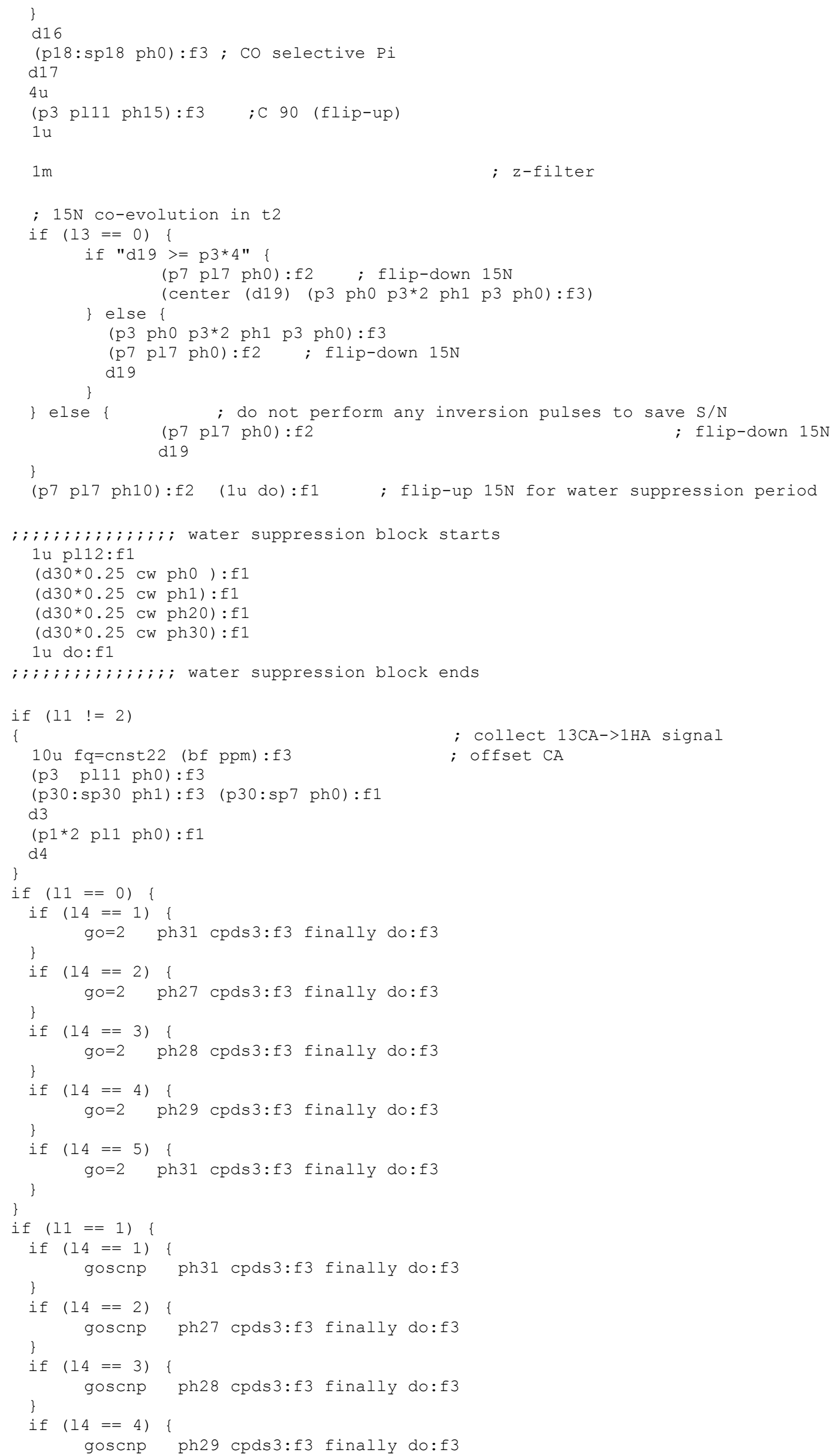




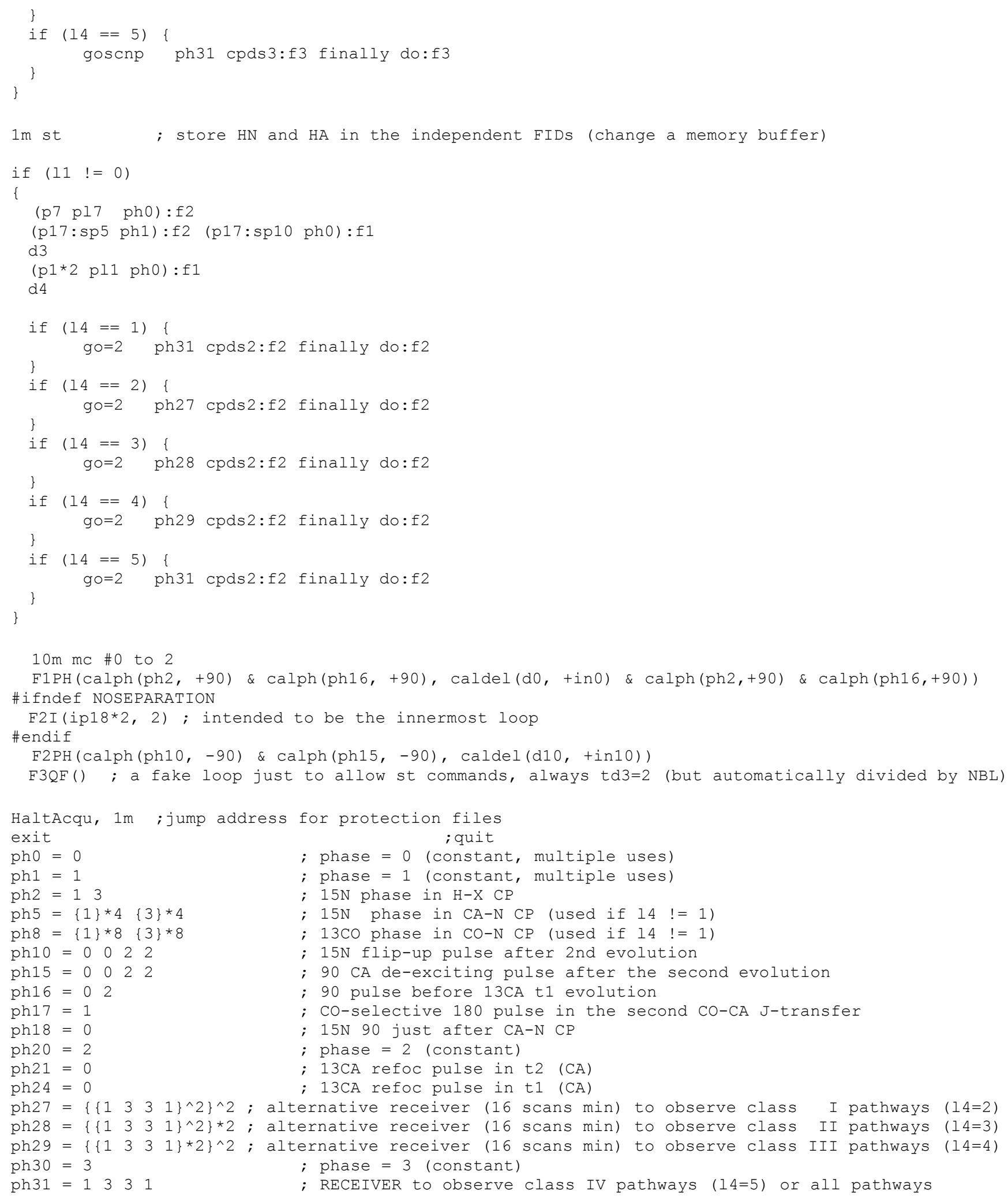




\section{K. References}

(1) Gopinath, T.; Veglia, G. Dual acquisition magic-angle spinning solid-state NMR-spectroscopy: simultaneous acquisition of multidimensional spectra of biomacromolecules; Angew. Chem. Int. Ed. Engl. 2012, 51, 2731-2735.

(2) Bak, M.; Rasmussen, J. T.; Nielsen, N. C. SIMPSON: a general simulation program for solid-state NMR spectroscopy; J. Magn. Reson. 2000, 147, 296-330.

(3) Emsley, L.; Bodenhausen, G. Optimization of Shaped Selective Pulses for NMR Using a Quaternion Description of Their Overall Propagators; J. Magn. Reson. 1992, 97, 135-148.

(4) Geen, H.; Freeman, R. Band-Selective Radiofrequency Pulses; J. Magn. Reson. 1991, 93, 93-141.

(5) Bennett, A. E.; Rienstra, C. M.; Auger, M.; Lakshmi, K. V.; Griffin, R. G. Heteronuclear decoupling in rotating solids; J. Chem. Phys. 1995, $103,6951-6958$.

(6) Lewandowski, J. R.; Sein, J.; Sass, H. J.; Grzesiek, S.; Blackledge, M.; Emsley, L. Measurement of site-specific 13C spin-lattice relaxation in a crystalline protein; J. Am. Chem. Soc. 2010, 132, 8252-8254.

(7) Shaka, A. J.; Keeler, J.; Frenkiel, T.; Freeman, R. An Improved Sequence for Broad-Band Decoupling - WALTZ-16; J. Magn. Reson. 1983, $52,335-338$.

(8) Shaka, A. J.; Lee, C. J.; Pines, A. Iterative schemes for bilinear operators; application to spin decoupling; J. Magn. Reson. (1969) 1988, 77, 274-293.

(9) Zhou, D. H.; Rienstra, C. M. High-performance solvent suppression for proton detected solid-state NMR; J. Magn. Reson. 2008, 192, 167172.

(10) States, D. J.; Haberkorn, R. A.; Ruben, D. J. A Two-Dimensional Nuclear Overhauser Experiment with Pure Absorption Phase in 4 Quadrants; J. Magn. Reson. 1982, 48, 286-292.

(11) Hediger, S.; Meier, B. H.; Kurur, N. D.; Bodenhausen, G.; Ernst, R. R. NMR cross polarization by adiabatic passage through the Hartmann-Hahn condition (APHH); Chem. Phys. Lett. 1994, 223, 283-288.

(12) Evenas, J.; Tugarinov, V.; Skrynnikov, N. R.; Goto, N. K.; Muhandiram, R.; Kay, L. E. Ligand-induced structural changes to maltodextrinbinding protein as studied by solution NMR spectroscopy; J. Mol. Biol. 2001, 309, 961-974.

(13) Venters, R. A.; Farmer, B. T., 2nd; Fierke, C. A.; Spicer, L. D. Characterizing the use of perdeuteration in NMR studies of large proteins: 13C, $15 \mathrm{~N}$ and $1 \mathrm{H}$ assignments of human carbonic anhydrase II; J. Mol. Biol. 1996, 264, 1101-1116.

(14) Zhou, D. H.; Shah, G.; Cormos, M.; Mullen, C.; Sandoz, D.; Rienstra, C. M. Proton-detected solid-state NMR spectroscopy of fully protonated proteins at $40 \mathrm{kHz}$ magic-angle spinning; J. Am. Chem. Soc. 2007, 129, 11791-11801. 